\title{
The Interaction between Throttling and Thrust Vectoring of an Annular Aerospike Nozzle
}

\author{
A Thesis \\ presented to \\ the Faculty of the College of Engineering \\ California Polytechnic State University, San Luis Obispo
}

\author{
In Partial Fulfillment \\ of the Requirements for the Degree \\ Master of Science in Mechanical Engineering \\ by
}

David Michael Imbaratto

September 2009 
(C) 2009

David Michael Imbaratto

ALL RIGHTS RESERVED 


\section{COMMITEE MEMBERSHIP}

TITLE: $\quad$ The Interaction between Throttling and Thrust Vectoring of an Annular Aerospike Nozzle

AUTHOR: $\quad$ David Michael Imbaratto

DATE SUBMITTED: September 11, 2009

COMMITTEE CHAIR: $\quad$ William R. Murray, Professor

COMMITTEE MEMBER: Tom Carpenter, Professor

COMMITTEE MEMBER: Patrick Lemieux, Professor 


\begin{abstract}
The Interaction between Throttling and Thrust Vectoring of an Annular Aerospike

Nozzle
\end{abstract}

David Michael Imbaratto

Applied research and testing has been conducted at the Cal Poly San Luis Obispo Highpressure Blow-Down facility to study the affects of throttling in a thrust-vectored aerospike nozzle. This study supports the ongoing research at Cal Poly to effectively thrust vector a hybrid rocket motor. Such thrust vectoring is achieved by small secondary ports in the nozzle body that are perpendicular to the main nozzle. The testing conducted included characterizing and comparing the performance of a straight aerospike nozzle to that of a thrust-vectored aerospike nozzle. Throttling effects on the aerospike nozzle in an unvectored and in a vectored configuration were also investigated. The interaction between throttling and thrust vectoring of an aerospike nozzle is the focus of this thesis research.

This research shows that large-throat/high-thrust operation of an aerospike nozzle provides little thrust vector generation. Conversely, small-throat/low-thrust operation provides ample thrust vector generation.

These results have implications in the effectiveness of thrust vectoring an aerospike nozzle with secondary ports. Rockets having an aerospike nozzle with throttling capabilities will be subject to the minimum and maximum turn angles for a given throttle position. As such, certain vehicle maneuvers might not be obtainable at certain throttle operations. Conversely, at lower throttling conditions, higher turn angles will be achievable. 


\section{ACKNOWLEDGEMENTS}

This section is dedicated to the help and knowledge of those who made this research possible. Professor Tom Carpenter's astounding knowledge and experience served as a well of knowledge for this thesis research. Professor William R. Murray headed the research of aerospike nozzles at Cal Poly San Luis Obispo. Professor William R. Murray was not only an adviser for this written thesis, but was instrumental in every aspect of the research conducted on aerospike nozzles at the Cal Poly San Luis Obispo facility. Terry Cooke is responsible for the design and integration of the pressure feedback system used to control the aerospike.

This work was supported in part be "Optimal Thrust Vectoring for an Annular Aerospike Nozzle”, NASA STTR Grants: Phase II, Contract NND06AB82C, 6/06 - 6/08; Phase I, Contract NND05AA53C, 1/05 - 1/06. 
TABLE OF CONTENTS

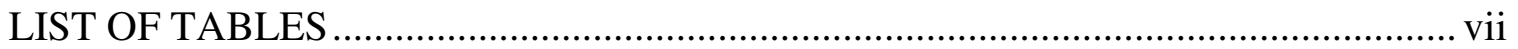

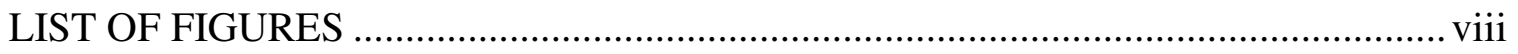

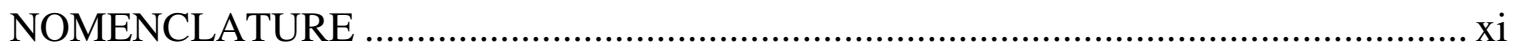

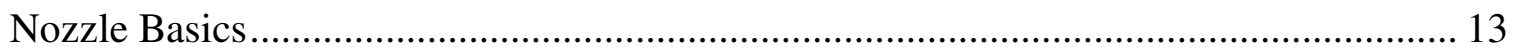

Low-pressure Blow-Down Experiments................................................................ 19

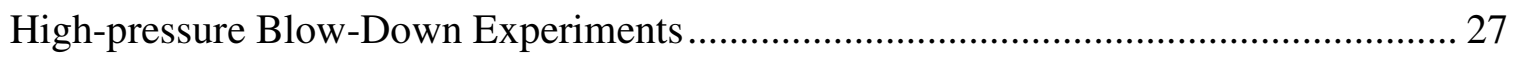

Aerospike Nozzle Design ....................................................................................... 37

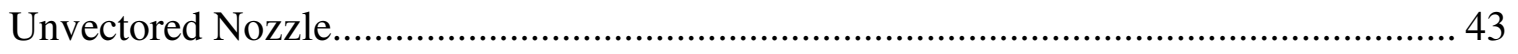

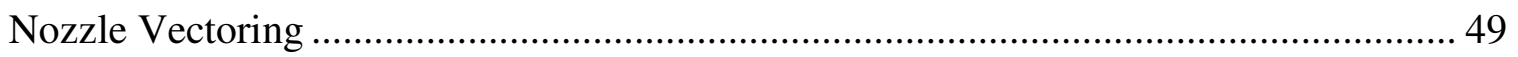

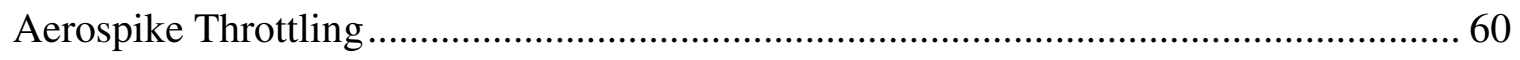

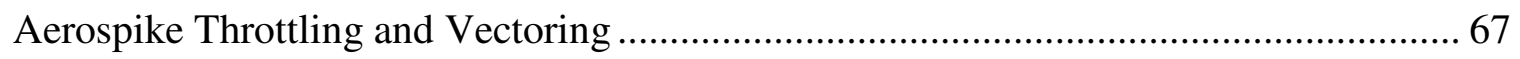

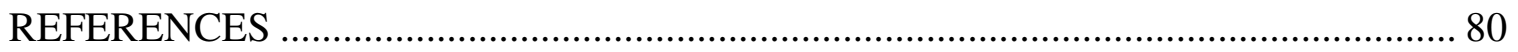

APPENDIX A: NOZZLE THRUST COEFFICIENT DERIVATION ……………........ 81

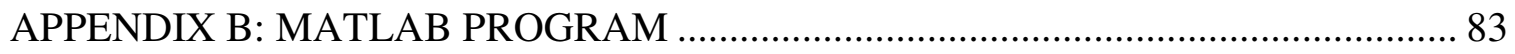

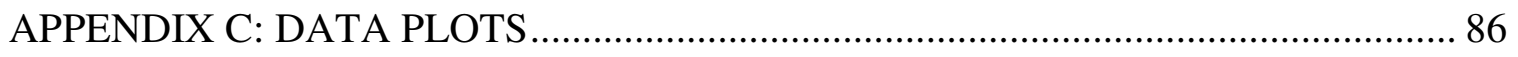

APPENDIX D: LINEAR STEPPER MOTOR CONTROLLER AND INTERFACE..... 88 


\section{LIST OF TABLES}

Table 1: Summary of the straight aerospike nozzle for the low-pressure system. .......... 24

Table 2: Summary of the vectored aerospike nozzle for the low-pressure system........... 24

Table 3: Summary of nozzle performance for the straight aerospike nozzle for the low-

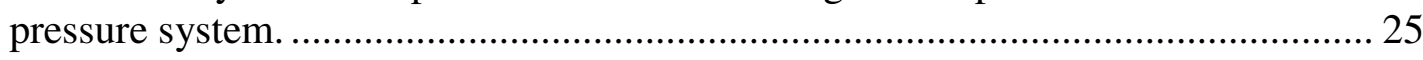

Table 4: Summary of nozzle performance for the vectored aerospike nozzle for the

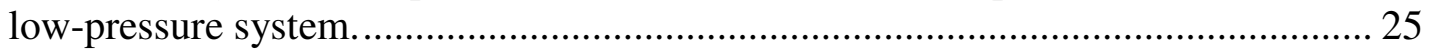

Table 5: Summary of the straight aerospike nozzle in various rotational positions........ 44

Table 6: Summary of nozzle performance for the straight aerospike nozzle. ................. 46

Table 7: Summary of the straight converging-diverging nozzle in one position............. 47

Table 8: Summary of nozzle performance for the straight converging-diverging nozzle. 48

Table 9: Summary for single-port thrust vectoring of the aerospike nozzle in various

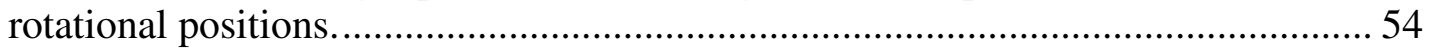

Table 10: Summary for double-port thrust vectoring of the aerospike nozzle in various

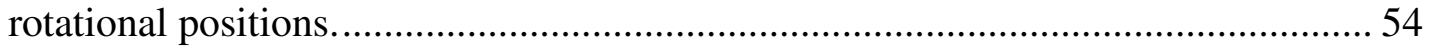

Table 11: Summary of nozzle performance for the vectored aerospike nozzle................ 55

Table 12: Summary of the vectored converging-diverging nozzle in one position.......... 58

Table 13: Summary of nozzle performance for the vectored converging-diverging

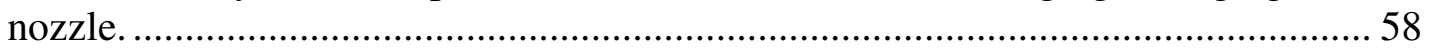

Table 14: Throat area as a function of spike translation.......................................... 61

Table 15: Summary of the straight aerospike nozzle throttled via moving the spike....... 62

Table 16: Summary of nozzle performance for the throttled straight aerospike nozzle... 62

Table 17: Turn angle and resultant thrust as a function of spike translation................... 67

Table 18: Summary of the vectored aerospike nozzle throttled via axially translating

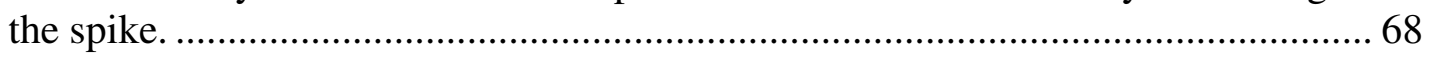

Table 19: Summary of nozzle performance for the throttled vectored aerospike nozzle. 72 


\section{LIST OF FIGURES}

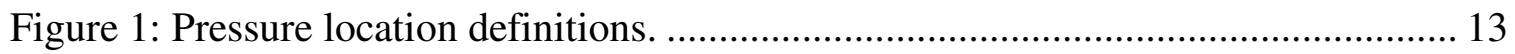

Figure 2: Aerospike nozzle operating at high altitudes. ............................................ 14

Figure 3: Aerospike nozzle operating at low altitudes........................................... 14

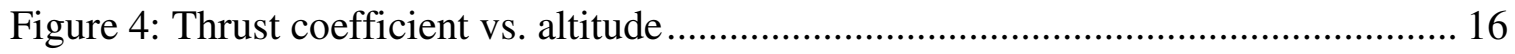

Figure 5: Low-pressure annular aerospike design with secondary vectoring port. ......... 20

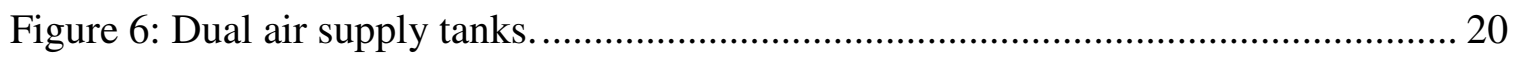

Figure 7: Thrust vector nozzle flow bench and six-component thrust stand................. 21

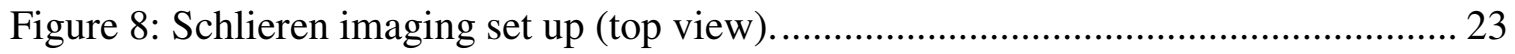

Figure 9: Schlieren images of the low-pressure nozzle. ........................................... 26

Figure 10: The high-pressure flow bench consists of the manifold, bellows, load cells,

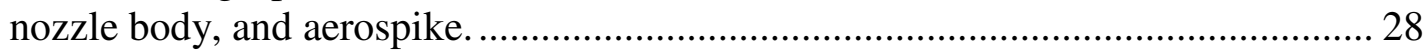

Figure 11: Parts for the high-pressure blow-down nozzle system. Front row: copper gaskets and Marmon clamps; middle row: spike centering ring, aerospike, four bellows; back row: nozzle liner, nozzle outer body (note: the outer shell shown is a preliminary version of the shell), base including a load cell to measure the force on the spike and an actuator to move the spike forward and/or backward in the axial direction, liner, and outer body................................................................. 28

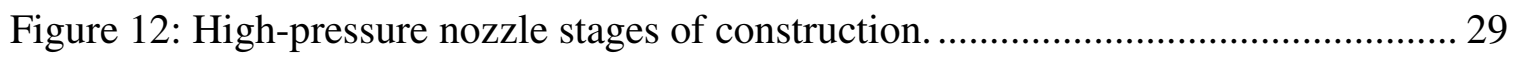

Figure 13: Nozzle components of the high-pressure system tests. ............................ 31

Figure 14: Aerospike and converging-diverging nozzle liners.................................. 32

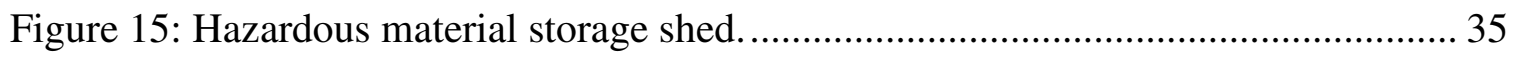

Figure 16: Major components of the high-pressure system...................................... 36

Figure 17: Geometry definition for the generic aerospike contour............................... 37

Figure 18: Geometry definition for the projected radius to find the throat area.............. 38

Figure 19: Geometry definition for the x-coordinate on the aerospike contour. ............. 40

Figure 20: Aerospike contour with the throat..................................................... 41 
Figure 21: Area contour of an aerospike nozzle. 42

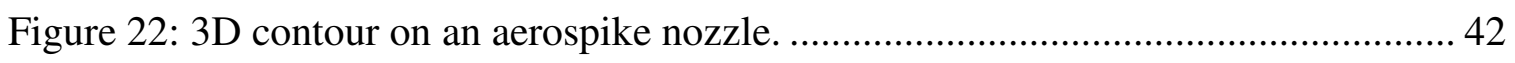

Figure 23: Unvectored aerospike nozzle................................................................ 44

Figure 24: Schlieren capture of straight aerospike nozzle....................................... 45

Figure 25: Unvectored converging-diverging nozzle. ........................................... 47

Figure 26: Schlieren capture of straight converging-diverging nozzle.......................... 48

Figure 27: Vectored aerospike nozzle ................................................................. 50

Figure 28: Thrust vectoring diagram. ................................................................... 51

Figure 29: Single-port thrust vectoring configuration. ........................................ 52

Figure 30: Double-port thrust vectoring configuration............................................. 53

Figure 31: Schlieren capture of vectored aerospike nozzle. ….................................. 55

Figure 32: Deflection of the main plume of the vectored aerospike nozzle.................... 56

Figure 33: Vectored converging-diverging nozzle. .................................................. 56

Figure 34: Schlieren capture of vectored converging-diverging nozzle........................ 57

Figure 35: Plot of vectored forces of a single- and double-port configuration of vectored nozzles at different rotational positions and their respected adjusted values. The adjusted data have been calibrated to remove the side loads associated with the straight nozzle.

Figure 36: Throttling an aerospike nozzle via moving the center spike. ....................... 61

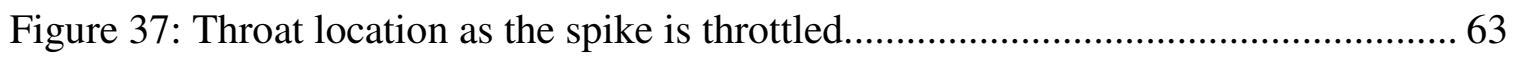

Figure 38: Schlieren images of the throttled straight aerospike nozzle......................... 65

Figure 39: Turn angle and spike force as a function of spike location for unvectored

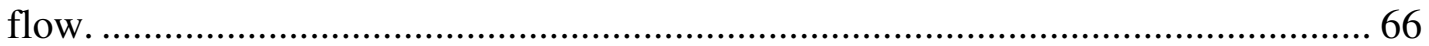

Figure 40: Schlieren images of the throttled vectored aerospike nozzle. ...................... 70

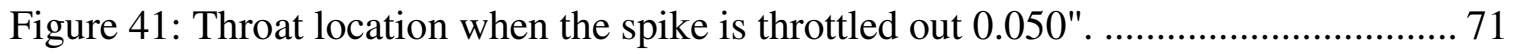

Figure 42: Turn angle and spike force as a function of throat area ratio for vectored flow. 
Figure 43: Resultant force and spike force as a function of spike location for vectored

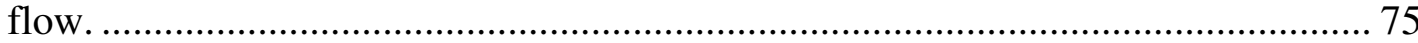

Figure 44: Plot of resultant turn angle as a function of spike location from nominal for the shimmed configuration and the servo motor controlled configuration.

Figure 45: Turn angles for active and static throttling............................................... 86

Figure 46: Pressure matching and spike location form Helios DAQ and encoder.......... 87 


\section{NOMENCLATURE}

\begin{tabular}{|c|c|}
\hline $\mathrm{F}_{\text {isen }}$ & Isentropic net thrust, $l_{\mathrm{f}}$ \\
\hline $\mathrm{F}_{\mathrm{x}}$ & Measure thrust along $\mathrm{y}$-axis, $\mathrm{lb}_{\mathrm{f}}$ \\
\hline $\mathrm{F}_{\mathrm{y}}$ & Measured side thrust, $1 b_{f}$ \\
\hline $\mathrm{F}_{\mathrm{z}}$ & Measured thrust along body axis, $\mathrm{lb}_{\mathrm{f}}$ \\
\hline $\mathrm{F}_{\mathrm{d}}$ & Force acting in the direction of the secondary port, $\mathrm{lb}_{\mathrm{f}}$ \\
\hline $\mathrm{F}_{\mathrm{p}}$ & Force acting perpendicular to the direction of the secondary port, $\mathrm{lb}_{\mathrm{f}}$ \\
\hline $\mathrm{F}_{\text {vector }}$ & Combination of normal and side thrust, $\mathrm{lb}_{\mathrm{f}}$ \\
\hline $\mathrm{F}_{\mathrm{r}}$ & Resultant thrust along $\mathrm{x}$-axis, $\mathrm{lb}_{\mathrm{f}}$ \\
\hline $\mathrm{P}_{1}$ & Chamber pressure, psia \\
\hline $\mathrm{P}_{2}$ & Exit pressure, psia \\
\hline $\mathrm{P}_{3}$ & Ambient pressure, psia \\
\hline$w_{i}$ & Ideal weight-flow, $\mathrm{lb}_{\mathrm{f}} / \mathrm{s}$ \\
\hline$w_{p}$ & Measured weight-flow, $\mathrm{lb}_{\mathrm{f}} / \mathrm{s}$ \\
\hline$\delta_{\text {pitch }}$ & Resultant pitch thrust vector angle \\
\hline$\delta_{\text {yaw }}$ & Resultant yaw thrust vector angle \\
\hline$\delta_{\mathrm{d}}$ & Thrust vector angle in the direction of the secondary port \\
\hline$\delta_{\perp}$ & Thrust vector angle orthogonal to the direction of the secondary port \\
\hline$\delta_{\mathrm{r}}$ & Resultant net thrust vector angle \\
\hline NPR & Nozzle pressure ratio $\left(\mathrm{P}_{1} / \mathrm{P}_{3}\right)$ \\
\hline $\mathrm{C}_{\mathrm{f}}$ & Nozzle thrust coefficient for the main nozzle \\
\hline $\mathrm{C}_{\mathrm{fsp}}$ & Nozzle thrust coefficient for the secondary port \\
\hline & Nozzle throat area of the main nozzle \\
\hline
\end{tabular}


$\mathrm{A}_{\mathrm{sp}} \quad$ Nozzle throat area of the secondary port

$\mathrm{F}_{\mathrm{T}} \quad$ Thrust force, $\mathrm{lb}_{\mathrm{f}}$

$\gamma \quad$ ratio of specific heat 


\section{CHAPTER 1}

Nozzle Basics

To fully understand the performance of the aerospike nozzle and the effects of making changes to such a nozzle, it is important understand the fundamentals of nozzle theory. A notable loss in performance in a nozzle can be attributed to the nozzle not operating at design condition, running at either an under-expanded or an over-expanded condition. In a conventional nozzle, the expansion of a nozzle is typically described in terms of the ratio of the exit area, $A_{2}$ to throat area, $A_{t}$. This ratio is called the area ratio. However, for an aerospike nozzle, it might be more appropriate to discuss the expansion of the nozzle in terms of throat area because the exit area is not fixed and is allowed to compensate for the ambient pressure. The exit area of an aerospike nozzle exists outside of the physical nozzle itself. In fact, the exit plane of the aerospike nozzle exists at the very tip of the spike. The definitions for the nozzle pressures and area for a conventional nozzle system are illustrated in Figure 1.

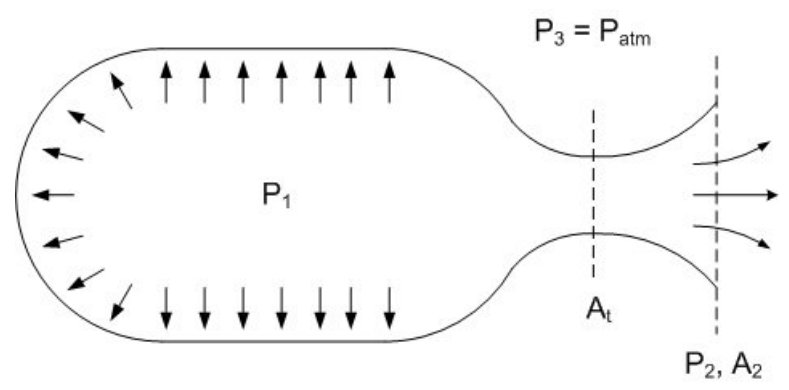

Figure 1: Pressure location definitions.

An under-expanded nozzle discharges fluid at an exit pressure greater than atmospheric (or external) pressure, or $\mathrm{P}_{2}>\mathrm{P}_{3}$. An under-expanded condition can happen when the actual throat area is larger for a given exit area, i.e., a smaller area ratio. When the exit pressure is greater than the ambient pressure, the expansion of the flow is 
incomplete within the nozzle, and therefore expansion continues outside of the nozzle. Expansion waves will appear at the exit of the nozzle [1].

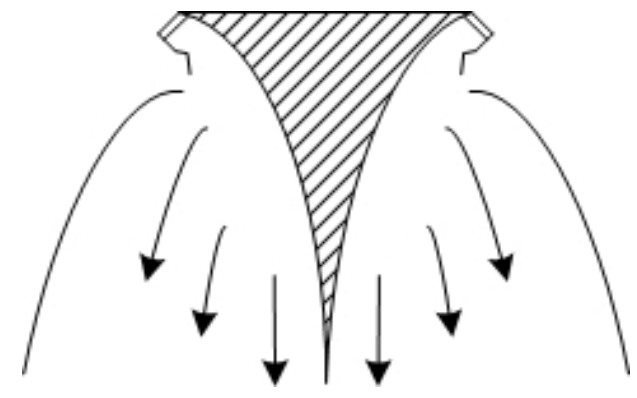

Figure 2: Aerospike nozzle operating at high altitudes.

An over-expanded nozzle discharges fluid at an exit pressure lower than atmospheric pressure, or $\mathrm{P}_{2}<\mathrm{P}_{3}$. An over-expanded condition can happen when the actual throat area is smaller for a given exit area, i.e., a larger area ratio. For ambient pressure, $\mathrm{P}_{3}$, slightly higher than the nozzle exit pressure, $\mathrm{P}_{2}$, shock waves exist at the exit of the nozzle. When ambient pressures are significantly higher than nozzle exit pressures, shock waves appear in the exhaust plume. Flow separation will occur [1].

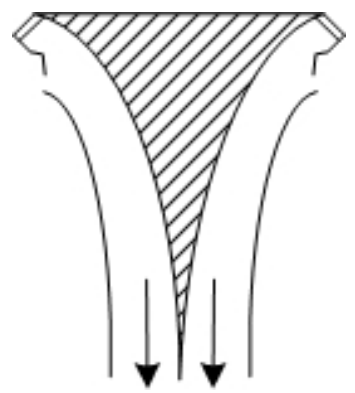

Figure 3: Aerospike nozzle operating at low altitudes.

A nozzle is fully expanded when the exit pressure of the nozzle equals the ambient pressure. A nozzle performs at an optimal condition when the exit pressure is equal to that of the ambient pressure. However, as a rocket changes altitude, the ambient pressure changes. The change in ambient pressure with a corresponding constant nozzle exit pressure results in flow expansion losses. 
At low altitudes, the design goal is to minimize over-expansion and at high altitudes the goal is to minimize under-expansion. However, both design goals cannot be achieved over a range of altitudes in a fixed geometry conventional nozzle. A conventional nozzle is defined as a nozzle that consists of a converging section followed by a diverging section where the expansion of the fluid occurs inside the nozzle.

An aerospike nozzle by nature compensates for altitude changes because the outer plume boundary of the expanding flow is acted upon by the ambient atmospheric pressure [11]. As a rocket climbs in altitude, the flow is allowed to expand to atmospheric conditions. At high ambient pressure or low altitude, the ambient pressure pushes the exhaust inward. At low ambient pressures or higher altitudes, the ambient pressure decreases allowing the exhaust flow to continue to expand to atmospheric conditions. In a conventional bell nozzle, the exhaust flow cannot continue to expand to atmospheric pressure because its expansion is limited by the nozzle walls.

A variable area nozzle can maximize the expansive performance of a nozzle over a range of altitudes as shown in Figure 4 [4]. 


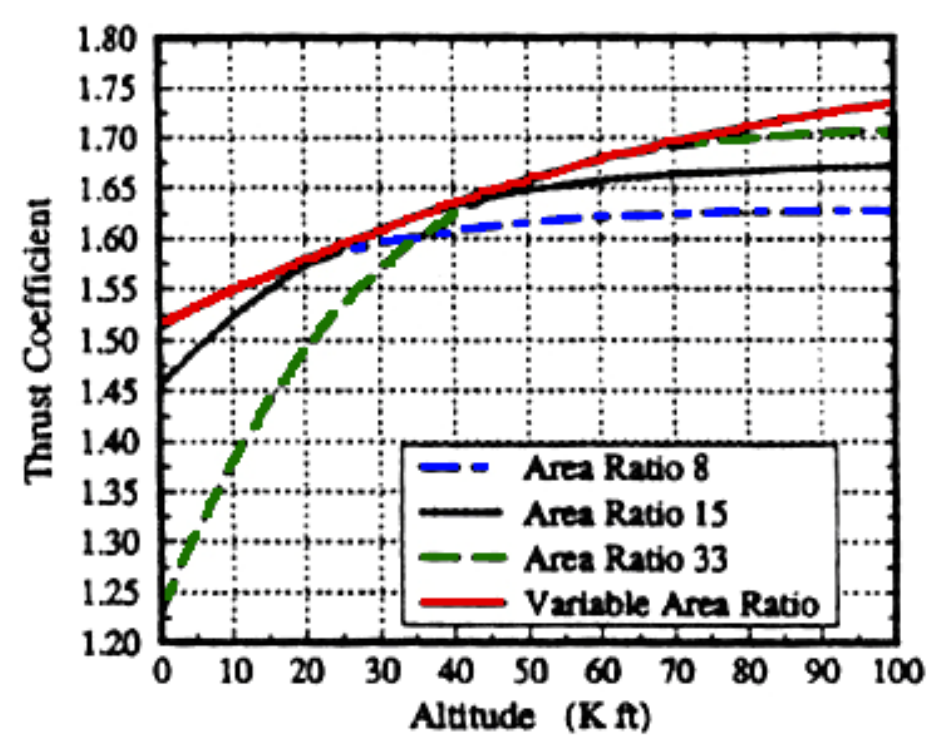

Figure 4: Thrust coefficient vs. altitude

The nozzle thrust coefficient, $\mathrm{C}_{\mathrm{f}}$, is the amplification or increase in thrust due to the expansion of the fluid as compared to the pressure of the fluid acting only over the area of the throat. The thrust coefficient can be used to determine the effectiveness of a nozzle. The thrust coefficient is defined in Equation (1.1). The nozzle thrust coefficient is derived in Appendix A and summarized below.

$$
\begin{gathered}
C_{f}=\frac{F_{T}}{A_{t} P_{1}} \\
C_{f}=\sqrt{\frac{2 \gamma^{2}}{\gamma-1}\left(\frac{2}{\gamma+1}\right)^{\frac{\gamma+1}{\gamma-1}}\left[1-\left(\frac{P_{2}}{P_{1}}\right)^{\frac{\gamma-1}{\gamma}}\right]}+\frac{P_{2}-P_{3}}{P_{1}}\left(\frac{A_{2}}{A_{t}}\right)
\end{gathered}
$$

The nozzle pressure ratio, or NPR, is defined as the plenum pressure (stagnation pressure) divided by the ambient pressure. The theoretical maximum of the nozzle thrust coefficient with air as the working fluid and an NPR of 20 at design condition (i.e., $\mathrm{P}_{2}=$ $\mathrm{P}_{3}$ ) is as follows: 


$$
C_{f}=\sqrt{\frac{2(1.4)^{2}}{0.4}\left(\frac{2}{2.4}\right)^{\frac{2.4}{0.4}}\left[1-\left(\frac{1}{20}\right)^{\frac{0.4}{1.4}}\right]}+0=1.374
$$

Nozzles that are under-expanded or over-expanded have lower nozzle efficiencies, or lower $\mathrm{C}_{\mathrm{f}}$ values. For an under-expanded nozzle, some thrust in the axial direction is lost due to the expanding fluid not fully acting in the desired axial direction as it reaches the exit of the nozzle. Flow separation occurs in an over-expanded nozzle and causes inefficiencies.

To vary the thrust in an aerospike nozzle, the throat area can be changed and flow be throttled simultaneously. The change in throat area is achieved by translating the spike axially such that the nozzle throat opens or closes, depending on the desired results. The chamber pressure, $\mathrm{P}_{1}$, can ideally remain constant. While a complex implementation, creating a variable area aerospike nozzle can provide the following benefits:

1. The chamber pressure spike that occurs during start-up can be reduced or even eliminated, which helps to contribute to weight reductions by the use of thinner engine walls.

2. Programmability [and subsequently optimization] of thrust force as a function of time can reduce the complexity of guidance systems, which can reduce payload costs.

3. Grain designs can be simplified.

4. Unburned propellant can be reduced, resulting in better rocket performance.

5. Throat erosion can be accommodated with a minimal loss in performance.

It should be noted that the use of a variable area aerospike nozzle could possibly offset weight savings associated with the above benefits because of the appropriate struts, 
linkages, and equipment that is needed to implement the nozzle [5]. Specifically, the weight savings from reduced motor pressure spikes (allowing for thinner rocket motor chamber walls) might not compensate from weight gained from the addition of the equipment necessary to implement an aerospike nozzle.

To simulate the aerospike throttling for this experiment, shims were initially inserted or removed from the shaft that supports the spike. Inserting or removing shims would move the spike axially but keep the nozzle stationary. Steady-state tests were then preformed to characterize the nozzle.

Subsequently, to fully simulate the realistic interaction of throttling the aerospike, a servomotor was installed in the spike assembly so that real-time spike position could be controlled and data recorded. The spike position was used in a feedback scheme to maintain a constant pressure in the plenum. The feedback configuration is discussed in detail in Chapter 8. 


\section{CHAPTER 2}

\section{Low-pressure Blow-Down Experiments}

A series of tests was conducted with the low-pressure blow-down system at Cal Poly San Luis Obispo to examine the general characteristics of an unvectored and a vectored aerospike nozzle. Several components were developed to accurately measure axial and vectored thrust forces of a cold-flow aerospike nozzle with air as the working fluid. The test results are shown in Table 1 and Table 2. Further analysis was performed on the tests to characterize the nozzle efficiency. Visual investigation of the flow characteristics of the aerospike nozzle was achieved with color Schlieren photography.

Although the aerospike nozzles were designed for an NPR of 20, initial proof-ofconcept tests were carried out at a lower NPR of approximately 7.5. The intricacies and high cost of implementing a high-pressure system are not involved in a low-pressure system.

The low-pressure nozzles were made with an Eden250 rapid prototyping machine from Objet Geometries using a high density, acrylic-based photopolymer material. A typical low-pressure nozzle is shown in Figure 5. 


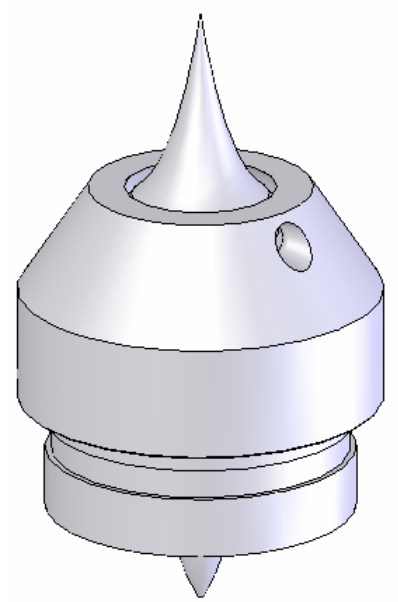

Figure 5: Low-pressure annular aerospike design with secondary vectoring port.

The low-pressure blow-down facility is supplied with air from two large reservoir tanks, which are shown in Figure 6. The tanks are interconnected so that they can supply air either separately or together. The supply pressure is rated at $125 \mathrm{psig}$, which is sufficient to test nozzles to nozzle pressure ratios up to approximately eight. The lowpressure tests were run at an NPR of approximately 7.5.

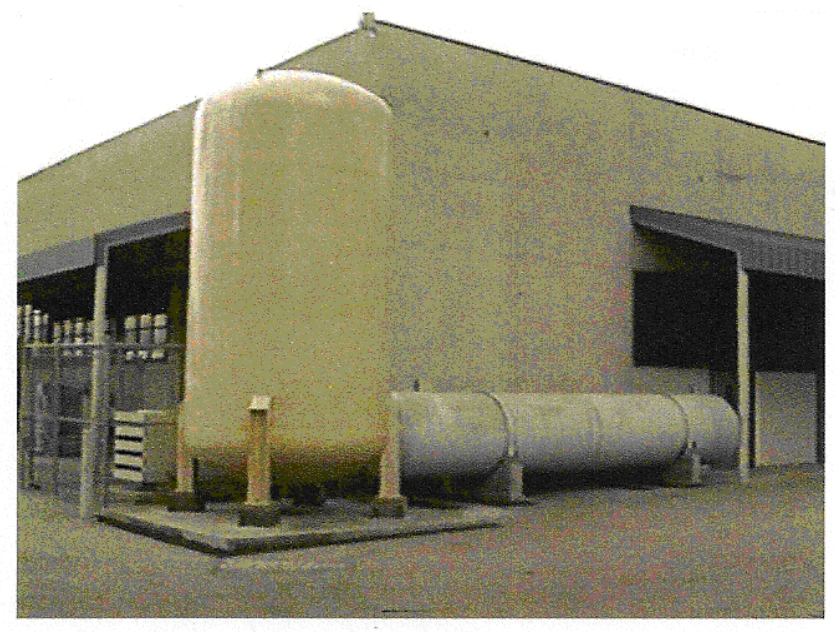

Figure 6: Dual air supply tanks.

A six-component thrust stand was used to accurately measure thrust forces. An air supply manifold system was and used in conjunction with the six-component thrust stand to research thrust-vectoring of aerospike nozzles. The six-component thrust stand and the 
thrust vector flow bench are shown in Figure 7. The six-component thrust stand consists of six miniature tension-compression load cells. Three load cells are positioned in vertical direction and three load cells are positioned in the horizontal position. A referential Cartesian coordinate system is placed in the plane of the horizontal load cells with the zdirection aligned in the vertical upward direction and the center of the coordinate system located at the center of the stand. With the position of each load cell known it is possible to convert the measured loads to forces and moments about the $x, y, z$ axes, i.e., $F_{x}, F_{y}$, $\mathrm{F}_{\mathrm{z}}, \mathrm{M}_{\mathrm{x}}, \mathrm{M}_{\mathrm{y}}, \mathrm{M}_{\mathrm{z}}$, and also determine the angles of pitch and yaw, $\delta_{\mathrm{p}}, \delta_{\mathrm{y}}$. Additional forces and angles can be calculated from these measurements for further analysis.

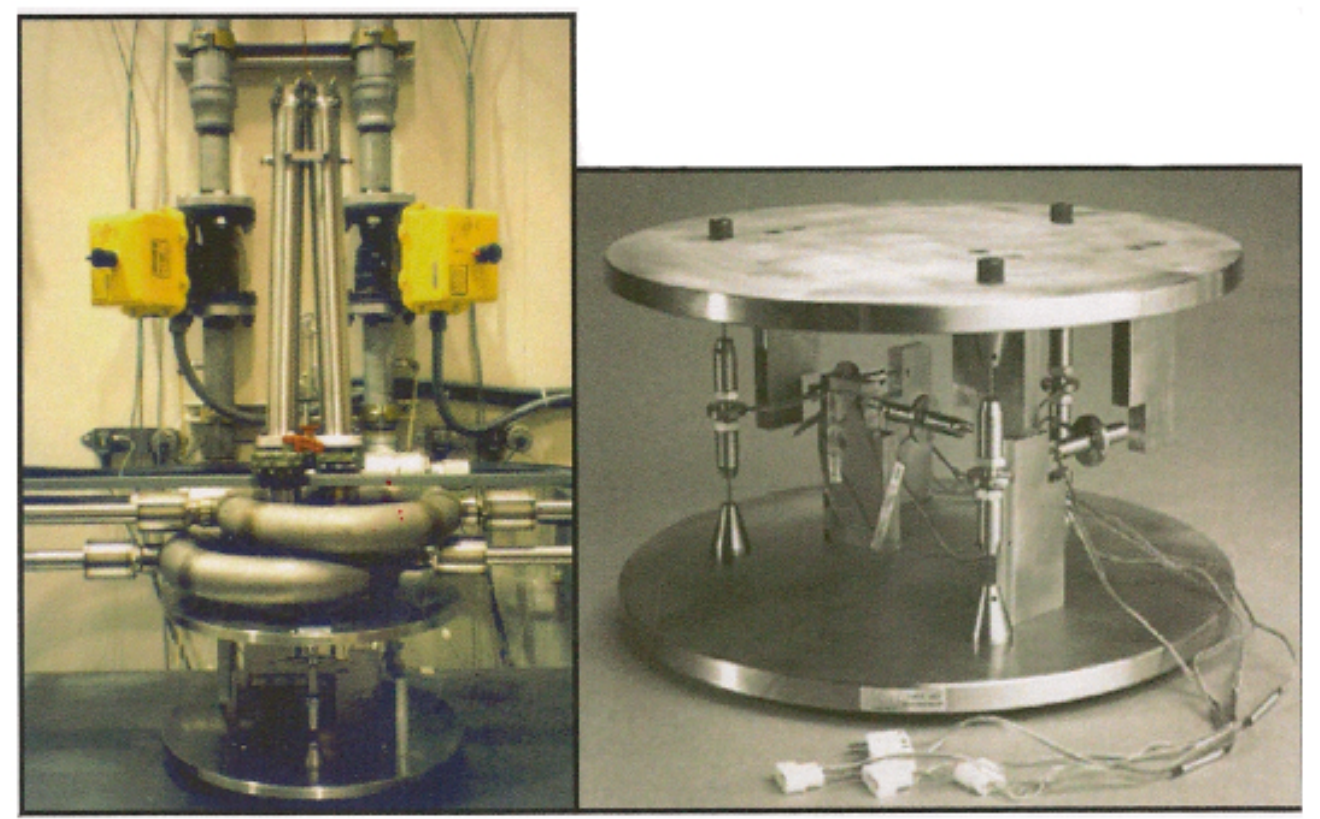

Figure 7: Thrust vector nozzle flow bench and six-component thrust stand.

In Figure 7, the thrust vector nozzle flow bench is shown combined with the sixcomponent thrust stand and the nozzle air supply manifold system. This particular nozzle configuration is the dual flow, side by side, $1 / 24^{\text {th }}$ scale F/A-18 with post-exit vanes. The manifold system consists of a plenum and bellows arrangement, which is supplied with 
air on opposite sides of the plenum. ${ }^{1}$ The bellows are externally pressurized to provide opposing forces to counteract the forces generated in the supply lines that supply the nozzle. Approximate equal amounts of the air are supplied to the plenum in order to cancel momentum and pressure effects due to the air supply. As a result, only the resultant loads from the propulsion of the gas emitted from the nozzle are seem by the load cells. Any remaining forces that are induced by the bellows are of a linear nature and can be accommodated by a relatively simple calibration. Therefore, accurate thrust vectoring measurements can be taken from a test nozzle. The use of the bellows system allows the low-pressure stand to provide pitch and yaw angle measurements within $\pm 0.5^{\circ}$. Schlieren images are captured through a two-mirror Schlieren system. A xenon light source is placed in front of the test nozzle as shown in Figure 8. A flat first surface mirror is placed directly behind the test nozzle to reflect the image cast by the light source to another first surface mirror. The second mirror is slightly concave, allowing the image to be focused into a camera. After the image is reflected off the second mirror, the image passes through a darkening filter, to de-intensify the image. The image then passes through a two-color film with an open slit in between the two colors. Finally, the image goes through a custom made lens and into the camera image sensor. The custom made lens is used to focus the image correctly into the camera. In the low-pressure testing, a video camera was originally used to record the Schlieren, and a relatively low resolution frame grabber was used to capture image stills. In subsequent testing, a high definition digital camera was used to acquire higher quality images.

\footnotetext{
${ }^{1}$ The bellows system was developed and patented by Tom Carpenter and Jim Gerhardt under U.S. patent number 6,032,545: Thrust Vector Nozzle Flow Bench, March 7, 2000.
} 
A summary of the performance of the straight and the vectored aerospike nozzle is shown in Table 1 and Table 2.

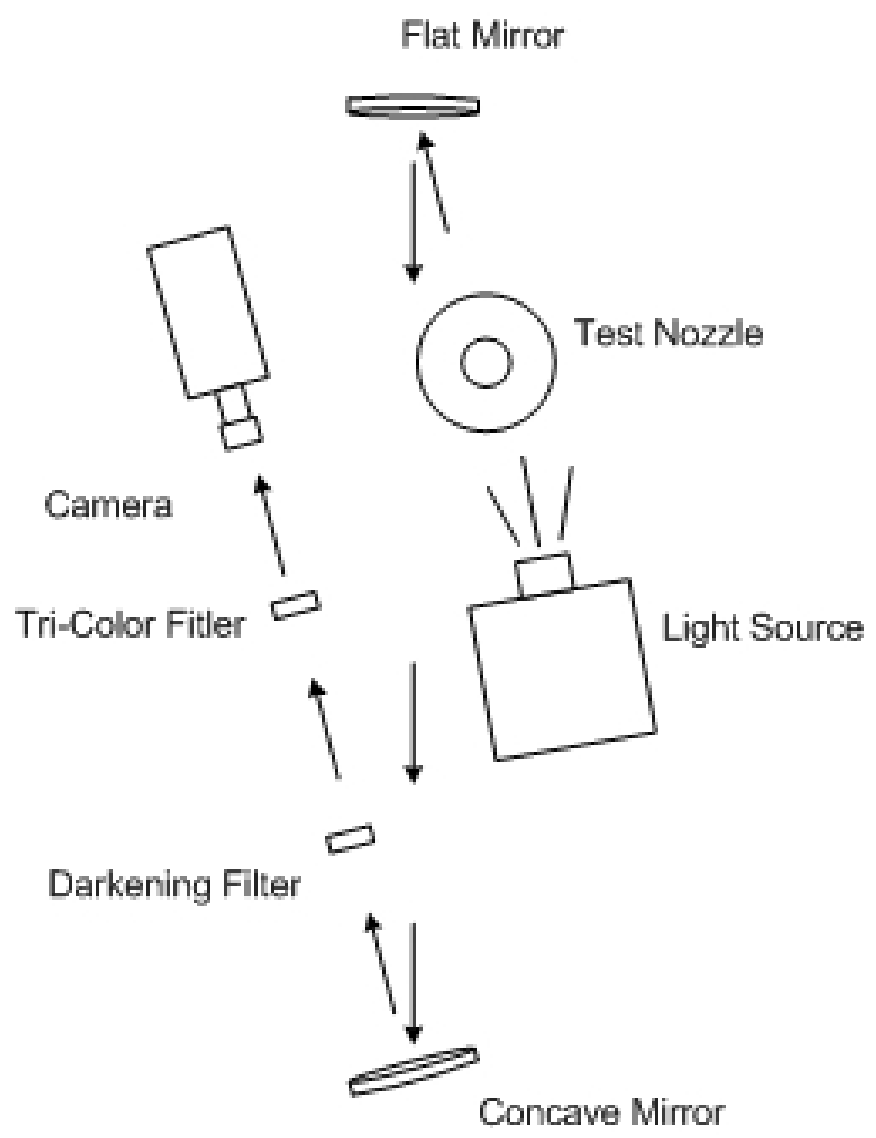

Figure 8: Schlieren imaging set up (top view). 
Table 1: Summary of the straight aerospike nozzle for the low-pressure system.

\begin{tabular}{|c|c|c|c|c|c|c|c|c|c|}
\hline Position / Run & $\begin{array}{c}\text { NPR } \\
-\end{array}$ & $\begin{array}{c}\mathbf{F}_{\mathbf{x}} \\
\mathrm{lbf}\end{array}$ & $\begin{array}{c}\mathbf{F}_{\mathbf{y}} \\
\mathrm{lb}_{\mathrm{f}}\end{array}$ & $\begin{array}{c}\mathbf{F}_{\mathbf{z}} \\
\mathrm{lb}_{\mathrm{f}}\end{array}$ & $\begin{array}{c}\mathbf{F}_{\text {vector }} \\
\mathrm{lb}_{\mathrm{f}}\end{array}$ & $\begin{array}{c}\mathbf{W}_{\mathbf{p}} \\
\mathrm{lb}_{\mathrm{m}} / \mathrm{s}\end{array}$ & $\begin{array}{c}\boldsymbol{\delta}_{\text {pitch }} \\
\circ\end{array}$ & $\begin{array}{c}\boldsymbol{\delta}_{\text {yaw }} \\
\circ\end{array}$ & $\begin{array}{c}\boldsymbol{\delta}_{\mathbf{r}} \\
\circ\end{array}$ \\
\hline Straight & & & & & & & & & \\
$1 / 1$ & 7.39 & 0.22 & 0.04 & -27.77 & 0.22 & 0.54 & -0.07 & -0.45 & -0.45 \\
$1 / 2$ & 7.52 & 0.18 & 0.01 & -27.73 & 0.18 & 0.54 & -0.02 & -0.37 & -0.37 \\
$1 / 3$ & 7.49 & 0.04 & -0.22 & -28.14 & 0.22 & 0.56 & 0.44 & -0.08 & -0.45 \\
\hline
\end{tabular}

Table 2: Summary of the vectored aerospike nozzle for the low-pressure system.

\begin{tabular}{|c|c|c|c|c|c|c|c|c|c|}
\hline Position / Run & $\begin{array}{c}\text { NPR } \\
-\end{array}$ & $\begin{array}{c}\mathbf{F}_{\mathbf{x}} \\
\mathrm{lbf}\end{array}$ & $\begin{array}{c}\mathbf{F}_{\mathbf{y}} \\
\mathrm{lb}_{\mathrm{f}}\end{array}$ & $\begin{array}{c}\mathbf{F}_{\mathbf{z}} \\
\mathrm{lb}_{\mathrm{f}}\end{array}$ & $\begin{array}{c}\mathbf{F}_{\text {vector }} \\
\mathrm{lb}_{\mathrm{f}}\end{array}$ & $\begin{array}{c}\mathbf{W}_{\mathbf{p}} \\
\mathrm{lb_{ \textrm {m } }} / \mathrm{s}\end{array}$ & $\begin{array}{c}\boldsymbol{\delta}_{\text {pitch }} \\
\circ\end{array}$ & $\begin{array}{c}\boldsymbol{\delta}_{\text {yaw }} \\
\circ\end{array}$ & $\begin{array}{c}\boldsymbol{\delta}_{\mathbf{r}} \\
\circ\end{array}$ \\
\hline $\begin{array}{c}\text { Single Port } \\
\text { Vectoring }\end{array}$ & & & & & & & & & \\
$1 / 1$ & 7.46 & -4.83 & 0.23 & -28.69 & 4.83 & 0.63 & -0.45 & 9.55 & -9.56 \\
$1 / 2$ & 7.43 & -4.86 & 0.22 & -28.45 & 4.87 & 0.62 & -0.44 & 9.70 & -9.71 \\
$1 / 3$ & 7.50 & -4.79 & 0.23 & -28.93 & 4.80 & 0.64 & -0.46 & 9.41 & -9.42 \\
\hline
\end{tabular}

The nozzle expansion efficiency is used to validate the results from the lowpressure system and compare to the high-pressure system. The nozzle used in this research is designed to perform at an NPR of 20. The nozzle efficiency plays a small role in how well the nozzle can support effective thrust vectoring.

The experimental values of the nozzle thrust coefficient are calculated based on the measured thrust force and the measured plenum pressure. The nozzle throat area is assumed to be the design area of $0.2163 \mathrm{in}^{2}$, although the exact area is subject to manufacturing and assembly tolerances.

As seen in Table 3, the average experimental nozzle thrust coefficient is approximately 1.17 for the low-pressure condition. This value is used to compare to the performance of the nozzle at the high-pressure design condition in Chapter 3 . The thrust coefficient for the vectored nozzle does not have much significance because the secondary port actually increases the size of the main nozzle throat slightly. This increase 
in the main nozzle throat explains the slightly higher nozzle thrust coefficient values. The secondary port also has its own nozzle thrust coefficient associated with it.

Table 3: Summary of nozzle performance for the straight aerospike nozzle for the low-pressure system.

\begin{tabular}{|c|c|c|c|}
\hline Position / Run & $\begin{array}{c}\text { NPR } \\
-\end{array}$ & $\begin{array}{c}\mathbf{A}_{\mathbf{t}} \\
\mathrm{in}^{2}\end{array}$ & $\begin{array}{c}\mathbf{C}_{\mathbf{f}} \\
-\end{array}$ \\
\hline Straight & & & \\
$1 / 1$ & 7.39 & 0.216 & 1.18 \\
$1 / 2$ & 7.52 & 0.216 & 1.16 \\
$1 / 3$ & 7.49 & 0.216 & 1.18 \\
\hline
\end{tabular}

Table 4: Summary of nozzle performance for the vectored aerospike nozzle for the low-pressure system.

\begin{tabular}{|c|c|c|c|c|c|}
\hline Position / Run & $\begin{array}{c}\text { NPR } \\
-\end{array}$ & $\begin{array}{c}\mathbf{A}_{\mathbf{t}} \\
\mathrm{in}^{2}\end{array}$ & $\begin{array}{c}\mathbf{C}_{\mathrm{f}} \\
-\end{array}$ & $\begin{array}{c}\mathbf{A}_{\mathrm{sp}} \\
\mathrm{in}^{2}\end{array}$ & $\begin{array}{c}\mathbf{C}_{\mathrm{f} s p} \\
-\end{array}$ \\
\hline $\begin{array}{c}\text { Single Port } \\
\text { Vectoring }\end{array}$ & & & & & \\
$1 / 1$ & 7.46 & 0.216 & 1.21 & 0.035 & 1.25 \\
$1 / 2$ & 7.43 & 0.216 & 1.21 & 0.035 & 1.27 \\
$1 / 3$ & 7.50 & 0.216 & 1.22 & 0.035 & 1.24 \\
\hline
\end{tabular}

The significance of these values is explained in Chapters 5 and 6 as it pertains to the high-pressure design conditions.

Schlieren images of the low-pressure tests are shown in Figure 9. However, it should be noted that the nozzles shown in Figure 9 are machined metal and not the rapid prototype material constructed nozzles. The metal finish gives a smoother flow field. 


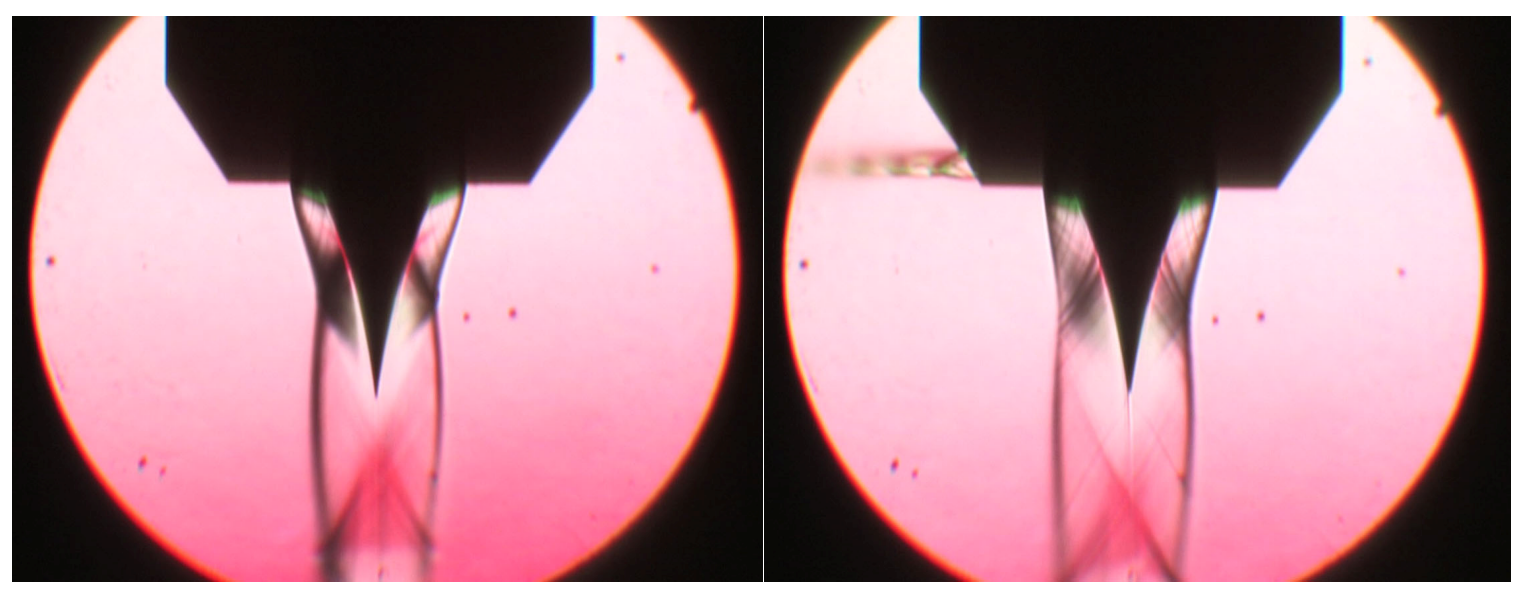

a) Straight metal nozzle.

b) Vectored metal nozzle.

Figure 9: Schlieren images of the low-pressure nozzle. 


\section{CHAPTER 3}

\section{High-pressure Blow-Down Experiments}

A series of tests was conducted with the high-pressure blow-down flow bench at Cal Poly San Luis Obispo to examine the general characteristics of an unvectored and a vectored aerospike nozzle. A modular design was developed to allow an aerospike nozzle to be tested in various configurations. The tests conducted include testing the following nozzles: an unvectored aerospike nozzle, a vectored aerospike nozzle, an unvectored conventional nozzle, a vectored conventional nozzle, a throttled unvectored aerospike nozzle, and a throttled vectored aerospike nozzle. Visual investigation of the flow characteristics of these aerospike nozzles was achieved with color Schlieren photography.

The high-pressure nozzle system can be seen mounted on the high-pressure flow bench in Figure 10. The parts comprising this nozzle can be seen in Figure 11, with various stages of construction shown in Figure 12. The geometry of this system corresponds to that of the hybrid rocket motor in the Cal Poly San Luis Obispo hot-flow facility. 


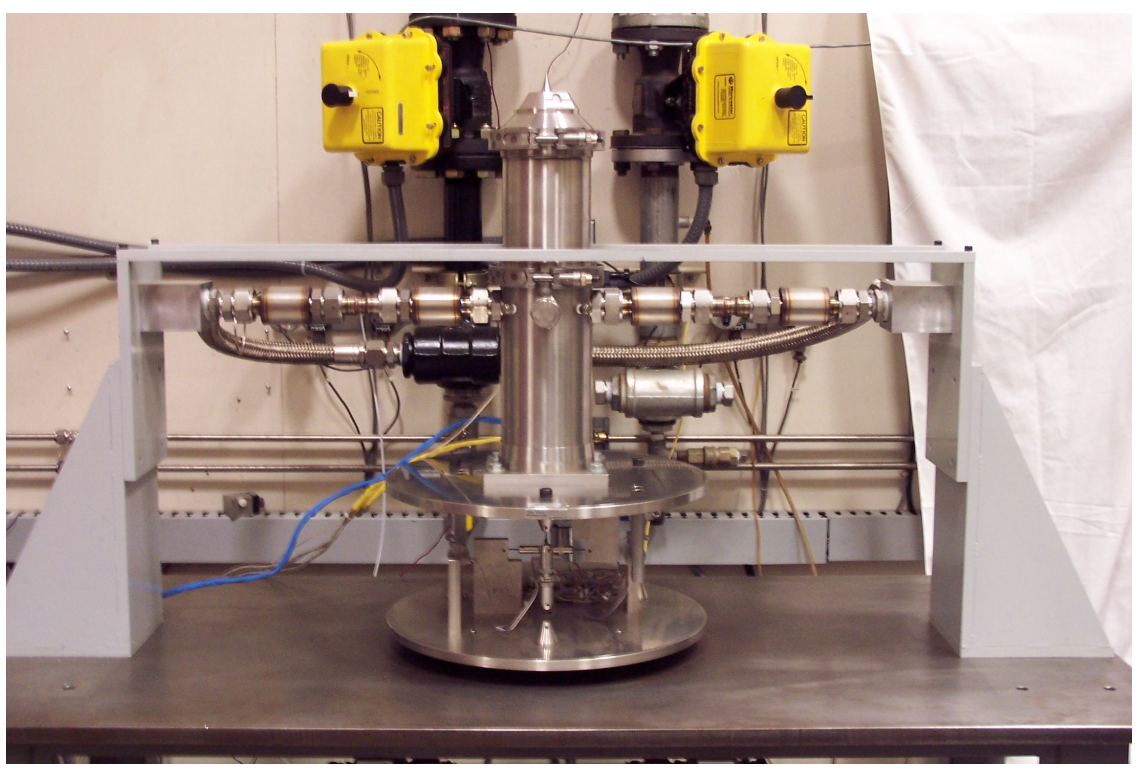

Figure 10: The high-pressure flow bench consists of the manifold, bellows, load cells, nozzle body, and aerospike.

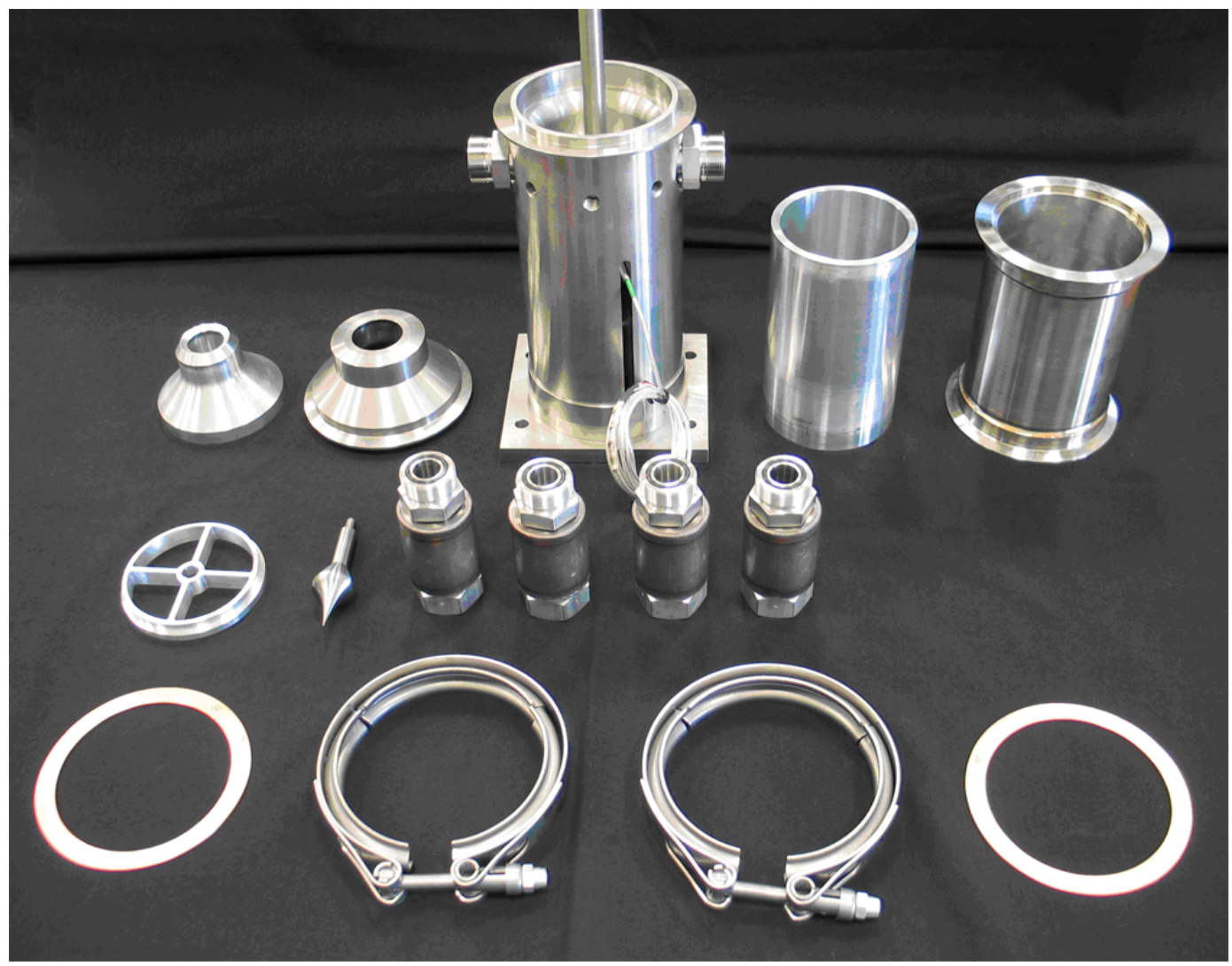

Figure 11: Parts for the high-pressure blow-down nozzle system. Front row: copper gaskets and Marmon clamps; middle row: spike centering ring, aerospike, four bellows; back row: nozzle liner, nozzle outer body (note: the outer shell shown is a preliminary version of the shell), base including a load cell to measure the force on the spike and an actuator to move the spike forward and/or backward in the axial direction, liner, and outer body. 

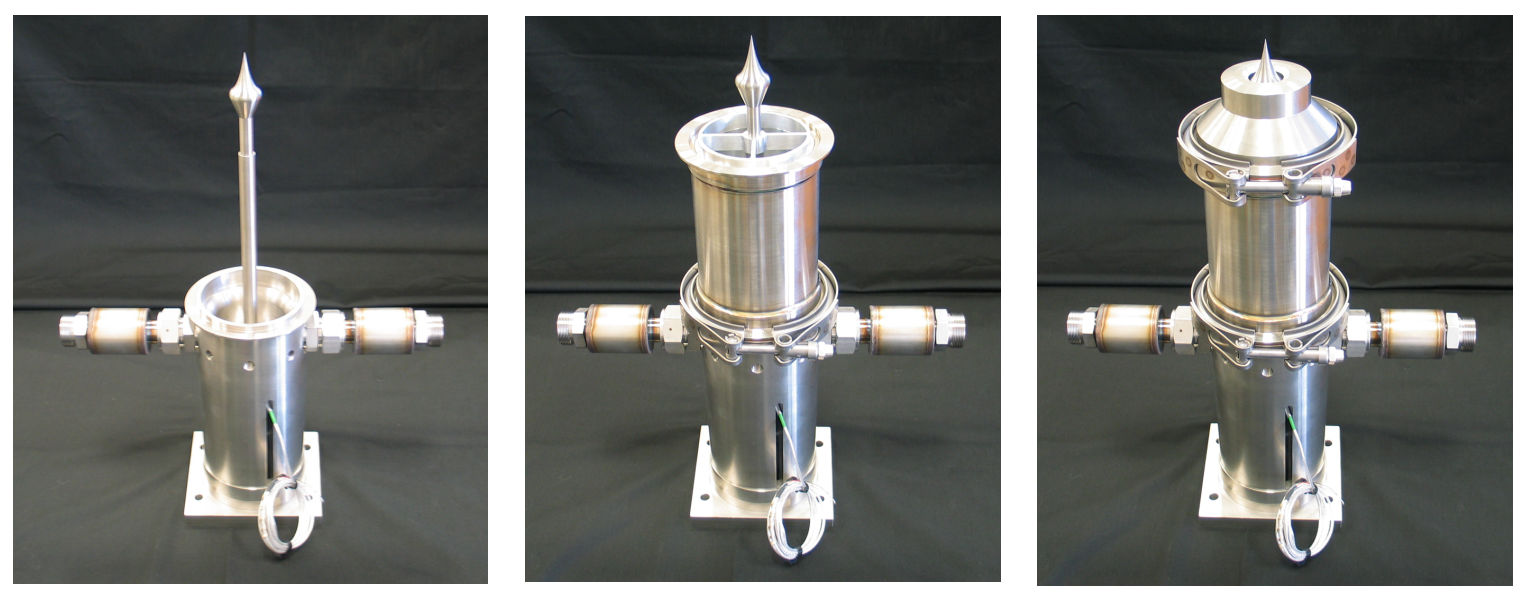

Figure 12: High-pressure nozzle stages of construction.

For ease of manufacturing, the nozzle outer body is constructed in two pieces: an outer nozzle body shell of stainless steel, and a polymer nozzle liner. The nozzle liners are made on an Eden250 rapid prototyping machine from Objet Geometries using a high density, acrylic-based photopolymer material.

The nozzle used for the straight, single-vectored, and double-vectored test runs was the same physical nozzle with modifications made for each specific test. The nozzle outer shell, shown in Figure 13a, b, and c, consists of a stainless steel nozzle shell with three holes that support single-port and double-port thrust vectoring for the aerospike nozzle as well as thrust vectoring for the converging-diverging nozzle. The hole shown in Figure $13 \mathrm{c}$ is for the secondary port of the converging-diverging nozzle. The other two holes shown in Figure 13a are $120^{\circ}$ apart and are for single-port or double-port thrust vectoring.

The corresponding nozzle liner, shown in Figure 14a, has two secondary port holes that match with the nozzle outer shell. For unvectored configurations, both holes in the nozzle liner are made inactive by means of plastering the secondary port hole shut and smoothing over the inner surface as to minimally affect the interior flow of the 
nozzle. In a single-port vectored configuration, the inner nozzle is rotated so that only one secondary port is active. For a double-port vectored configuration, both secondary ports are active. The nozzle outer shell and inner liner for the aerospike nozzle are shown in Figure 13c through Figure 13f. The liner for the converging-diverging nozzle is shown in Figure 14b. 


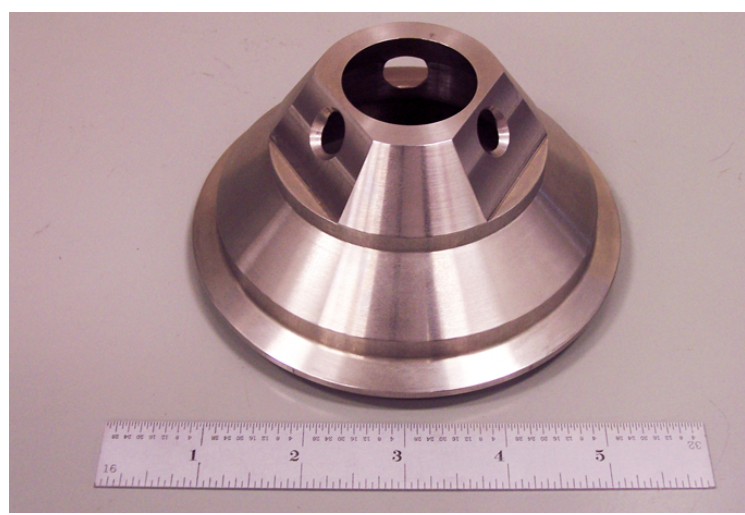

a) Outer shell.

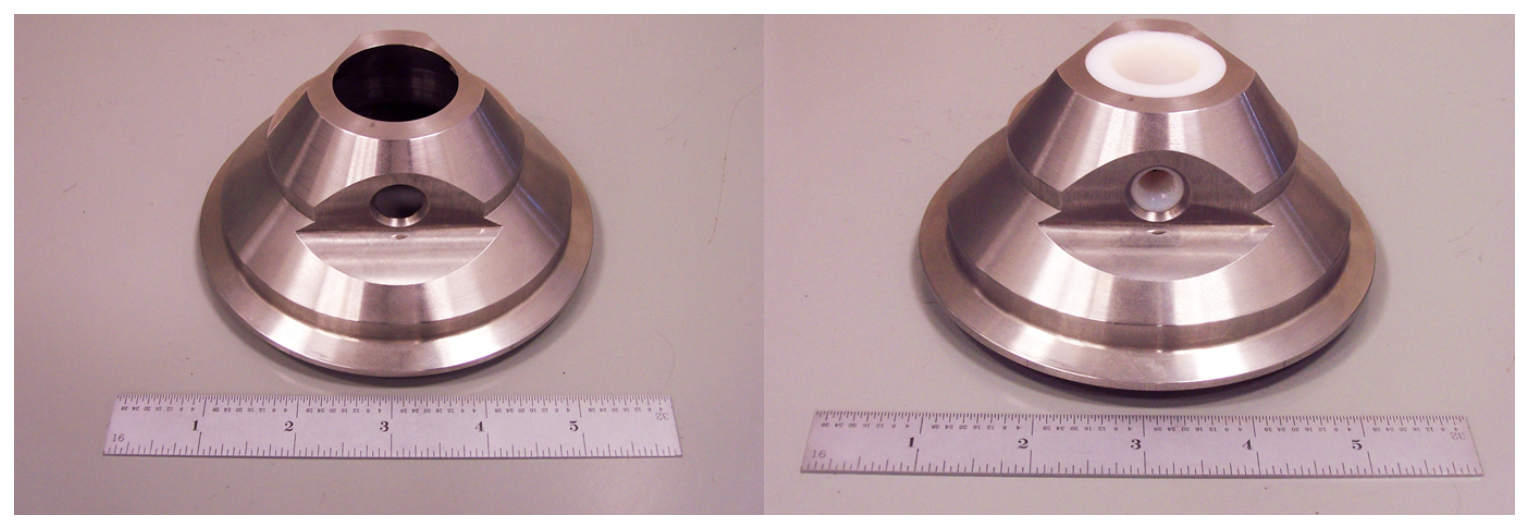

c) Outer shell, converging-diverging secondary port d) Outer shell and liner for the converging-diverging view.

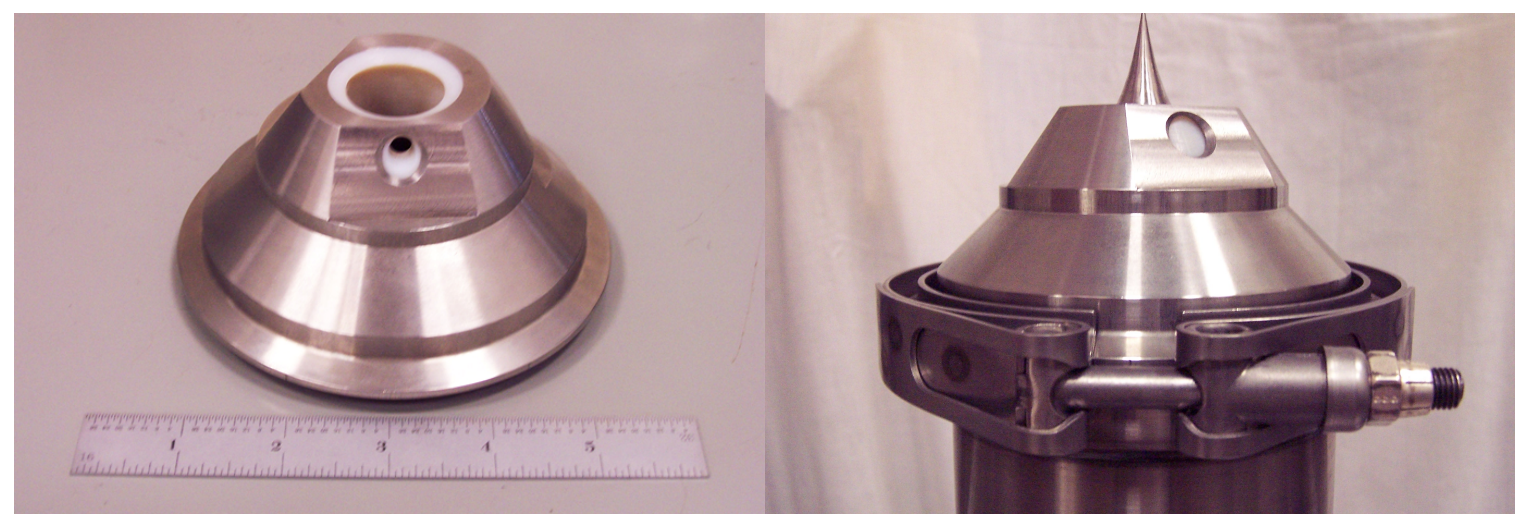

e) Outer shell and liner for the aerospike nozzle.

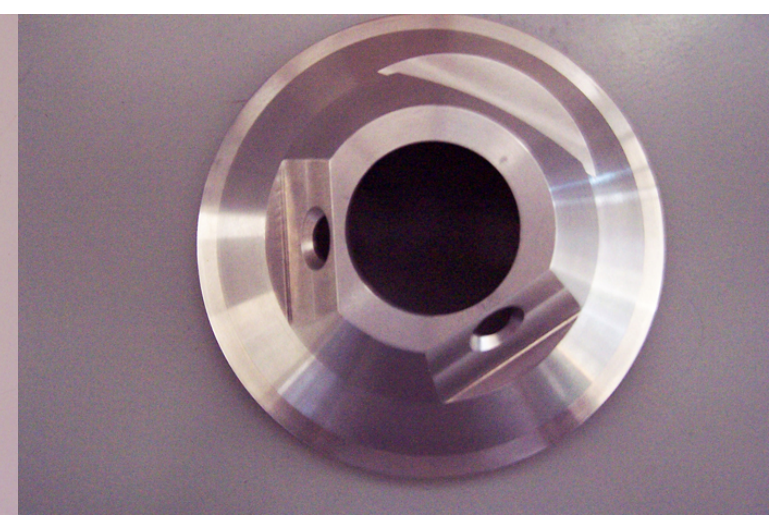

b) Outer shell, top view. nozzle.

f) Mounted aerospike nozzle.

Figure 13: Nozzle components of the high-pressure system tests. 


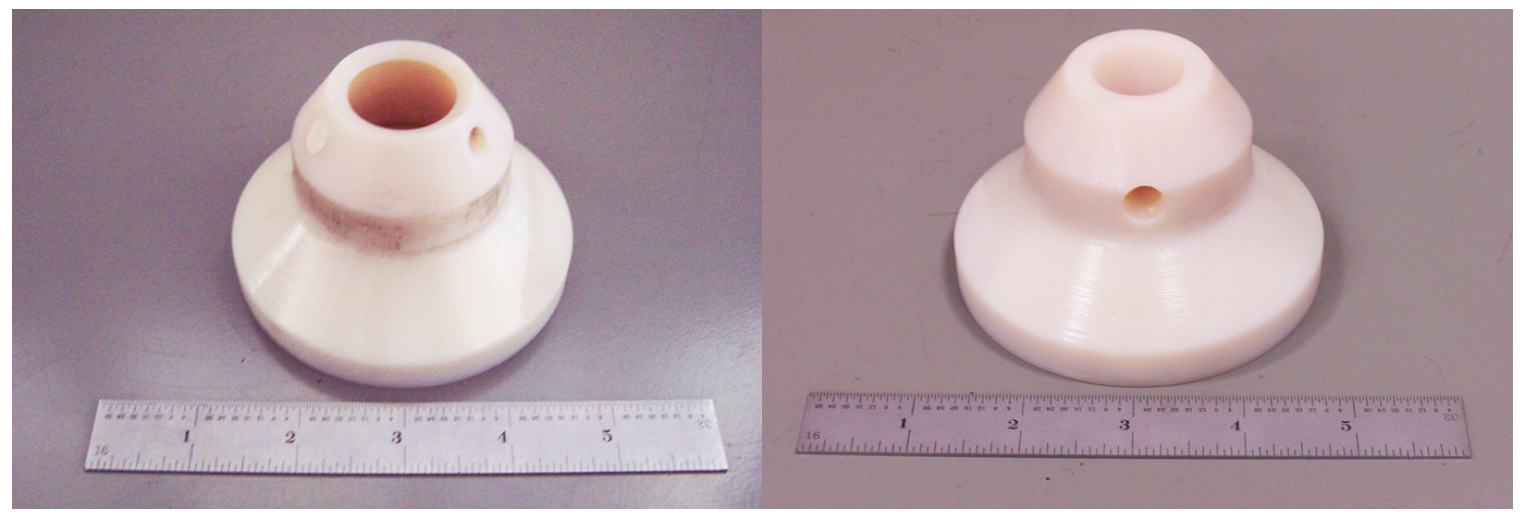

a) Aerospike liner with one secondary port plastered shut.

b) Converging-diverging liner.

Figure 14: Aerospike and converging-diverging nozzle liners.

Using one nozzle for all three tests allows any imperfections in the nozzle construction itself to be taken into account. The nozzle can be tested in both a vectored configuration and a straight configuration. The unvectored configuration was tested and the average resultant forces are subtracted from the vectored runs to remove bias due to imperfections in the nozzle and/or flow bench, thereby yielding a more accurate assessment of the turning performance provided by thrust vectoring.

To generate the higher pressures needed to operate at the design condition of an NPR 20 nozzle (294 psig), the low-pressure blow-down system was upgraded. An 18 ' $x 5^{\prime} \times 9$ ' hazardous material storage shed is located outside the test facilities that houses twelve 4000 psig air cylinders that supply the new high-pressure blow-down flow bench, shown in Figure 10, and a high-pressure compressor for charging the air cylinders as shown in Figure 15. The twelve air cylinders are arranged into two banks of six cylinders. Blow-down tests can be supplied from either bank, or both banks of air cylinders. The 4000 psig air is regulated down to approximately 500 psig and passes through a series of two pressure relief valves, one set to vent at 525 psig and the other to set to vent at 550 psig. The dual pressure relief valves add redundancy for safety purposes. From the 
primary exit of the relief valves, the regulated air is piped out of the storage shed, through the building wall, and into the test cell. There it passes through a flow meter and enters the high-pressure manifold, where it is split to the left and right bellows, as shown in Figure 16a.

The manifold system consists of a plenum and bellows arrangement, which is supplied with air on opposite sides of the plenum. ${ }^{2}$ The bellows are externally pressurized to provide opposing forces to counteract the forces generated in the supply lines that supply the nozzle. Approximate equal amounts of the air are supplied to the plenum in order to cancel momentum and pressure effects due to the air supply. As a result, only the resultant loads from the propulsion of the gas emitted from the nozzle are seem by the load cells. Any remaining forces from that are incurred by the bellows are of a linear nature and can be calibrated out. Therefore, accurate thrust vectoring measurements can be taken from a test nozzle. The use of the bellow system allows the high-pressure stand to provide pitch and yaw angle measurements within $\pm 0.5^{\circ}$. The bellows are shown in Figure 16b.

The plenum pressure is controlled by a pressure control valve that matches the pressure measured in the plenum to a set point. On exiting the bellows, the air flow then enters the plenum of the nozzle. Burst disks were inserted into the plenum structure for safety and component protection as seen in Figure 16c. In case of a large surge in pressure in the plenum, the burst disks will burst allowing for a rapid reduction in pressure. The flow then exits the plenum through the nozzle, shown in Figure 13d.

\footnotetext{
${ }^{2}$ The bellow system was developed and patented by Tom Carpenter and Jim Gerhardt under U.S. patent number 6,032,545: Thrust Vector Nozzle Flow Bench, March 7, 2000.
} 
A six-component thrust stand measures the loads that are incurred by the propulsion of gas by the test nozzle. The thrust stand consists of six miniature tensioncompression load cells. Three load cells are positioned in vertical direction and three load cells are positioned in the horizontal position. A referential Cartesian coordinate system is placed in the plane of the horizontal load cells with the z-direction aligned in the vertical upward direction and the center of the coordinate system located at the center of the stand. With the position of each load cell known it is possible to convert the measured loads to forces and moments about the $\mathrm{x}, \mathrm{y}, \mathrm{z}$ axes, i.e., $\mathrm{F}_{\mathrm{x}}, \mathrm{F}_{\mathrm{y}}, \mathrm{F}_{\mathrm{z}}, \mathrm{M}_{\mathrm{x}}, \mathrm{M}_{\mathrm{y}}, \mathrm{M}_{\mathrm{z}}$, and also determine the angles of pitch and yaw, $\delta_{\mathrm{p}}, \delta_{\mathrm{y}}$. Additional forces and angles can be calculated from these measurements for further analysis.

To actively control the spike position, additional electronics were incorporated. The electronics circuit board and servo-controlled stepper motor can be seen in Figure 16d and in Figure 16e, respectively. The programming and implementation of the feedback scheme was developed and implemented by Terry Cooke.

Schlieren images are captured through a two-mirror Schlieren step up. A xenon light source is placed in front of the test nozzle as shown in Figure 8. A flat first surface mirror is placed directly behind the test nozzle to reflect the image cast by the light source to another first surface mirror. The second mirror is slightly concave, allowing the image to be focused into a camera. After the image is reflected off the second mirror, the image passes through a darkening filter, to de-intensify the image. The image then passes through a two color film with an open slit in between the two colors. Finally, the image goes through a custom made lens and into the camera image sensor. The custom made 
lens is used to focus the image correctly into the camera. In the high-pressure testing, a high definition camera was used to record the video and capture image stills.

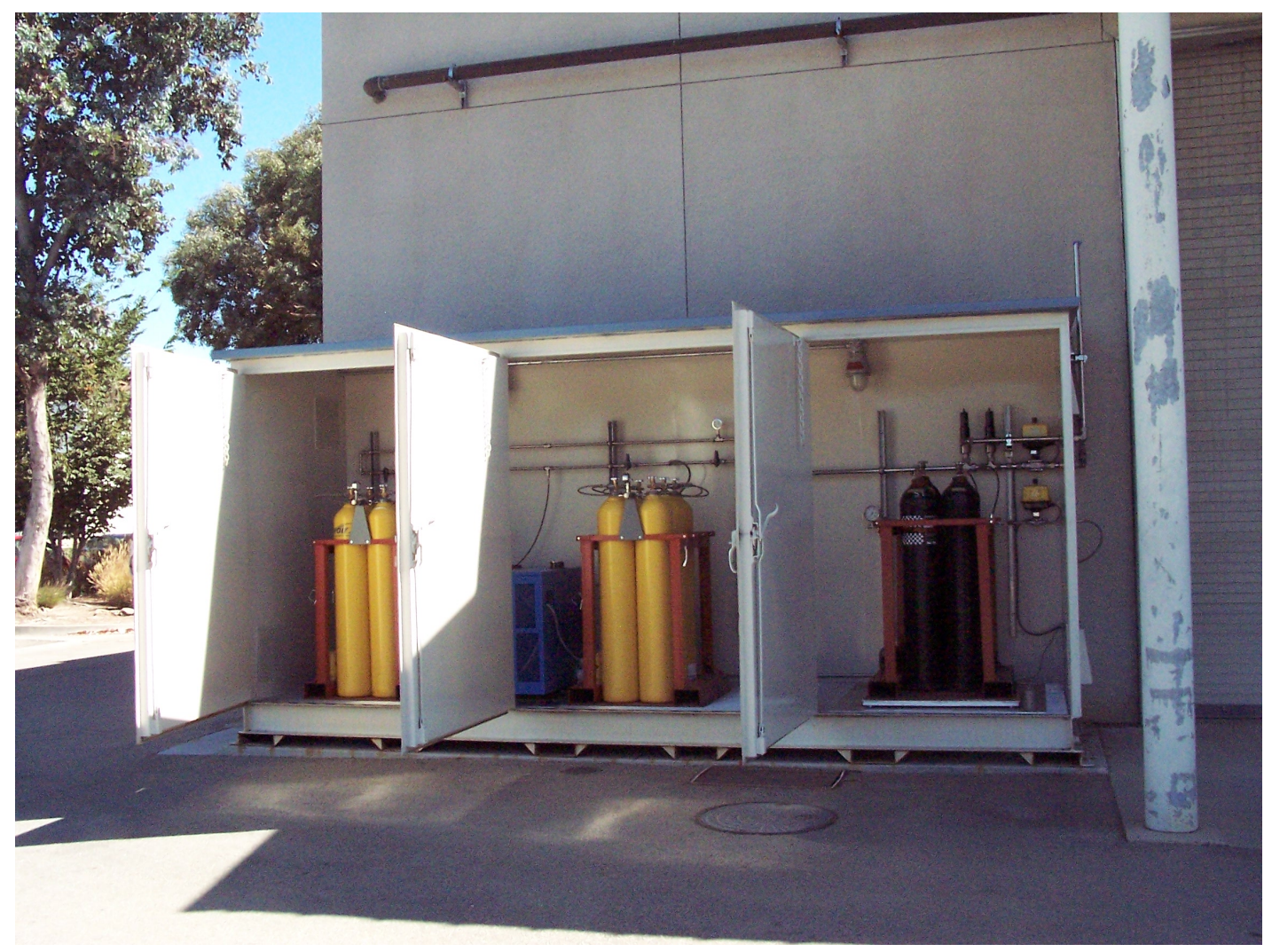

Figure 15: Hazardous material storage shed. 


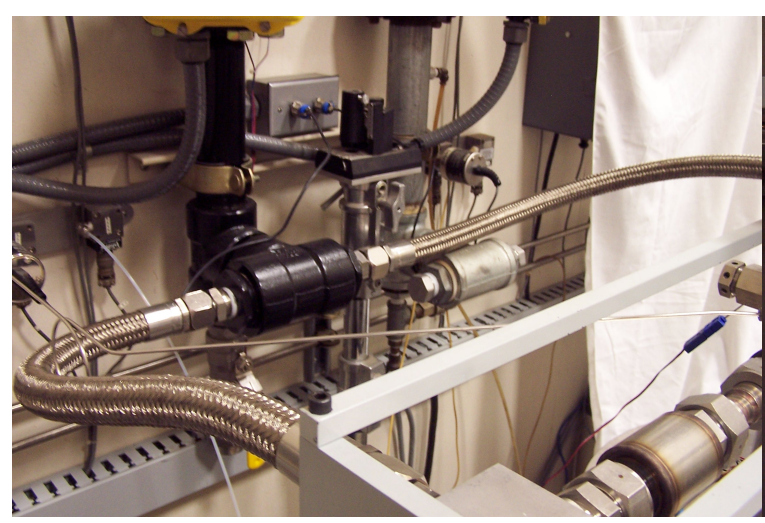

a) Manifold.

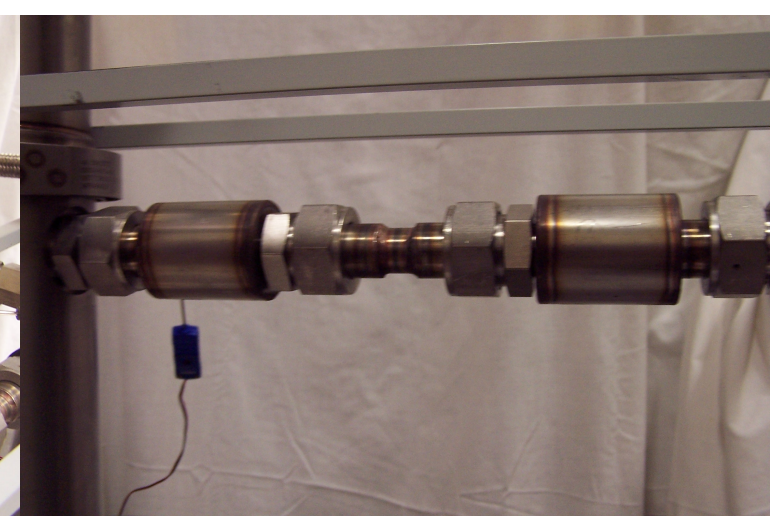

b) Bellows.

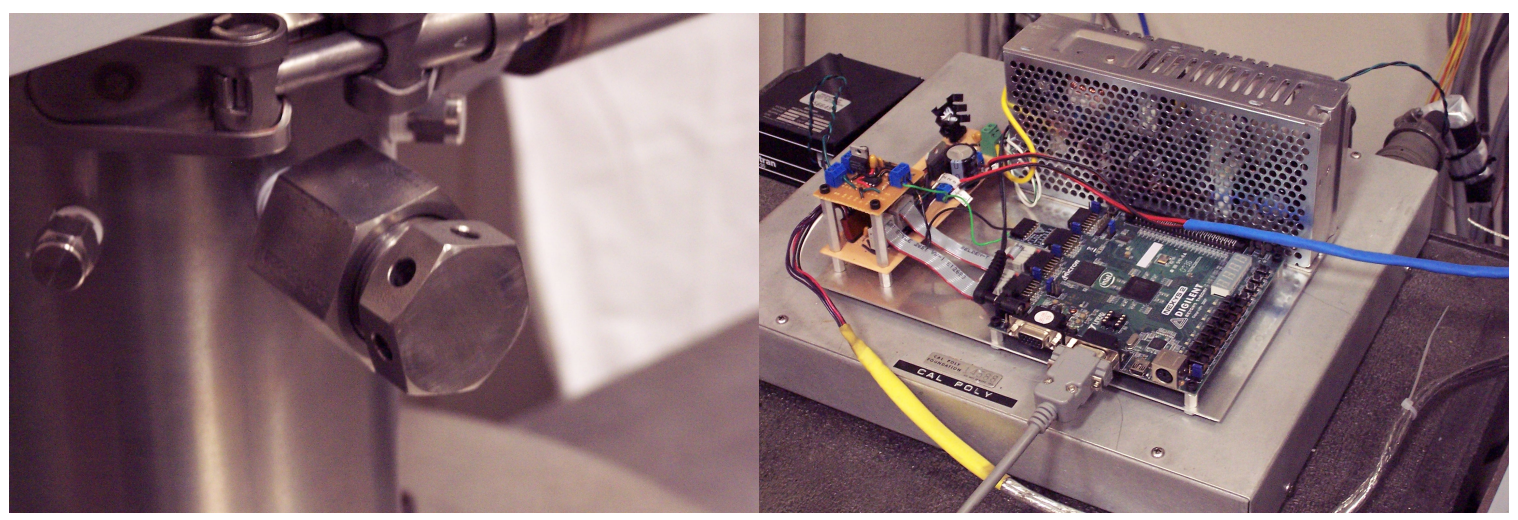

c) Burst disks.

d) Controller for the active spike throttling.

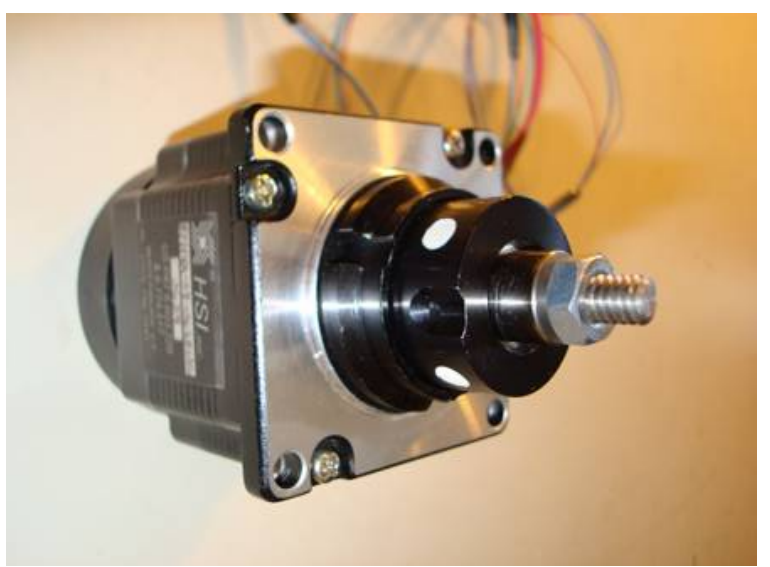

e) Stepper motor.

Figure 16: Major components of the high-pressure system. 


\section{CHAPTER 4}

\section{Aerospike Nozzle Design}

There are several ways to develop the contour of an aerospike, but the method laid out in this document uses a Prandtl expansion function similar to the methods shown by Besnard [3]. The reference geometry definitions used for calculating the geometry of an aerospike is shown in Figure 17.

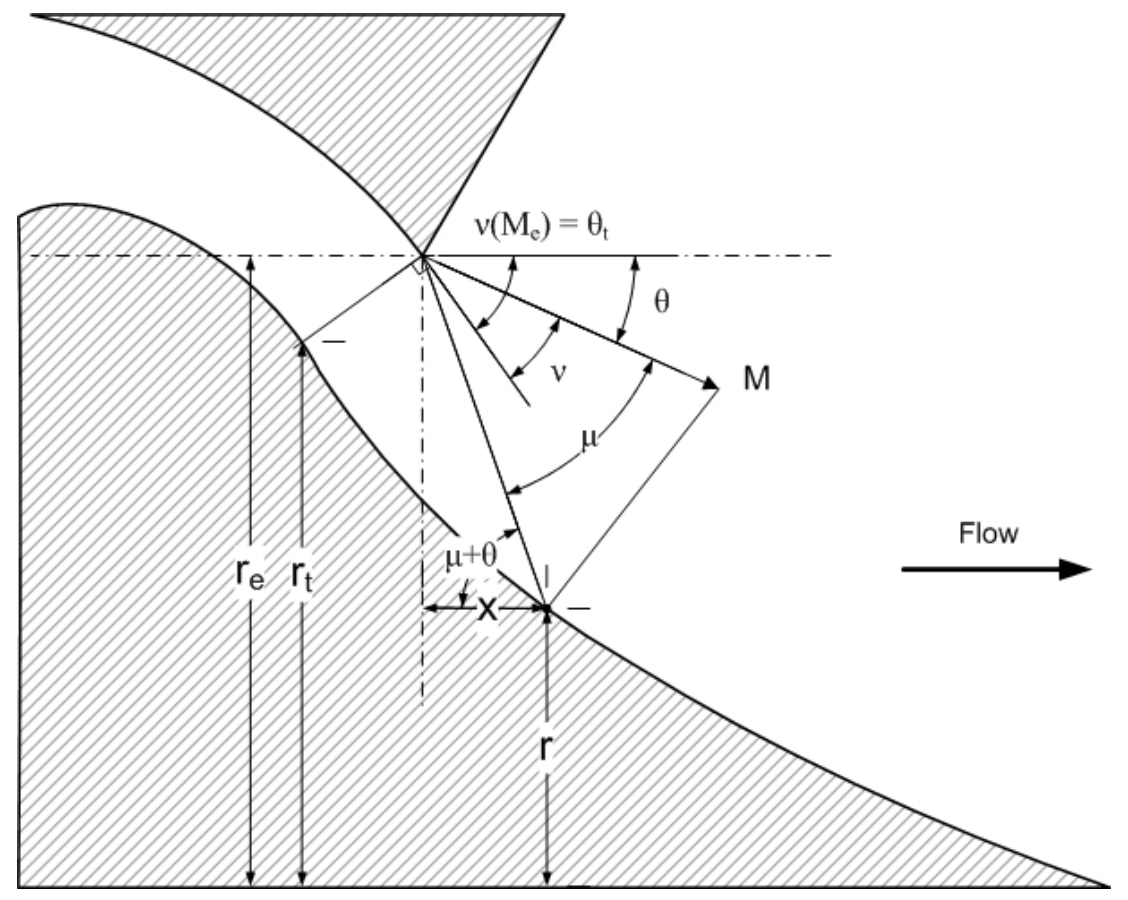

Figure 17: Geometry definition for the generic aerospike contour.

Starting with a basic isentropic flow equation [2]:

$$
\frac{P_{c}}{P_{e}}=\left[1+\frac{\gamma-1}{2} M_{e}^{2}\right]^{\frac{\gamma}{\gamma-1}}
$$

Choosing a design pressure will determine an exit Mach number and area ratio. For $\mathrm{NPR}=20$, 


$$
\begin{gathered}
20=\left[1+\frac{1.4-1}{2} M_{e}^{2}\right]^{\frac{1.4}{0.4}} \Rightarrow M_{e}=2.601 \\
\frac{A_{e}}{A_{t}}=\frac{1}{M_{e}}\left[\frac{2}{\gamma+1}\left(1+\frac{\gamma-1}{2} M_{e}^{2}\right)\right]^{\frac{\gamma+1}{2(\gamma-1)}} \\
\frac{A_{e}}{A_{t}}=\frac{1}{2.601}\left[\frac{2}{1.4+1}\left(1+\frac{1.4-1}{2} \cdot 2.601^{2}\right)\right]^{\frac{1.4+1}{2(1.4-1)}}=2.898
\end{gathered}
$$

For a value of $r_{e}$ as unity $\left(r_{e}=1\right)$, exit and throat areas can be calculated:

$$
\begin{gathered}
A_{e}=\pi \cdot r_{e}^{2} \\
A_{e}=3.14159 \mathrm{in}^{2} \\
A_{t}=\frac{3.14159}{2.898}=1.08379 \mathrm{in}^{2}
\end{gathered}
$$

Using the geometrical definitions in Figure 17 as a guideline, the following geometries can be derived:

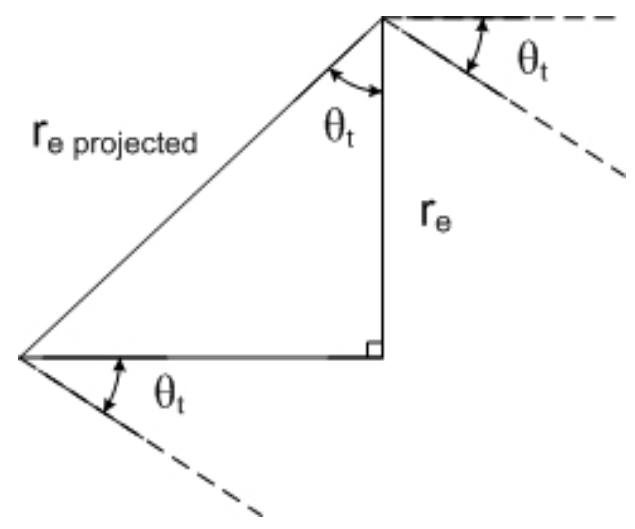

Figure 18: Geometry definition for the projected radius to find the throat area.

$$
\begin{gathered}
A_{t}=A_{e p r o j}-A_{t p r o j} \\
r_{e}=\frac{r_{e p r o j}}{\cos \left(\theta_{t}\right)}
\end{gathered}
$$




$$
\begin{gathered}
A_{\text {eproj }}=\frac{\pi \cdot r_{e}^{2}}{\cos \left(\theta_{t}\right)} \\
A_{t}=\frac{\pi\left(r_{e}^{2}-r_{t}^{2}\right)}{\cos \left(\theta_{t}\right)} \\
\theta_{t}=v_{e}
\end{gathered}
$$

The Prandtl-Meyer function, $v$, is defined as follows:

$$
v(M)=\int \frac{\sqrt{M^{2}-1}}{1+\frac{\gamma-1}{2} \cdot M^{2}} \cdot \frac{d M}{M}
$$

Integrating gives the following equation:

$$
v=K \cdot \tan ^{-1}\left(\frac{\sqrt{M^{2}-1}}{K}\right)-\tan ^{-1}\left(\sqrt{M^{2}-1}\right)
$$

$\mathrm{K}$ is defined as follows:

$$
K=\sqrt{\frac{\gamma+1}{\gamma-1}}
$$

For air, $\gamma=1.4$,

$$
K=\sqrt{\frac{1.4+1}{1.4-1}}=2.449
$$

The Prandtl-Meyer function at the exit condition is:

$$
v_{e}=2.449 \cdot \tan ^{-1}\left(\frac{\sqrt{2.601^{2}-1}}{2.449}\right)-\tan ^{-1}\left(\sqrt{2.601^{2}-1}\right)=41.43^{\circ}
$$

Solving for the throat radius,

$$
1.08379=\frac{\pi\left(1^{2}-r_{t}^{2}\right)}{\cos (41.43)} \quad \Rightarrow \quad r_{t}=0.8610 \quad \text { in }
$$


The axial coordinate of the spike contour is derived as follows:

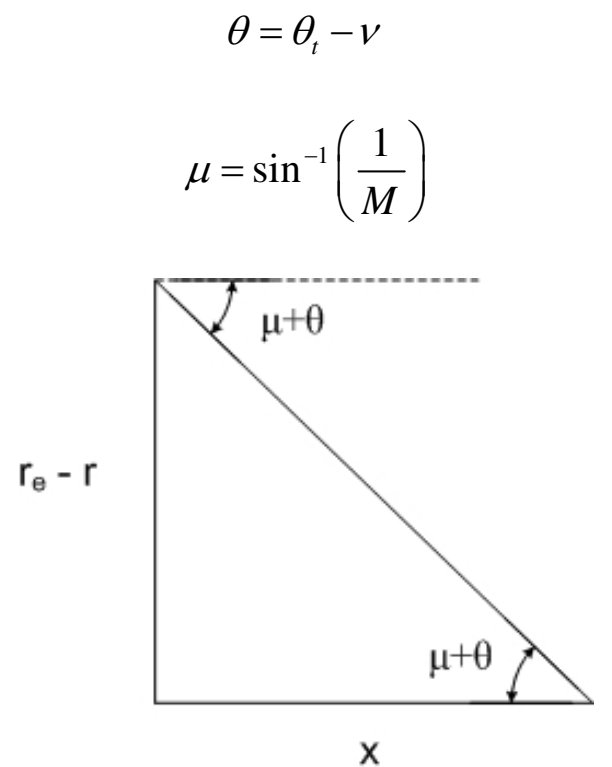

Figure 19: Geometry definition for the x-coordinate on the aerospike contour.

$$
\begin{gathered}
\tan (\mu+\theta)=\frac{r_{e}-r}{x} \\
x=\frac{r_{e}-r}{\tan (\mu+\theta)}
\end{gathered}
$$

The area at any given point along the spike can be described as follows:

$$
\begin{gathered}
A=\pi \cdot\left(r_{e}^{2}-r^{2}\right) \frac{\sin (\mu)}{\sin (\mu+\theta)} \\
\frac{A}{A_{t}}=\frac{\pi \cdot\left(r_{e}^{2}-r^{2}\right)}{\pi \cdot\left(r_{e}^{2}-r_{t}^{2}\right)} \cdot \frac{\cos \left(\theta_{t}\right) \cdot \sin (\mu)}{\sin (\mu+\theta)}
\end{gathered}
$$

Solving for the radial coordinate of the spike contour $r$,

$$
r=r_{e}^{2}-\left(r_{e}^{2}-r_{t}^{2}\right) \cdot \frac{A}{A_{t}} \cdot \frac{\sin (\mu+\theta)}{\sin \mu \cos \theta_{t}}
$$


A MATLAB program was written to derive and show the spike contours for any desired fluid and/or NPR. The following graph shown in Figure 20, Figure 21, and Figure 22 are example outputs from the program. The source code is included in Appendix B.

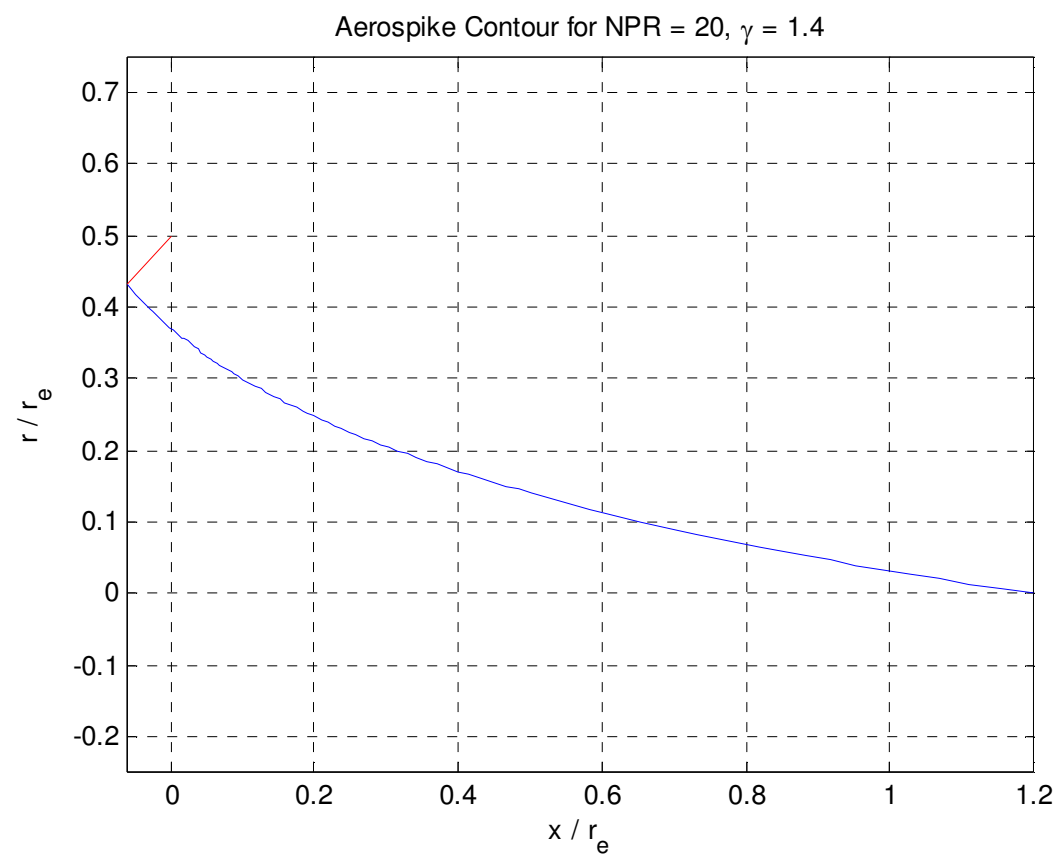

Figure 20: Aerospike contour with the throat. 


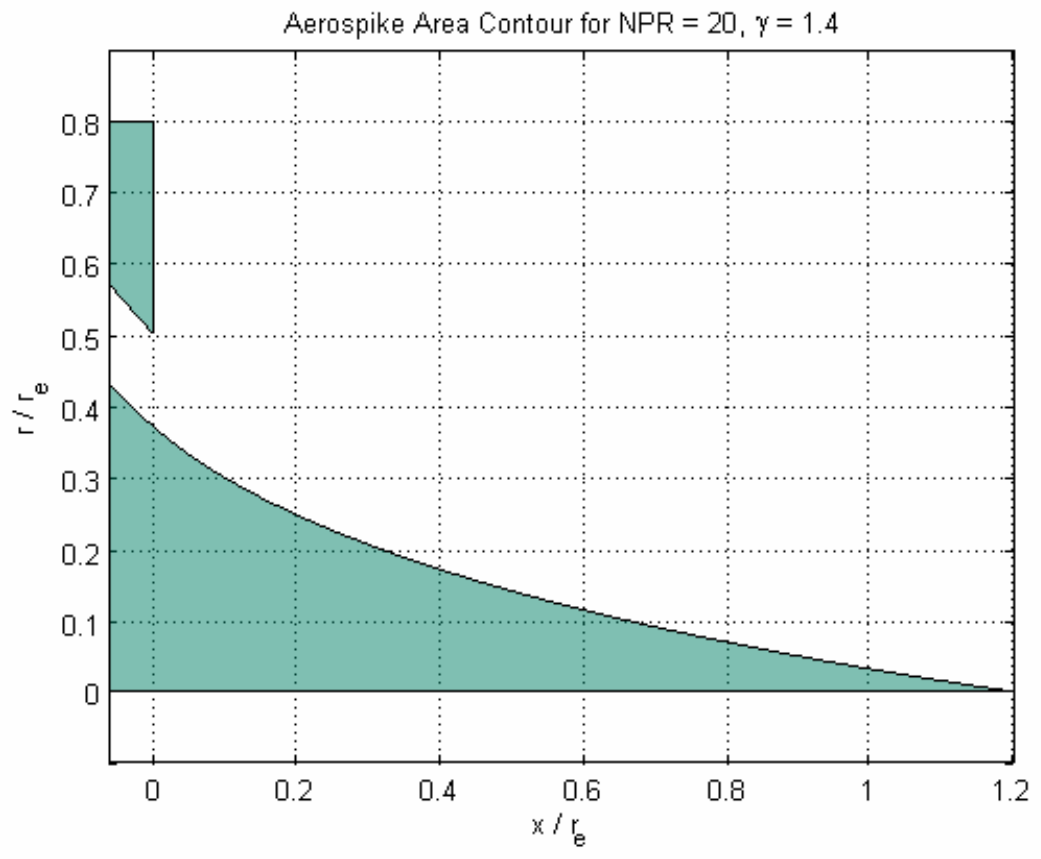

Figure 21: Area contour of an aerospike nozzle.

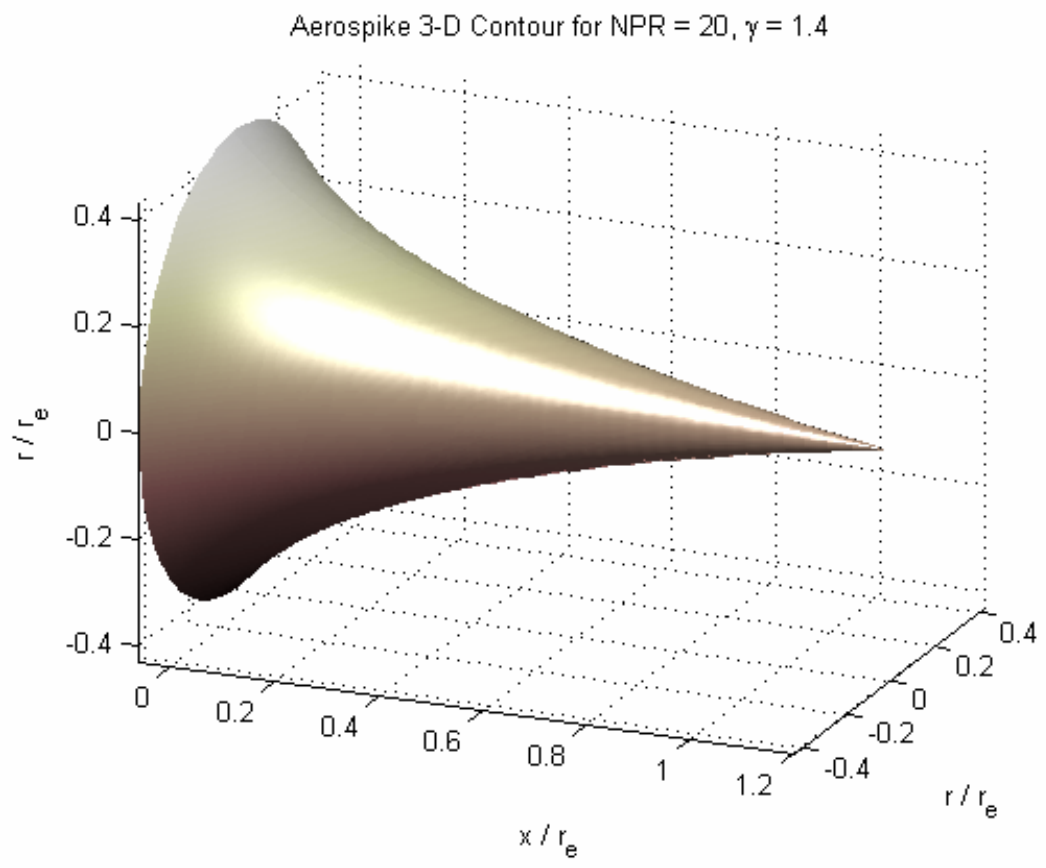

Figure 22: 3D contour on an aerospike nozzle. 


\section{CHAPTER 5}

\section{Unvectored Nozzle}

A series of tests was conducted with the high-pressure flow bench with both an unvectored aerospike nozzle and an unvectored conventional nozzle to determine the baseline performance of each nozzle. Both of the nozzles were tested in three different rotational positions. The test results are shown in Table 5 and Table 7. Further analysis was performed on the tests to characterize the nozzle efficiencies and those results are shown in Table 6 and Table 8 . Visual investigation of the flow characteristics of the unvectored aerospike nozzle and the unvectored conventional nozzle was achieved with color Schlieren photography.

A drawing cross-section of the unvectored aerospike nozzle assembly is shown in Figure 23 which shows the basic layout of the nozzle structure. The ideal unvectored nozzle should flow straight, generating no side force. However, actual unvectored nozzles do generate side forces. To the extent that these side forces are repeatable, these nonidealities may be accommodated through the following calibration procedure. The results from tests conducted at different nozzle rotational positions are averaged based on multiple runs for each respective position. That average is then subtracted from the force data for the single runs to accommodate imperfections in the nozzle and/or flow bench. In tabulated results, data are listed in rows designated using the following nomenclature: (rotational position) / (run number), where the rotational positions are described in Figure 29 in Chapter 6. By testing the nozzle in different rotational positions, the straightness and symmetry of the nozzle and the repeatability of the flow bench and six-component thrust stand may be evaluated. 
The Schlieren image in Figure 24 illustrates the flow visualization for the straight aerospike nozzle. It can be seen in the Schlieren image that the flow for this design pressure is fully expanded.

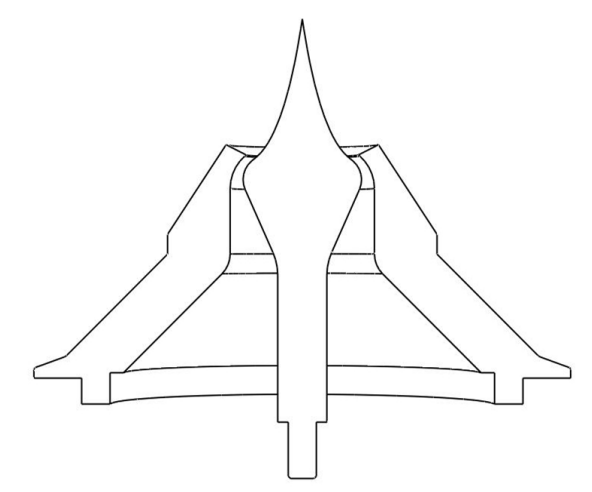

Figure 23: Unvectored aerospike nozzle.

As can be seen in Table 5, the resultant turn angle was minimal. However, side forces are produce as previously mentioned. The biased turn angle can be attributed to the fact that the inside nozzle liner is made of a plastic rapid prototype material and was not machined to tight tolerances. The thrust produced from the unvectored aerospike nozzle is approximately $92 \mathrm{lb}_{\mathrm{f}}$. With this baseline data set for comparison, the results from the high-pressure blow-down tests are discussed in detail in subsequent sections.

Table 5: Summary of the straight aerospike nozzle in various rotational positions.

\begin{tabular}{|c|c|c|c|c|c|c|c|c|c|}
\hline Position / Run & $\begin{array}{c}\text { NPR } \\
- \\
\end{array}$ & $\begin{array}{l}\mathbf{F}_{\mathbf{x}} \\
\mathrm{lbf}\end{array}$ & $\begin{array}{l}\mathbf{F}_{\mathbf{y}} \\
\mathrm{lb}_{\mathrm{f}} \\
\end{array}$ & $\begin{array}{l}\mathbf{F}_{z} \\
l b_{\mathrm{f}} \\
\end{array}$ & $\begin{array}{c}\mathbf{F}_{\text {vector }} \\
\mathrm{lb}_{\mathrm{f}} \\
\end{array}$ & $\begin{array}{c}\mathbf{W}_{\mathbf{p}} \\
\mathrm{lb}_{\mathrm{m}} / \mathrm{s} \\
\end{array}$ & 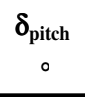 & 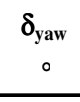 & $\begin{array}{c}\delta_{\mathrm{r}} \\
\circ\end{array}$ \\
\hline \multicolumn{10}{|l|}{ Straight } \\
\hline $1 / 1$ & 20.37 & -0.03 & -0.10 & -92.41 & 0.10 & 1.49 & 0.06 & 0.02 & -0.06 \\
\hline $1 / 2$ & 20.39 & 0.03 & 0.10 & -92.62 & 0.10 & 1.48 & -0.06 & -0.02 & -0.06 \\
\hline $2 / 1$ & 20.46 & 0.12 & 0.00 & -92.22 & 0.12 & 1.52 & 0.00 & -0.07 & -0.07 \\
\hline $2 / 2$ & 20.45 & -0.12 & 0.00 & -91.88 & 0.12 & 1.52 & 0.00 & 0.08 & -0.08 \\
\hline $3 / 1$ & 20.31 & 0.08 & -0.41 & -91.78 & 0.42 & 1.49 & 0.26 & -0.05 & -0.26 \\
\hline $3 / 2$ & 20.29 & 0.47 & 0.16 & -92.21 & 0.50 & 1.49 & -0.10 & -0.29 & -0.31 \\
\hline $3 / 3$ & 20.46 & -0.70 & 0.23 & -91.85 & 0.74 & 1.53 & -0.14 & 0.44 & -0.46 \\
\hline $3 / 4$ & 20.51 & 0.15 & 0.01 & -92.29 & 0.15 & 1.53 & -0.01 & -0.09 & -0.09 \\
\hline
\end{tabular}




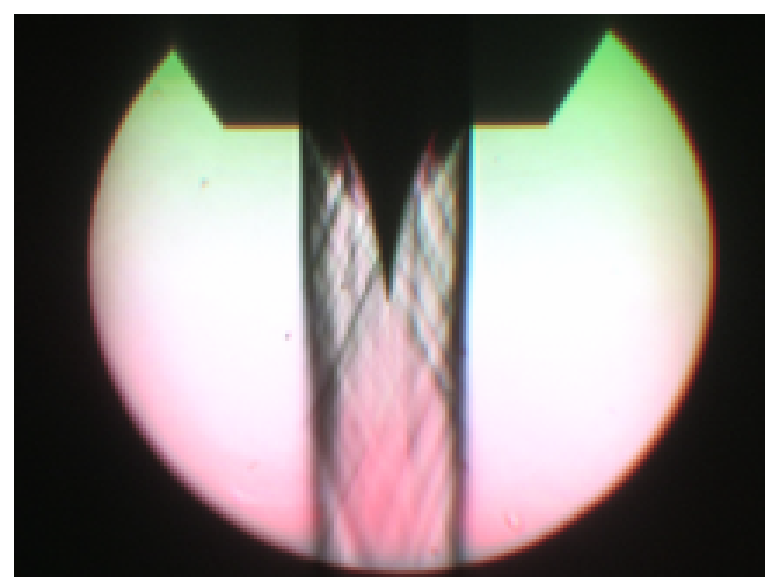

Figure 24: Schlieren capture of straight aerospike nozzle.

The nozzle thrust coefficient, $\mathrm{C}_{\mathrm{f}}$, for the unvectored nozzle is approximately 1.42 as shown in Table 6 . Note that the theoretical value of $\mathrm{C}_{\mathrm{f}}$ for a nozzle with an NPR of 20 is 1.374, as shown in Equation (1.3). The nozzle thrust coefficient shows how well the nozzle expands the fluid and translates that expansion into thrust. The discrepancies in the nozzle thrust coefficients can be attributed two factors: firstly, the experiments were run at an NPR of approximately 20.5, and secondly, the throat area is not exactly $0.2163 \mathrm{in}^{2}$. Given the curvature of the spike contour, a few thousandths of an inch in axial translation can significantly change the throat area of the nozzle. Also, the rapid prototype process with which the nozzle liners were made is unable to produce precise sharp edges on the nozzle lip such as those achievable on a machined metal surface. It should be also noted that the experimental values should be slightly less than theoretical values due to flow losses such a friction. These numbers suggest that the throat of the unvectored aerospike nozzle configuration was slightly too large.

The nozzle thrust coefficient values are also noticeably higher for the highpressure tests than the low-pressure tests. Compare the high-pressure value of 1.42 to the low-pressure value (NPR of 7.5) of 1.17. There is a significant loss associated with 
running the nozzle at a lower pressure (NPR of 7.5) than the design pressure (NPR of 20). A decrease in pressure of $63.4 \%$ corresponds to a $17.6 \%$ decrease in the nozzle thrust coefficient. Using Equation (1.2), theoretical values of the nozzle thrust coefficient suggest that a decrease in NPR of $63.4 \%$ (NPR 20 to NPR 7.5) corresponds to a $13.0 \%$ in the nozzle thrust coefficient (1.377 to 1.198). As expected, experimental losses are greater than theoretical losses.

Table 6: Summary of nozzle performance for the straight aerospike nozzle.

\begin{tabular}{|c|c|c|c|}
\hline Position / Run & $\begin{array}{c}\text { NPR } \\
-\end{array}$ & $\begin{array}{c}\mathbf{A}_{\mathbf{t}} \\
\mathrm{in}^{2}\end{array}$ & $\begin{array}{c}\mathbf{C}_{\mathbf{f}} \\
-\end{array}$ \\
\hline Straight & & & \\
$1 / 1$ & 20.37 & 0.216 & 1.43 \\
$1 / 2$ & 20.39 & 0.216 & 1.43 \\
$2 / 1$ & 20.46 & 0.216 & 1.42 \\
$2 / 2$ & 20.45 & 0.216 & 1.42 \\
$3 / 1$ & 20.31 & 0.216 & 1.42 \\
$3 / 2$ & 20.29 & 0.216 & 1.43 \\
$3 / 3$ & 20.46 & 0.216 & 1.41 \\
$3 / 4$ & 20.51 & 0.216 & 1.42 \\
\hline
\end{tabular}

A conventional nozzle was also tested in an unvectored configuration. A drawing cross-section of the unvectored conventional nozzle liner is shown in Figure 25. The converging-diverging nozzle is not completely optimized in the diverging section for the purpose of easy production. Ideally, the diverging section would follow more of a bell shape and be extended to the correct length to allow for fully-expanded flow. 


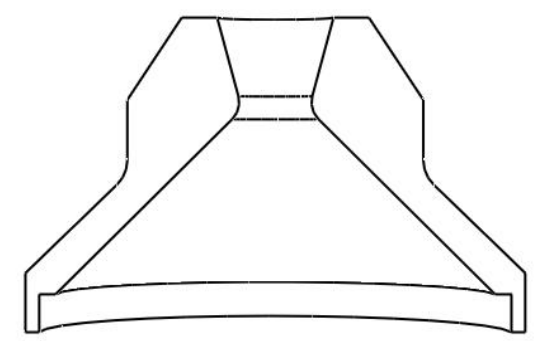

Figure 25: Unvectored converging-diverging nozzle.

As seen with the unvectored aerospike nozzle, the turn angle was minimal, as expected. The turn angle results for the converging-diverging nozzle are shown in Table 7. The thrust force for the straight conventional nozzle is approximately $81 \mathrm{lb}_{\mathrm{f}}$, which is lower than the thrust force for the straight aerospike nozzle. The mass flow rate in the straight conventional nozzle is also lower than the mass flow rate in the straight aerospike nozzle. The throat area of the converging-diverging nozzle is designed to be the same as the throat area of the aerospike nozzle. However, the lack of thrust production in the conventional nozzle due to the unoptimized design is apparent.

The Schlieren image shown in Figure 26 depicts the flow visualization for the straight converging-diverging nozzle. It can be seen in the Schlieren image that the flow for this design pressure is clearly under-expanded.

Table 7: Summary of the straight converging-diverging nozzle in one position.

\begin{tabular}{|c|c|c|c|c|c|c|c|c|c|}
\hline Position / Run & $\begin{array}{c}\text { NPR } \\
-\end{array}$ & $\begin{array}{c}\mathbf{F}_{\mathbf{x}} \\
\mathrm{lbf}\end{array}$ & $\begin{array}{c}\mathbf{F}_{\mathbf{y}} \\
\mathrm{lb}\end{array}$ & $\begin{array}{c}\mathbf{F}_{\mathbf{z}} \\
\mathrm{lb}\end{array}$ & $\begin{array}{c}\mathbf{F}_{\text {vector }} \\
\mathrm{lb}_{\mathrm{f}}\end{array}$ & $\begin{array}{c}\mathbf{W}_{\mathbf{p}} \\
\mathrm{lb} \mathrm{b}_{\mathrm{m}} / \mathrm{s}\end{array}$ & $\begin{array}{c}\boldsymbol{\delta}_{\text {pitch }} \\
\circ\end{array}$ & $\begin{array}{c}\boldsymbol{\delta}_{\text {yaw }} \\
\circ\end{array}$ & $\begin{array}{c}\boldsymbol{\delta}_{\mathbf{r}} \\
\circ\end{array}$ \\
\hline $\begin{array}{c}\text { Conv-Div } \\
\text { Straight }\end{array}$ & & & & & & & & & \\
$1 / 1$ & 20.49 & -0.30 & -0.06 & -81.63 & 0.30 & 1.43 & 0.04 & 0.21 & -0.21 \\
$1 / 2$ & 20.31 & 0.30 & 0.06 & -81.15 & 0.30 & 1.39 & -0.04 & -0.21 & -0.21 \\
\hline
\end{tabular}




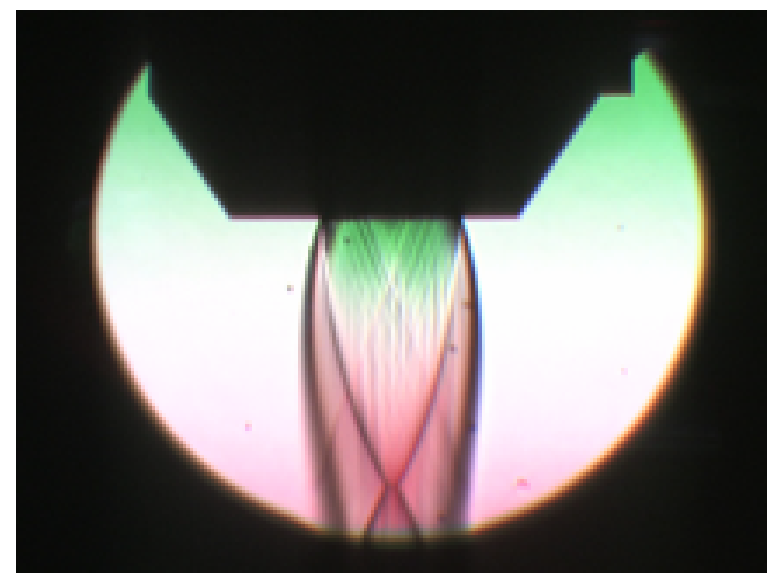

Figure 26: Schlieren capture of straight converging-diverging nozzle.

The experimental nozzle thrust coefficient, $\mathrm{C}_{\mathrm{f}}$, for the straight convergingdiverging nozzle is approximately 1.26 , as shown in Table 8 . Compared to the straight aerospike nozzle, the straight converging-diverging nozzle is less efficient, as expected. The diverging section of the nozzle probably needs to be lengthened to allow the fluid to further expand.

Table 8: Summary of nozzle performance for the straight converging-diverging nozzle.

\begin{tabular}{|c|c|c|c|}
\hline Position / Run & $\begin{array}{c}\text { NPR } \\
-\end{array}$ & $\begin{array}{c}\mathbf{A}_{\mathbf{t}} \\
\mathrm{in}^{2}\end{array}$ & $\begin{array}{c}\mathbf{C}_{\mathbf{f}} \\
-\end{array}$ \\
\hline Conv-Div & & & \\
Straight & & & \\
$1 / 1$ & 20.49 & 0.216 & 1.25 \\
$1 / 2$ & 20.31 & 0.216 & 1.26 \\
\hline
\end{tabular}




\section{CHAPTER 6}

\section{Nozzle Vectoring}

To investigate the effectiveness of thrust vector generation, a series of tests was conducted with the high-pressure flow bench with both a vectored aerospike nozzle and a vectored conventional nozzle. The vectored aerospike nozzle was tested in two different configurations: using a single port for thrust vector generation and using two ports for thrust vector generation. The vectored conventional nozzle was tested only in a single secondary port configuration for means of thrust vector generation. Both of the nozzles were tested in three different rotational positions for each configuration. Further analysis was performed on the tests to characterize the nozzle efficiencies, and those results are shown in Table 11 and Table 13. Visual investigation of the flow characteristics of the vectored aerospike nozzle and the vectored conventional nozzle was achieved with color Schlieren photography.

To implement thrust vectoring in this research, secondary ports are used to produce a net thrust force perpendicular to the main axis of flow. The secondary ports for thrust vectoring are designed to have a $12^{\circ}$ divergent half-angle and a nominal centerline axial position of 0.175 inches forward from the nozzle lip. There is a radius of 0.075 inches applied to the inlet of the secondary port. A cross-sectional view of the aerospike nozzle with a secondary port is shown in Figure 27. 


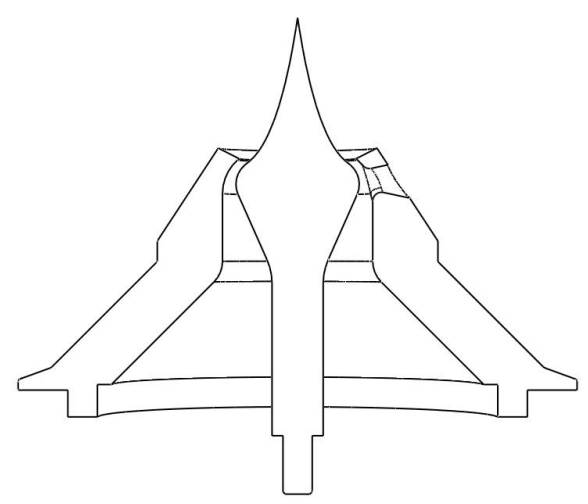

Figure 27: Vectored aerospike nozzle.

The definition for angles and forces used to define thrust vectoring are shown in Figure 28. Pitch moments cause the nose of a rocket to raise or lower. Yaw moments cause the nose of a rocket to turn sideways. Roll moments cause the vehicle to roll about its body axis.

The vectored forces calculated are based on the side forces measured in the vectored run from the respective rotational position of the nozzle less the side forces measured from the straight nozzle in that same rotational position. This procedure, which is done to accommodate imperfections in the nozzle construction, the flow bench, and/or thrust stand, is a calibration procedure that nulls out any sides forces that would be present if the nozzle were the straight nozzle rather than the vectored nozzle. Applying the calibration procedure would result in side forces on the order of measurement noise for the unvectored nozzle test.

To thrust vector effectively in practice, it is necessary to be able to produce the required magnitude of turn angle in any desired direction. By having a specified number of secondary ports spaced equally around the aerospike nozzle, the appropriate combination of secondary ports can be activated to produce the desired direction of the resultant turn angle. As a first step of studying multi-port thrust vectoring, a nozzle with 
two secondary ports was designed, built and tested. The multi-port thrust vectoring is described further in this chapter.

The definitions of the turn angles used to describe thrust vectoring are defined as follows:

$$
\begin{aligned}
& \delta_{\text {pitch }}=\tan ^{-1}\left(\frac{F_{y}}{F_{z}}\right) \\
& \delta_{\text {yaw }}=\tan ^{-1}\left(\frac{F_{x}}{F_{z}}\right) \\
& \delta_{r}=\tan ^{-1}\left(\frac{F_{\text {vector }}}{F_{z}}\right)
\end{aligned}
$$

Where the vectored force, $F_{\text {vector }}$, is defined as follows:

$$
F_{\text {vector }}=\sqrt{F_{x}^{2}+F_{y}^{2}}
$$

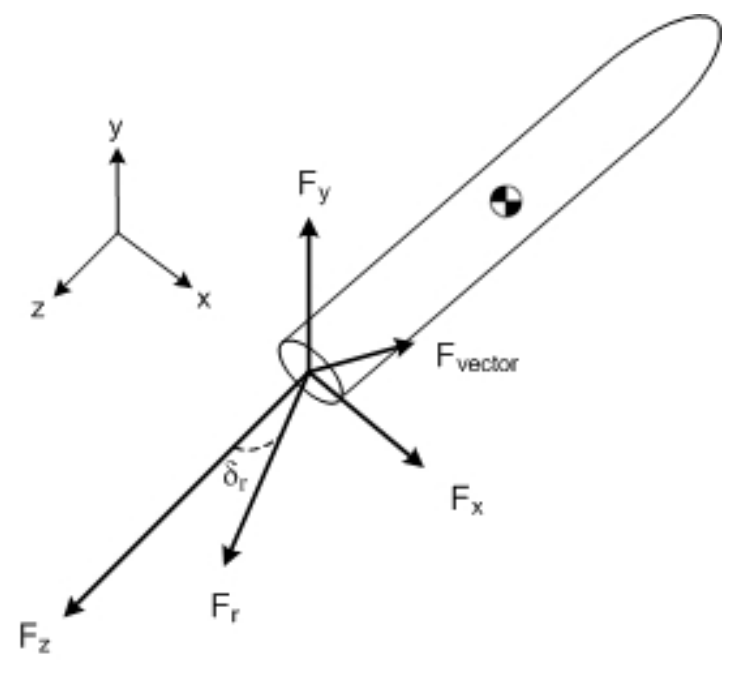

Figure 28: Thrust vectoring diagram.

To confirm that turn angles could be produced in any desired direction, the singlevectored aerospike nozzle was rotated to three different positions. The resultant vectored 
thrusts from the rotated nozzles projected very closely to the direction that the secondary port was physically oriented in and are shown graphically in Figure 35.

Table 9 and Table 10 list the values of the turn angles. The turn angles $\delta_{d}$ and $\delta_{\perp}$ refer to the resultant turn angles in the direction of the secondary port flow and the direction perpendicular to the secondary port flow, respectively. The perpendicular component of the turn angle is minimal at each position.

A single-port configuration is used to show the direction and magnitude of the vectoring forces. The single-port configuration is oriented in the three different directions, with $120^{\circ}$ between each position. The three different nozzle positions are shown in Figure 29. By rotating the nozzle, the straightness of the nozzle and test stand is verified. Ideally, what rotational position the nozzle is oriented in would not cause a difference to the magnitude of the resultant vectored force.

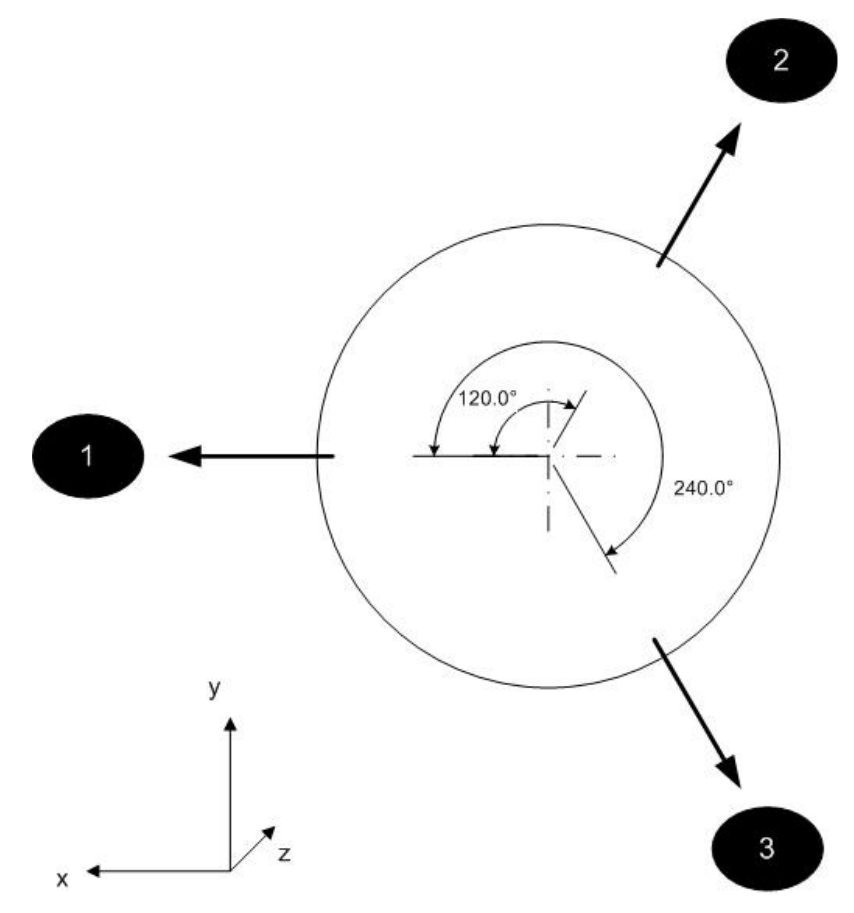

Figure 29: Single-port thrust vectoring configuration. 
A double-port configuration was used to confirm that multiple vectoring ports can be used in conjunction with each other to produce an expected resultant vectored force. Ideally, combining vectoring ports in different directions should create vectoring forces and turn angles in the resultant direction; however, testing was performed to ensure that there is no unexpected interaction between the multiple ports. The combinations of two secondary ports were rotated into three positions, each $120^{\circ}$ apart from each other, similarly to the single-vectored configuration. The three different nozzle locations are shown in Figure 30.

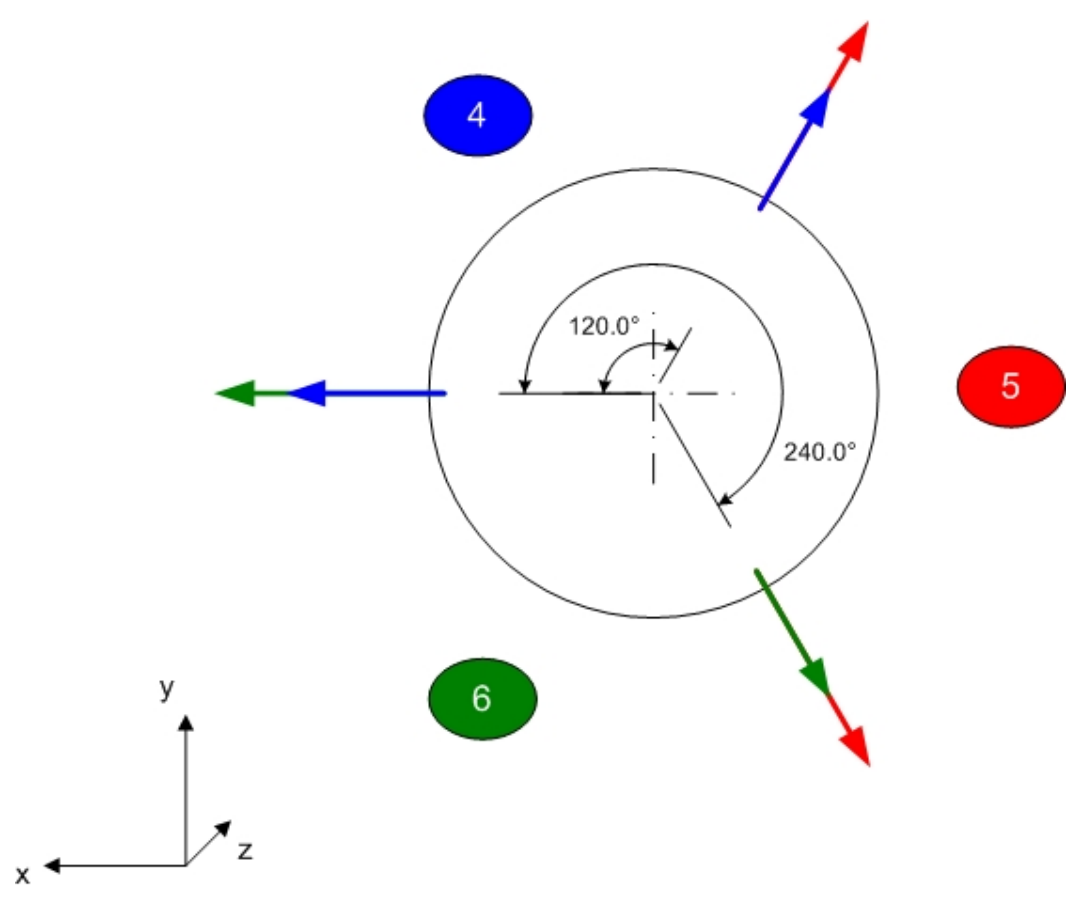

Figure 30: Double-port thrust vectoring configuration.

The results presented in Table 9 show the variation in turn angle produced based on rotational position. This variation in turn angle can be attributed to the fact that nozzle is made of rapid prototype material and the nozzle throat is not perfectly circular. Measurements performed on the nozzle showed that the main nozzle is out of round in the radial direction, thus skewing the flow in the radial direction. 
The thrust produced from the vectored aerospike nozzle is approximately $94 \mathrm{lb}_{\mathrm{f}}$, and the resultant turn angle is approximately $8.56^{\circ}$.

Table 9: Summary for single-port thrust vectoring of the aerospike nozzle in various rotational positions.

\begin{tabular}{|c|c|c|c|c|c|c|c|c|c|}
\hline Position / Run & $\begin{array}{c}\text { NPR } \\
- \\
\end{array}$ & $\begin{array}{l}F_{\mathbf{x}} \\
\mathrm{lbf}\end{array}$ & $\begin{array}{l}F_{y} \\
1 b_{f}\end{array}$ & $\begin{array}{l}F_{z} \\
l b_{f}\end{array}$ & $\begin{array}{c}\mathbf{F}_{\text {vector }} \\
1 b_{f} \\
\end{array}$ & $\begin{array}{r}\mathbf{W}_{\mathrm{p}} \\
1 \mathrm{~b}_{\mathrm{m}} / \mathrm{s}\end{array}$ & $\begin{array}{c}\delta_{\text {pitch }} \\
\circ\end{array}$ & $\begin{array}{c}\delta_{\text {yaw }} \\
\circ \\
\end{array}$ & $\begin{array}{c}\delta_{\mathrm{r}} \\
\circ \\
\end{array}$ \\
\hline \multicolumn{10}{|l|}{$\begin{array}{l}\text { Single Port } \\
\text { Vectoring }\end{array}$} \\
\hline $1 / 1$ & 20.25 & -13.40 & 0.31 & -93.96 & 13.40 & 1.75 & -0.19 & 8.11 & -8.12 \\
\hline $2 / 1$ & 20.35 & 5.94 & 13.16 & -96.15 & 14.44 & 1.77 & -7.80 & -3.53 & -8.54 \\
\hline $3 / 1$ & 20.39 & 7.13 & -12.87 & -92.66 & 14.71 & 1.69 & 7.91 & -4.40 & -9.02 \\
\hline
\end{tabular}

The combination of two vectoring ports results in the expected resultant direction and magnitude. In Table 10, the directional turn angle, $\delta_{\mathrm{d}}$, represents how much of the resultant turn angle, $\delta_{\mathrm{r}}$, is in the desired direction of the secondary port.

Table 10: Summary for double-port thrust vectoring of the aerospike nozzle in various rotational positions.

\begin{tabular}{|c|c|c|c|c|c|c|c|c|c|c|c|}
\hline Position / Run & $\begin{array}{c}\text { NPR } \\
-\end{array}$ & $\begin{array}{l}\mathbf{F}_{\mathbf{x}} \\
\mathrm{lbf}\end{array}$ & $\begin{array}{l}\mathbf{F}_{\mathrm{y}} \\
l \mathrm{~b}_{\mathrm{f}}\end{array}$ & $\begin{array}{l}\mathbf{F}_{\mathbf{z}} \\
l \mathrm{~b}_{\mathrm{f}}\end{array}$ & $\begin{array}{l}\mathbf{F}_{\mathbf{d}} \\
\mathrm{lb}_{\mathrm{f}}\end{array}$ & $\begin{array}{l}\mathbf{F}_{\perp} \\
\mathrm{lb}_{\mathrm{f}}\end{array}$ & $\begin{array}{c}\mathbf{F}_{\text {vector }} \\
\mathrm{lb}_{\mathrm{f}}\end{array}$ & $\begin{array}{r}\mathbf{W}_{\mathbf{p}} \\
1 \mathrm{~b}_{\mathrm{m}} / \mathrm{s}\end{array}$ & $\begin{array}{c}\delta_{d} \\
\circ\end{array}$ & $\delta_{\perp}$ & $\begin{array}{c}\delta_{\mathrm{r}} \\
\circ\end{array}$ \\
\hline \multicolumn{12}{|l|}{$\begin{array}{l}\text { Double Port } \\
\text { Vectoring }\end{array}$} \\
\hline $4 / 1$ & 20.39 & -7.14 & 12.55 & -94.32 & 14.44 & -0.09 & 14.44 & 1.89 & -8.70 & 0.06 & -8.70 \\
\hline $5 / 1$ & 20.38 & 13.73 & 0.27 & -93.19 & 13.73 & 0.27 & 13.74 & 1.93 & -8.38 & -0.17 & -8.38 \\
\hline $6 / 1$ & 20.36 & -7.02 & -12.88 & -92.22 & 14.67 & 0.36 & 14.67 & 1.94 & -9.04 & -0.22 & -9.04 \\
\hline
\end{tabular}

The nozzle thrust coefficients can apply to both the main nozzle port and the secondary vectoring port. The nozzle thrust coefficient for the secondary port is less than the thrust coefficient for the main nozzle. The secondary port is not optimally designed. The length for the diverging sectioned is not necessarily designed to allow for full flow expansion. The length is simply determined by the dimensions of the nozzle and thickness of the nozzle walls. 
Table 11: Summary of nozzle performance for the vectored aerospike nozzle.

\begin{tabular}{|c|c|c|c|c|c|}
\hline Position / Run & $\begin{array}{c}\text { NPR } \\
-\end{array}$ & $\begin{array}{c}\mathbf{A}_{\mathbf{t}} \\
\mathrm{in}^{2}\end{array}$ & $\begin{array}{c}\mathbf{C}_{\mathbf{f}} \\
-\end{array}$ & $\begin{array}{c}\mathbf{A}_{\mathbf{s p}} \\
\mathrm{in}^{2}\end{array}$ & $\begin{array}{c}\mathbf{C}_{\mathbf{f s p}} \\
-\end{array}$ \\
\hline $\begin{array}{c}\text { Single Port } \\
\text { Vectoring }\end{array}$ & & & & & \\
$1 / 1$ & 20.25 & 0.216 & 1.46 & 0.035 & 1.28 \\
$2 / 1$ & 20.35 & 0.216 & 1.49 & 0.035 & 1.37 \\
$3 / 1$ & 20.39 & 0.216 & 1.43 & 0.035 & 1.39 \\
\hline
\end{tabular}

The Schlieren image shown in Figure 31 depicts a shift in the direction of the primary nozzle exhaust for the vectored nozzles. Note that the mainstream primary nozzle exhaust is angled in the direction favorable to producing a vectored turn, possibly due to a radial distortion in the mass flow around the annulus of the nozzle [10]. Through CFD simulations done by Rolling Hills Research Corporation, there is a slight drop in mass flow around the location of the secondary port [10]. Also, the Schlieren image in Figure 31 clearly shows that secondary port design is under-expanded, consistent with the very short diverging section of that port.

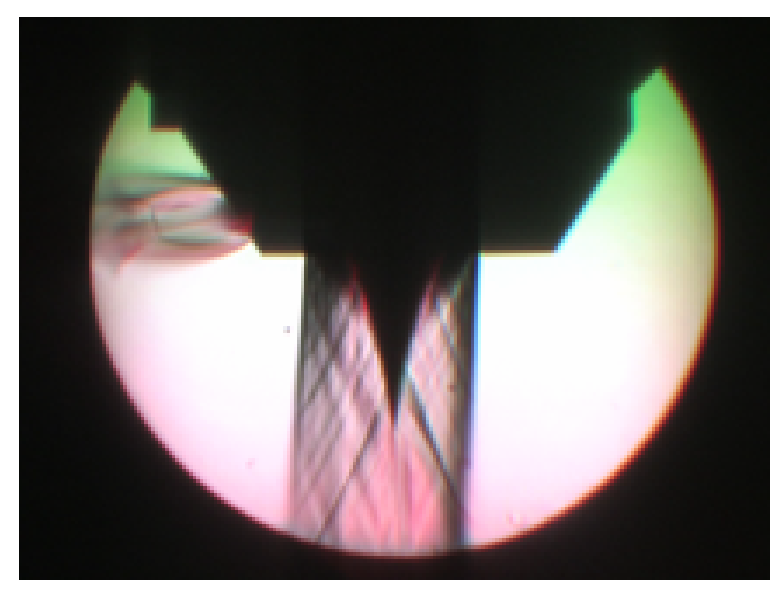

Figure 31: Schlieren capture of vectored aerospike nozzle.

Further investigation into the specific contribution of the main plume turning of the vectored aerospike nozzle is shown in Figure 32. The main plume turns approximately $3.08^{\circ}$ in a direction favorable to thrust vector generation, which counts for 
approximately $36 \%$ of the total $8.56^{\circ}$ resultant turn angle. Furthermore, the thrust vector generation contribution from the secondary port is approximately $5.45^{\circ}$.

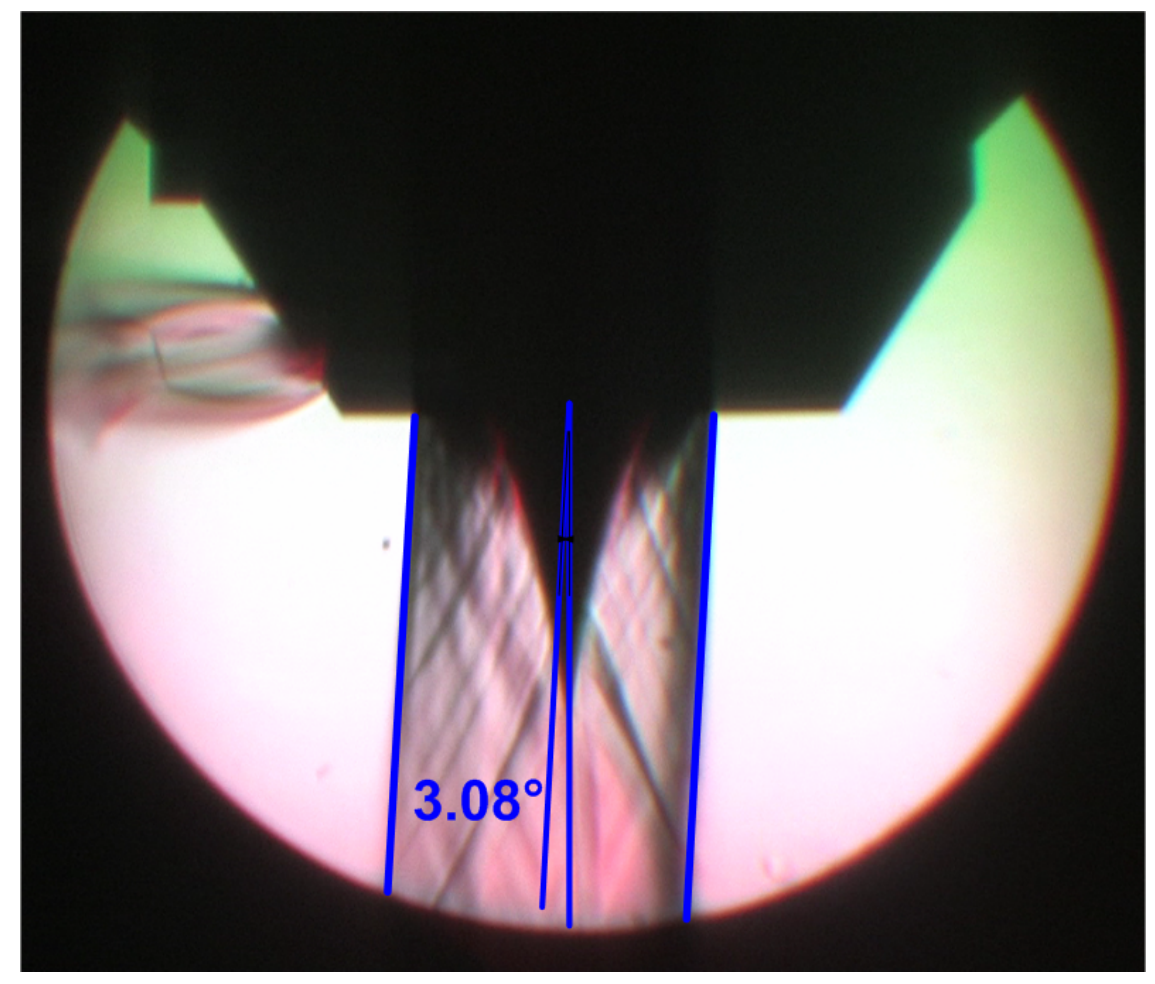

Figure 32: Deflection of the main plume of the vectored aerospike nozzle.

The conventional nozzle was also tested to offer a comparison as to how effective it is to thrust vector specifically with an aerospike nozzle. To make the comparisons between the aerospike nozzle and the conventional nozzle as appropriate as possible, the secondary port for both of the nozzles has the same throat area and exit area. A drawing cross-section of the vectored conventional nozzle liner is shown in Figure 33.

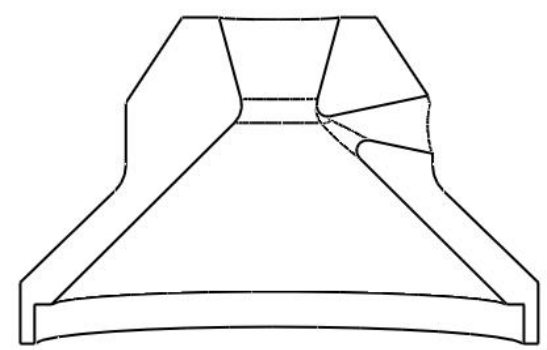

Figure 33: Vectored converging-diverging nozzle. 
In the Schlieren image shown in Figure 34, the flow from the secondary port is not under-expanded, as previously seen with the secondary port of the aerospike nozzle, but the diverging section of the secondary port is significantly larger here, due to the larger nozzle body. The flow also seems angled upstream of the secondary port and could be the result of flow separation in the secondary port.

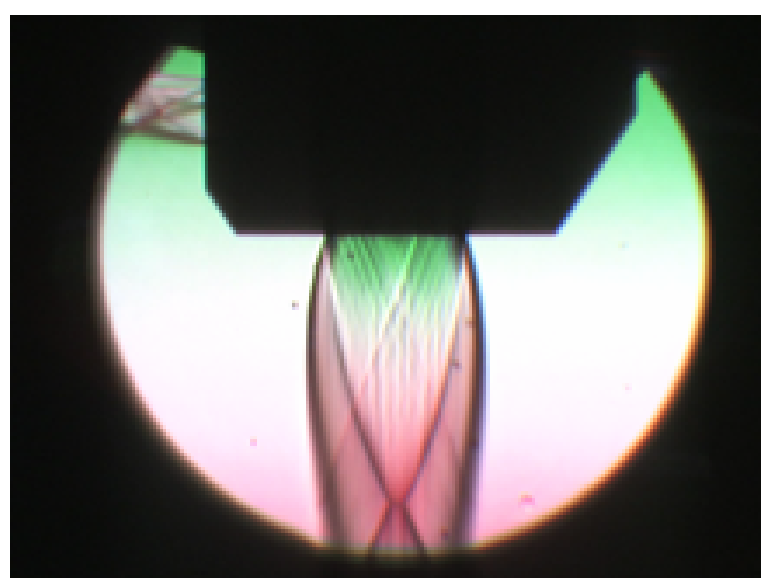

Figure 34: Schlieren capture of vectored converging-diverging nozzle.

Data in Table 12 show that for an approximately equal NPR as the aerospike nozzle, the conventional nozzle produces less resultant turn angle, less vectored thrust, and less axial thrust. The thrust produced from the vectored conventional nozzle is approximately $80 \mathrm{lb}_{\mathrm{f}}$, and the resultant turn angle is approximately $5.40^{\circ}$. The smaller thrust brings into question how well the converging-diverging nozzle is optimized.

However, if the converging-diverging nozzle is optimized further (perhaps by lengthening the diverging section) to produce more axial thrust (with the same plenum pressure), the resultant turn angle would be slightly less. Recall, the turning angle contribution associated with the secondary port for the aerospike nozzle is approximately $5.48^{\circ}$, close to that of the conventional nozzle. The smaller turn angle for the 
conventional nozzle suggests that perhaps the aerospike is more efficient at thrust vector generation due to the turning of the main plume as described previously.

Table 12: Summary of the vectored converging-diverging nozzle in one position.

\begin{tabular}{|c|c|c|c|c|c|c|c|c|c|}
\hline Position / Run & $\mathbf{N P R}$ & $\begin{array}{c}\mathbf{F}_{\mathbf{x}} \\
\mathrm{lbf}\end{array}$ & $\begin{array}{c}\mathbf{F}_{\mathbf{y}} \\
\mathbf{l} \mathrm{b}_{\mathrm{f}}\end{array}$ & $\begin{array}{c}\mathbf{F}_{\mathbf{z}} \\
\mathrm{bb}_{\mathrm{f}}\end{array}$ & $\begin{array}{c}\mathbf{F}_{\text {vector }} \\
\mathrm{lb}_{\mathrm{f}}\end{array}$ & $\begin{array}{c}\mathbf{W}_{\mathbf{p}} \\
\mathrm{lb}_{\mathrm{m}} / \mathrm{s}\end{array}$ & $\begin{array}{c}\boldsymbol{\delta}_{\text {pitch }} \\
{ }^{\circ}\end{array}$ & $\begin{array}{c}\boldsymbol{\delta}_{\text {yaw }} \\
{ }^{\prime}\end{array}$ & $\begin{array}{c}\boldsymbol{\delta}_{\mathbf{r}} \\
\circ\end{array}$ \\
\hline $\begin{array}{c}\text { Conv-Div } \\
\text { Vectored }\end{array}$ & & & & & & & & & \\
$1 / 1$ & 20.33 & -7.42 & -0.05 & -80.40 & 7.42 & 1.53 & 0.04 & 5.27 & -5.27 \\
$1 / 2$ & 20.31 & -6.87 & -0.64 & -79.57 & 6.90 & 1.53 & 0.46 & 4.93 & -4.95 \\
$1 / 3$ & 20.32 & -8.29 & -0.09 & -79.02 & 8.29 & 1.54 & 0.07 & 5.99 & -5.99 \\
\hline
\end{tabular}

The performance of the main nozzle and secondary port is shown in Table 13. Nozzle thrust coefficients are less for the converging-diverging nozzle than nozzle thrust coefficients for the aerospike nozzle, 1.23 to 1.46 , respectively. The nozzle thrust coefficient values show further evidence that at an approximately equal NPR the conventional nozzle is not fully optimized for performance.

Table 13: Summary of nozzle performance for the vectored converging-diverging nozzle.

\begin{tabular}{|c|c|c|c|c|c|}
\hline Position / Run & $\begin{array}{c}\text { NPR } \\
-\end{array}$ & $\begin{array}{c}\mathbf{A}_{\mathbf{t}} \\
\mathrm{in}^{2}\end{array}$ & $\begin{array}{c}\mathbf{C}_{\mathbf{f}} \\
-\end{array}$ & $\begin{array}{c}\mathbf{A}_{\mathbf{s p}} \\
\mathrm{in}^{2}\end{array}$ & \begin{tabular}{c}
$\mathbf{C}_{\mathbf{f}} \mathbf{s p}$ \\
\hline $\begin{array}{c}\text { Conv-Div } \\
\text { Vectored }\end{array}$ \\
$1 / 1$
\end{tabular} \\
& 20.33 & 0.216 & 1.24 & 0.035 & 0.70 \\
$1 / 2$ & 20.31 & 0.216 & 1.23 & 0.035 & 0.65 \\
$1 / 3$ & 20.32 & 0.216 & 1.22 & 0.035 & 0.79 \\
\hline
\end{tabular}

The resultant turn angles from the single- and double-port configuration tests are not perfectly concentric about the center of the stand. Figure 35 shows the adjustment of the resultant turn angles from their raw values. The blue circle in Figure 35 also shows a circular curve fit of the adjusted resultant turn angles. 


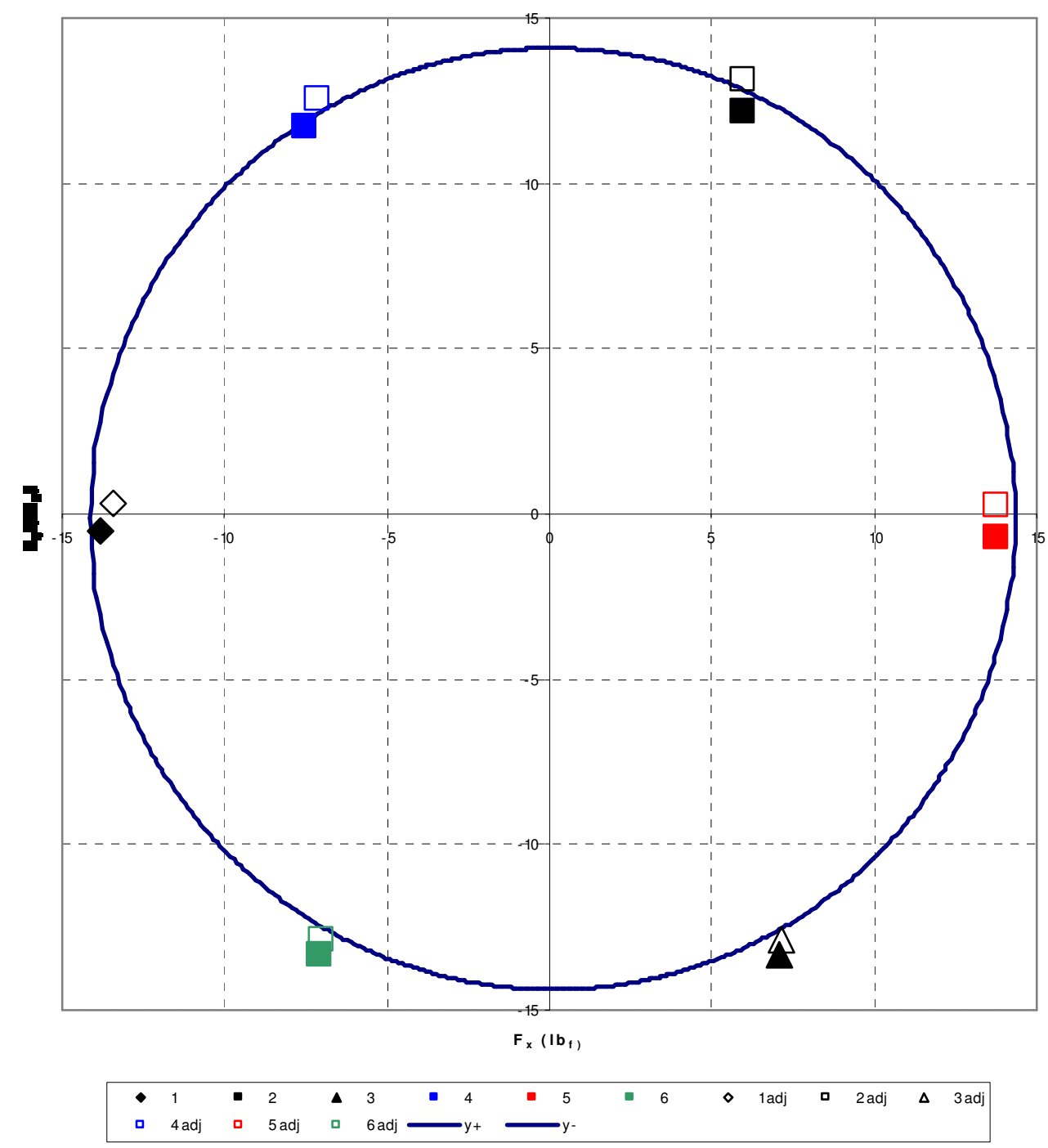

Figure 35: Plot of vectored forces of a single- and double-port configuration of vectored nozzles at different rotational positions and their respected adjusted values. The adjusted data have been calibrated to remove the side loads associated with the straight nozzle. 


\section{CHAPTER 7}

\section{Aerospike Throttling}

Five different steady-state tests were conducted for spike positions at different locations: nominal, \pm 0.025 inches from nominal, and \pm 0.050 inches from nominal to investigate the effects of throttling an unvectored aerospike. The cold-flow blow-down tests were performed with a constant plenum pressure. The results are shown in Table 15 . Analysis was performed on the test results to characterize the nozzle efficiencies at different throttled positions, and those results are shown in Table 16. Visual investigation of the flow characteristics of the throttled, unvectored aerospike nozzle was achieved with color Schlieren photography.

Throttling the flow of the aerospike nozzle in this research was accomplished by translating the spike axially from its nominal position. In turn, translating the spike changes the size of the throat, resulting in either a larger or smaller thrust force. Axially translating the spike into the throat causes the throat area to decrease and axially translating the spike out of the throat causes the throat area to increase. A drawing crosssection of the spike translation direction is shown in Figure 36. 


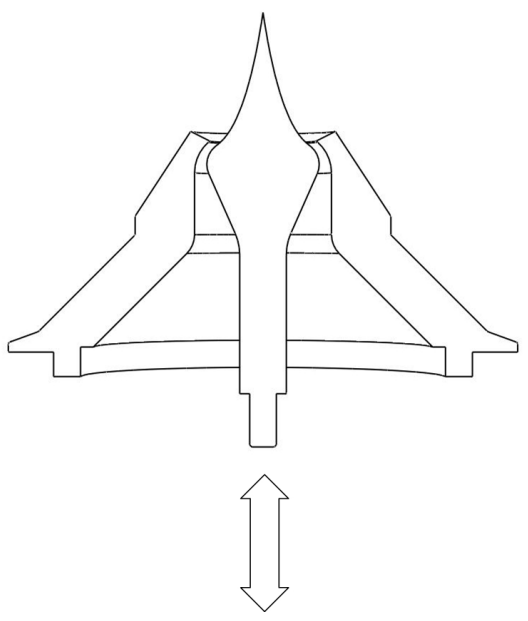

Figure 36: Throttling an aerospike nozzle via moving the center spike.

The high-pressure stand and nozzle were constructed to have an axially repositionable spike. The positioning of the spike is achieved by two separate means: by mechanical shimming and by a servo-controlled stepper motor that positions the spike. The variation of nozzle throat area with axial displacement of the spike from the nominal position for the unvectored aerospike nozzle is shown in Table 14.

Table 14: Throat area as a function of spike translation.

\begin{tabular}{|c|c|c|c|}
\hline$\Delta \mathbf{x}$ & $\begin{array}{c}\text { Throat } \\
\text { Height } \\
\text { (in) }\end{array}$ & $\begin{array}{c}\text { Throat } \\
\text { Area } \mathbf{A}_{\mathbf{t}} \\
\left.\text { (in }^{2}\right)\end{array}$ & $\begin{array}{c}\mathbf{A}_{\mathbf{t}} / \\
\mathbf{A}_{\text {nominal }} \\
(\%)\end{array}$ \\
\hline-0.080 & 0.0183 & 0.0569 & 26.3 \\
-0.070 & 0.0237 & 0.0733 & 33.9 \\
-0.050 & 0.0366 & 0.1120 & 51.8 \\
-0.025 & 0.0539 & 0.1637 & 75.7 \\
\hline 0.000 & 0.0723 & 0.2163 & 100.0 \\
\hline 0.025 & 0.0911 & 0.2783 & 128.7 \\
0.050 & 0.1069 & 0.3955 & 182.8 \\
\hline
\end{tabular}


The effectiveness with which the axial motion of the spike provides throttling for the aerospike nozzle is shown in Table 15 and Figure 39. The force acting on the spike as a function of spike location is shown in Figure 39.

Table 15: Summary of the straight aerospike nozzle throttled via moving the spike.

\begin{tabular}{|c|c|c|c|c|c|c|c|c|c|}
\hline Position / Run & $\begin{array}{c}\text { NPR } \\
-\end{array}$ & $\begin{array}{c}\mathbf{F}_{\mathbf{x}} \\
\mathrm{lbf}\end{array}$ & $\begin{array}{c}\mathbf{F}_{\mathbf{y}} \\
\mathrm{lb}_{\mathrm{f}}\end{array}$ & $\begin{array}{c}\mathbf{F}_{\mathbf{z}} \\
\mathrm{lb}_{\mathrm{f}}\end{array}$ & $\begin{array}{c}\mathbf{F}_{\text {vector }} \\
\mathrm{lb}_{\mathrm{f}}\end{array}$ & $\begin{array}{c}\mathbf{W}_{\mathbf{p}} \\
\mathrm{lb}_{\mathrm{m}} / \mathrm{s}\end{array}$ & $\begin{array}{c}\boldsymbol{\delta}_{\text {pitch }} \\
0\end{array}$ & $\begin{array}{c}\boldsymbol{\delta}_{\text {yaw }} \\
0\end{array}$ & $\begin{array}{c}\boldsymbol{\delta}_{\mathbf{r}} \\
0\end{array}$ \\
\hline $\begin{array}{c}\text { Straight } \\
\text { Throttling }\end{array}$ & & & & & & & & & \\
0.050 & 20.37 & -0.13 & 0.04 & -132.25 & 0.14 & 2.14 & -0.02 & 0.06 & -0.06 \\
0.025 & 20.46 & 0.58 & -0.07 & -114.11 & 0.58 & 1.84 & 0.04 & -0.29 & -0.29 \\
0 & 20.47 & -0.10 & -0.20 & -92.80 & 0.22 & 1.47 & 0.12 & 0.06 & -0.14 \\
-0.025 & 20.56 & -0.82 & -0.61 & -72.32 & 1.02 & 1.14 & 0.48 & 0.65 & -0.81 \\
-0.050 & 20.60 & 0.36 & -0.17 & -51.31 & 0.40 & 0.82 & 0.19 & -0.40 & -0.44 \\
\hline
\end{tabular}

Table 16: Summary of nozzle performance for the throttled straight aerospike nozzle.

\begin{tabular}{|c|c|c|c|}
\hline Position / Run & $\begin{array}{c}\text { NPR } \\
-\end{array}$ & $\begin{array}{c}\mathbf{A}_{\mathbf{t}} \\
\mathrm{in}^{2}\end{array}$ & $\begin{array}{c}\mathbf{C}_{\mathbf{f}} \\
-\end{array}$ \\
\hline $\begin{array}{c}\text { Straight } \\
\text { Throttling }\end{array}$ & & & \\
0.050 & 20.37 & 0.396 & 1.12 \\
0.025 & 20.46 & 0.278 & 1.37 \\
0 & 20.47 & 0.216 & 1.43 \\
-0.025 & 20.56 & 0.164 & 1.46 \\
-0.050 & 20.60 & 0.112 & 1.52 \\
\hline
\end{tabular}

There are a few concerns to note about this testing. Ideally, while axially translating the spike in and out to throttle the thrust, the throat location will not change and be located at the cowl exit. However, for this aerospike design, the throat location can change if the spike is throttled open too much. The location of the throat as the spike is throttled is shown in Figure 37. This phenomenon is strictly a function of how the nozzle was internally designed. 
Even though the throat locations change within the aerospike nozzle, the flow is still not allowed to expand much further after the location of the throat until the flow reaches the cowl exit. The flow cannot expand much further past the throat because the internal nozzle area does not change significantly until the flow reaches the cowl lip and is allowed to expand to ambient conditions.

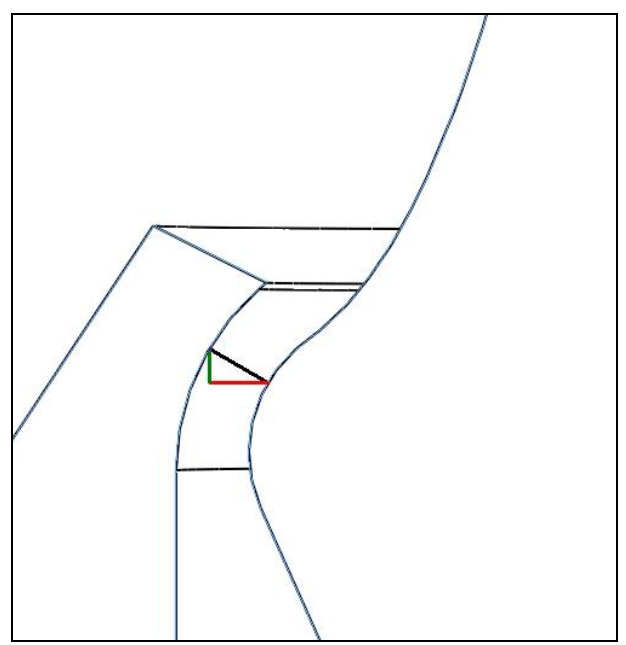

a) Spike location $+0.050 "$.

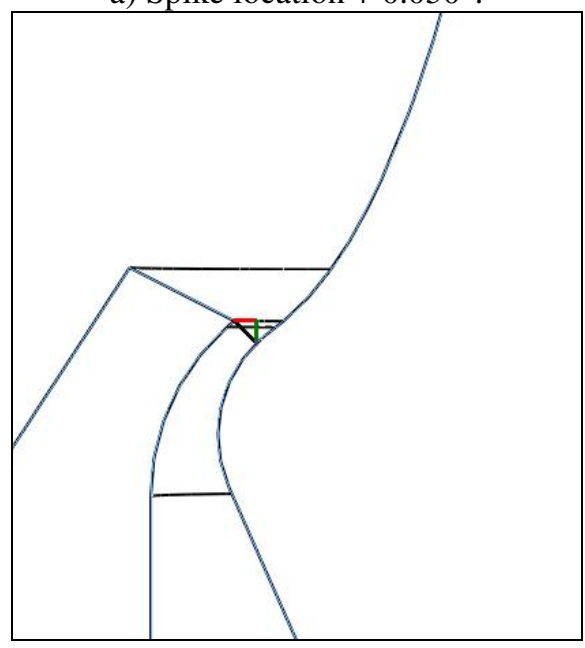

c) Spike location - 0.025".

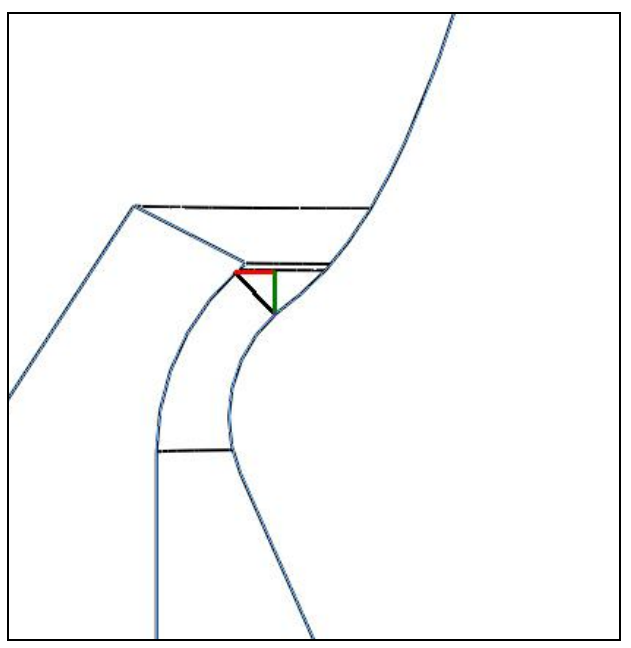

b) Spike location $+0.025^{\prime \prime}$.

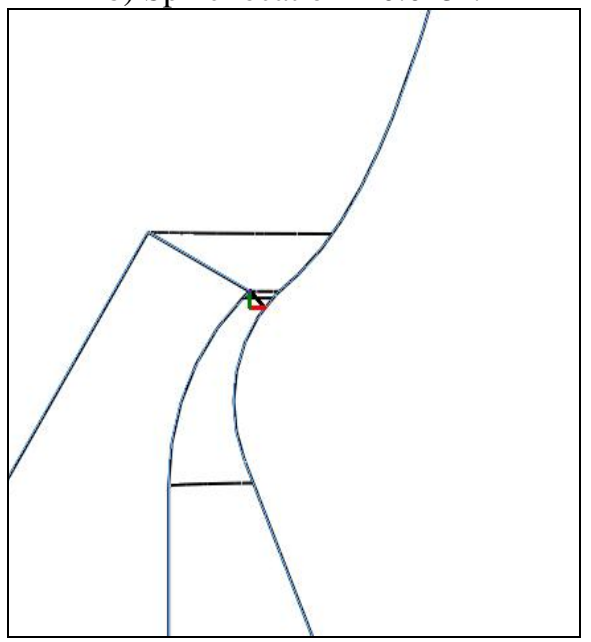

d) Spike location - 0.050".

Figure 37: Throat location as the spike is throttled. 
For each nozzle configuration, Schlieren videos were taken for each spike displacement and a still image of the steady-state flow patterns was extracted from the videos. These Schlieren results are presented in Figure 38.

These Schlieren images illustrate that the nozzle flows optimally at its nominal spike position. The nominal spike position is the design condition, an NPR of approximately 20 . When the spike recesses into the nozzle and opens up the throat, the exit area of the flow increases. Conversely, when the spike protrudes out of the nozzle and closes down the throat, the exit area of the flow decreases. 


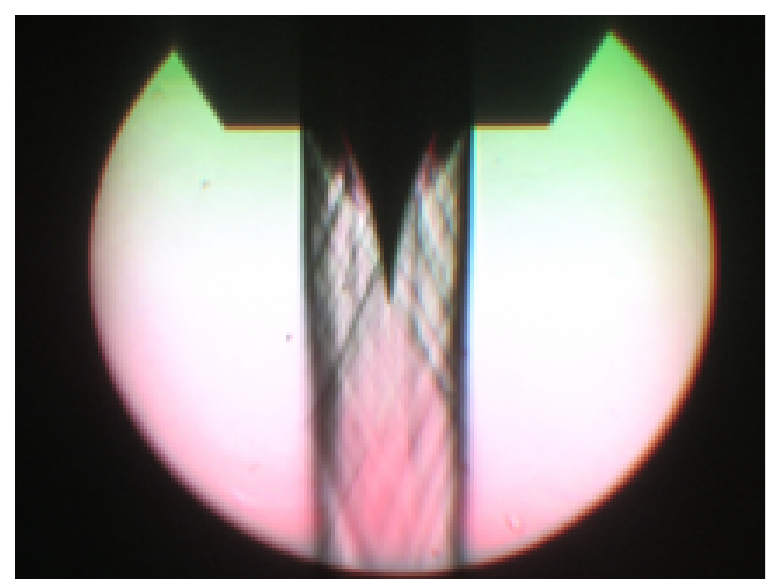

a) Nominal spike position.

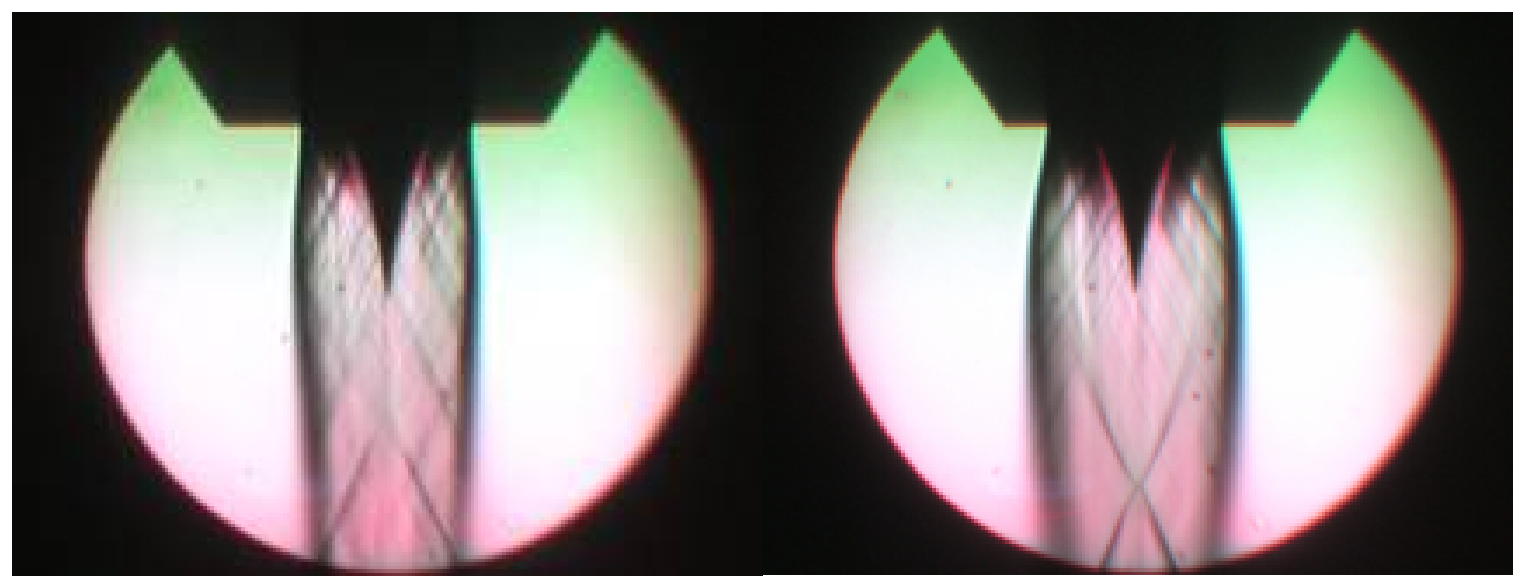

b) Spike position +0.025 " from nominal.

c) Spike position +0.050 " from nominal.

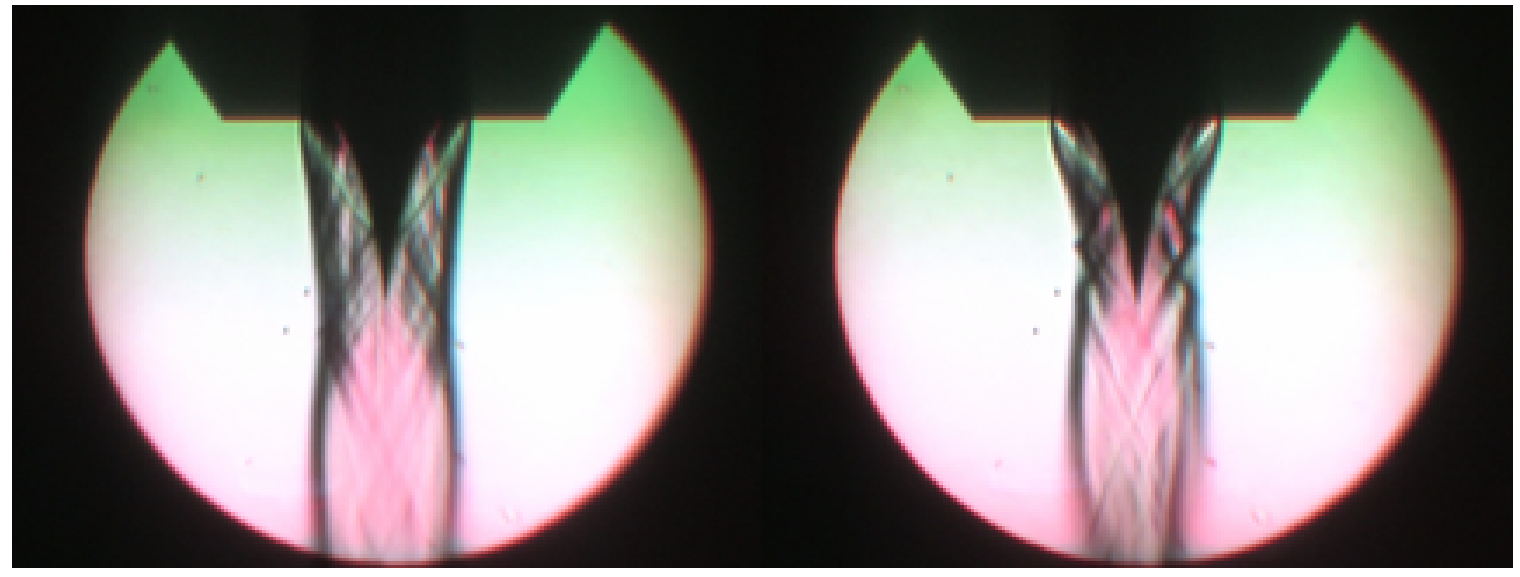

d) Spike position -0.025" from nominal.

e) Spike position -0.050 " from nominal.

Figure 38: Schlieren images of the throttled straight aerospike nozzle. 


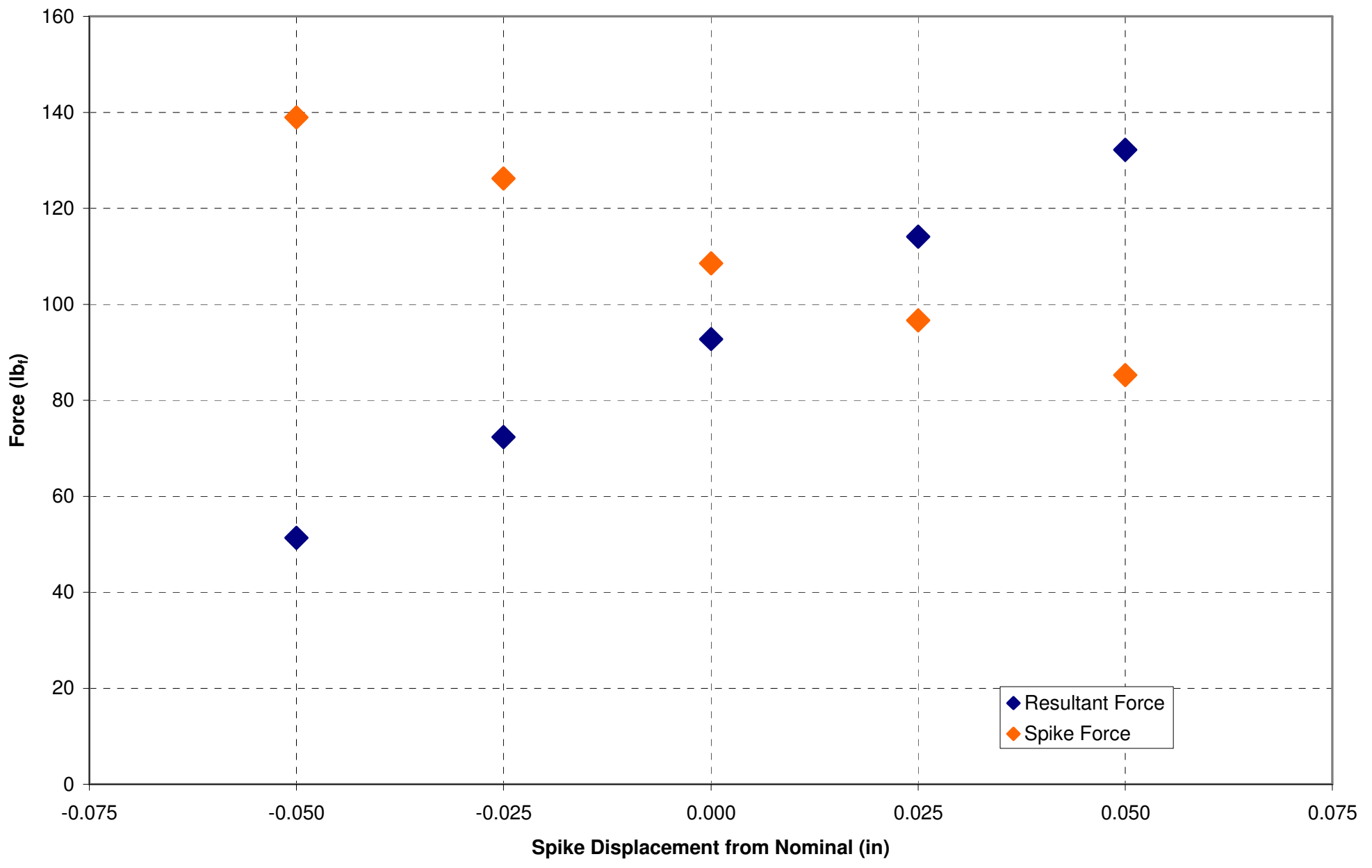

Figure 39: Turn angle and spike force as a function of spike location for unvectored flow. 


\section{CHAPTER 8}

Aerospike Throttling and Vectoring

Six different steady-state tests were conducted for spike positions at different locations: nominal, \pm 0.025 inches from nominal, \pm 0.050 inches from nominal, and -0.070 inches from nominal to ascertain the interaction between throttling and thrust vectoring for an annular aerospike nozzle. For the tests conducted, spike displacement, plenum pressure, and resultant thrust are shown in Table 18, and resultant thrust is plotted as a function of spike displacement in Figure 43. In addition to the plenum pressure and resultant thrust results shown in Table 18, color Schlieren videos were taken for each spike displacement. For each nozzle configuration, a still image of the steady-state flow patterns was extracted from the videos, and these Schlieren images are presented in Figure 40 .

Throttling the spike changes the resultant thrust and the resultant turn angle as shown in Table 17, while a more detailed breakdown of forces and turn angles is shown in Table 18.

Table 17: Turn angle and resultant thrust as a function of spike translation.

\begin{tabular}{|c|c|c|c|}
\hline$\Delta \mathbf{x}$ & $\begin{array}{c}\text { Plenum } \\
\text { Pressure } \\
\text { (psig) }\end{array}$ & $\mathbf{F}_{\mathbf{r}}\left(\mathbf{l b}_{\mathbf{f}}\right)$ & $\left|\boldsymbol{\delta}_{\mathbf{r}}\right|$ \\
\hline 0.070 & 287.19 & 38.51 & 20.17 \\
0.050 & 287.92 & 53.60 & 14.11 \\
0.025 & 285.58 & 73.52 & 9.73 \\
\hline 0.000 & 284.40 & 94.46 & 7.81 \\
\hline-0.025 & 285.87 & 114.30 & 6.68 \\
-0.050 & 283.82 & 129.69 & 5.08 \\
\hline
\end{tabular}


The turn angle increases substantially as the aerospike nozzle is throttled closed. The change in turn angle occurs because the turn angle is a geometric function of vectored force and the axial force. Effectively, throttling the spike does not affect the pressure seen by the secondary port; therefore the vectored force remains unchanged while the spike is throttled. However, the axial force, which is a function of the nozzle throat area, does change. With a constant vectored force, the changing axial thrust force results in a change in the resultant turn angle.

Throttling should not change the pressure seen by the secondary throat in all positions. However, this is not true for when the spike is throttled open 0.050 inches. The throat location is shown to coincide with the secondary port in Figure 41. The coinciding throat location can cause a deviation in pressure from the static chamber pressure, which could cause a change in the vectored force.

In future designs, the above effects can be nullified by simply changing the geometry on the inner surface of the main nozzle and/or the location of the secondary port on the nozzle such that the throat location does not move.

Table 18: Summary of the vectored aerospike nozzle throttled via axially translating the spike.

\begin{tabular}{|c|c|c|c|c|c|c|c|c|c|}
\hline Position / Run & $\begin{array}{c}\text { NPR } \\
-\end{array}$ & $\begin{array}{c}\mathbf{F}_{\mathbf{x}} \\
\mathrm{lbf}\end{array}$ & $\begin{array}{c}\mathbf{F}_{\mathbf{y}} \\
\mathrm{lb}_{\mathrm{f}}\end{array}$ & $\begin{array}{c}\mathbf{F}_{\mathbf{z}} \\
\mathrm{lb_{ \textrm {f } }}\end{array}$ & $\begin{array}{c}\mathbf{F}_{\text {vector }} \\
\mathrm{lb}_{\mathrm{f}}\end{array}$ & $\begin{array}{c}\mathbf{W}_{\mathbf{p}} \\
\mathrm{lb}_{\mathrm{m}} / \mathrm{s}\end{array}$ & $\begin{array}{c}\boldsymbol{\delta}_{\text {pitch }} \\
{ }^{\prime}\end{array}$ & $\begin{array}{c}\boldsymbol{\delta}_{\text {yaw }} \\
\circ\end{array}$ & $\begin{array}{c}\boldsymbol{\delta}_{\mathbf{r}} \\
\circ\end{array}$ \\
\hline $\begin{array}{c}\text { Vectored } \\
\text { Throttling }\end{array}$ & & & & & & & & & \\
0.050 & 20.36 & -11.46 & -0.57 & -129.18 & 11.48 & 2.25 & 0.25 & 5.07 & -5.08 \\
0.025 & 20.51 & -13.29 & -0.40 & -113.53 & 13.29 & 2.00 & 0.20 & 6.68 & -6.68 \\
0 & 20.40 & -12.80 & -0.92 & -93.58 & 12.83 & 1.69 & 0.56 & 7.79 & -7.81 \\
-0.025 & 20.49 & -12.42 & -0.45 & -72.47 & 12.43 & 1.39 & 0.35 & 9.72 & -9.73 \\
-0.050 & 20.64 & -13.06 & -0.36 & -51.98 & 13.07 & 1.04 & 0.39 & 14.11 & -14.11 \\
-0.070 & 20.59 & -13.26 & -0.57 & -36.15 & 13.28 & 0.85 & 0.90 & 20.15 & -20.17 \\
\hline
\end{tabular}

The Schlieren images in Figure 40 suggest that the secondary port flow causes the main thrust flow to angle in the direction of the desired turn. The main plume deflection 
is less apparent when the nozzle throttled closed. The secondary port itself is underexpanded and visual evidence can be seen in Figure 40. The secondary exhaust flow expands immediately after it exits the secondary port.

Looking very closely at the flow from the secondary port when the spike position is -0.050 inches from nominal, less flow from the secondary port is apparent. The size of the secondary port exhaust plume is smaller than that of the other spike locations. The size of the exhaust plume at the -0.050 inches from nominal spike position corresponds to the situation in which the main nozzle throat area location affects the secondary port as mentioned above. 


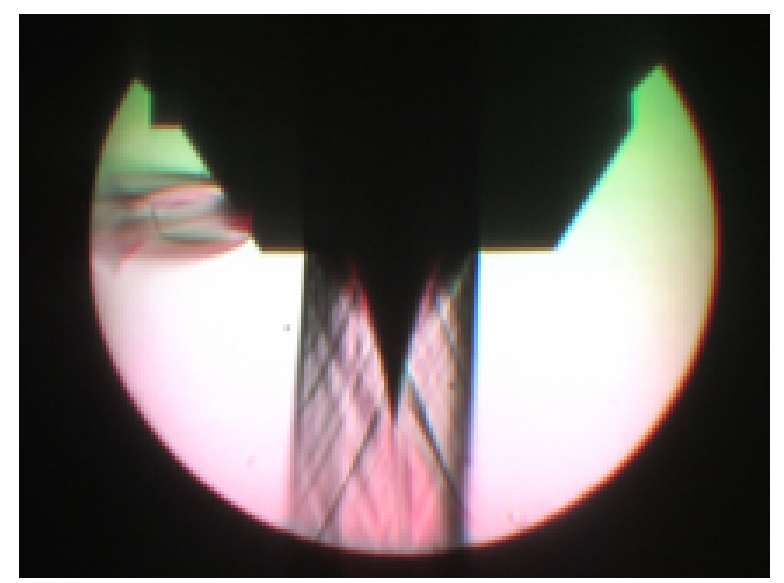

a) Nominal spike position.

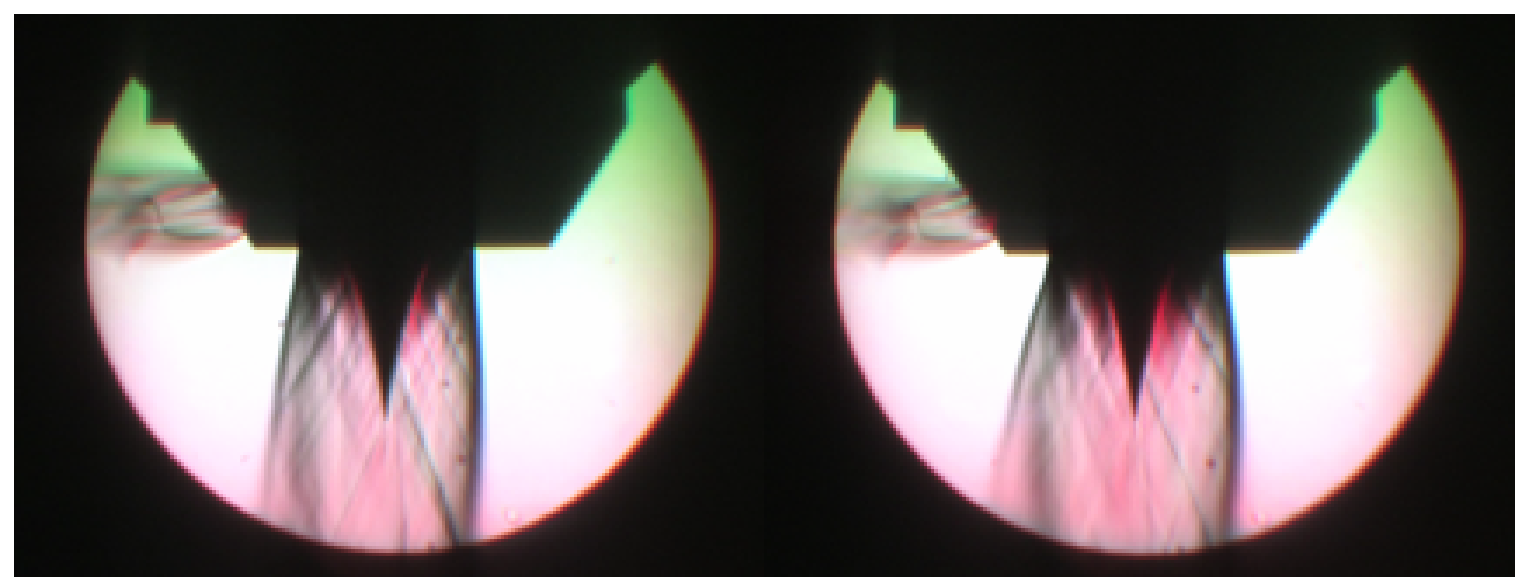

b) Spike position +0.025 " from nominal.

c) Spike position +0.050 " from nominal.

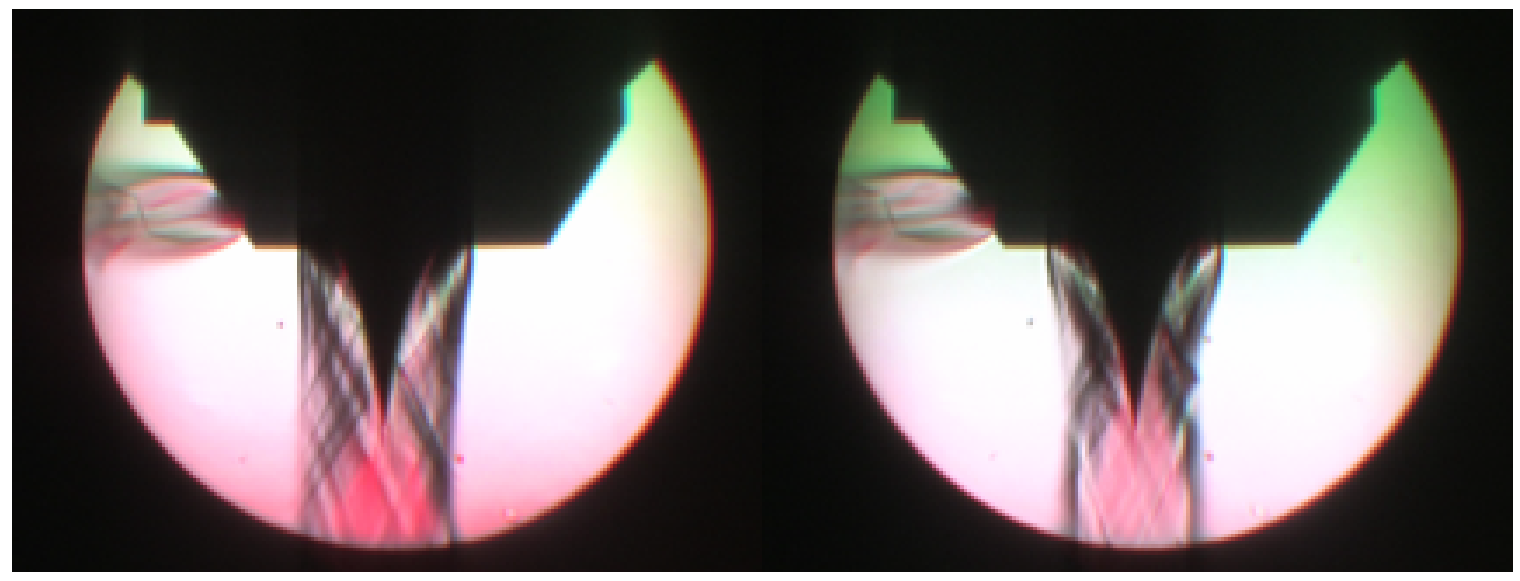

d) Spike position -0.025" from nominal.

e) Spike position -0.050" from nominal.

Figure 40: Schlieren images of the throttled vectored aerospike nozzle. 
The main nozzle performance and the secondary port performance are shown in Table 19. In general, the secondary nozzle thrust coefficient remains unaffected by throttling the spike, except when the spike is throttled open 0.050 inches. When the spike is throttled 0.050 inches open, the throat location moves inward as described and shown in Figure 41. The new throat location coincides with the location of the secondary port. The coincidence of the throat location and secondary port location can explain why the secondary nozzle thrust coefficient and vectored thrust are less that of other spike positions.

Since the chamber pressure stays relatively constant, the secondary port would not be expected to produce different thrusts at differently throttled spike positions.

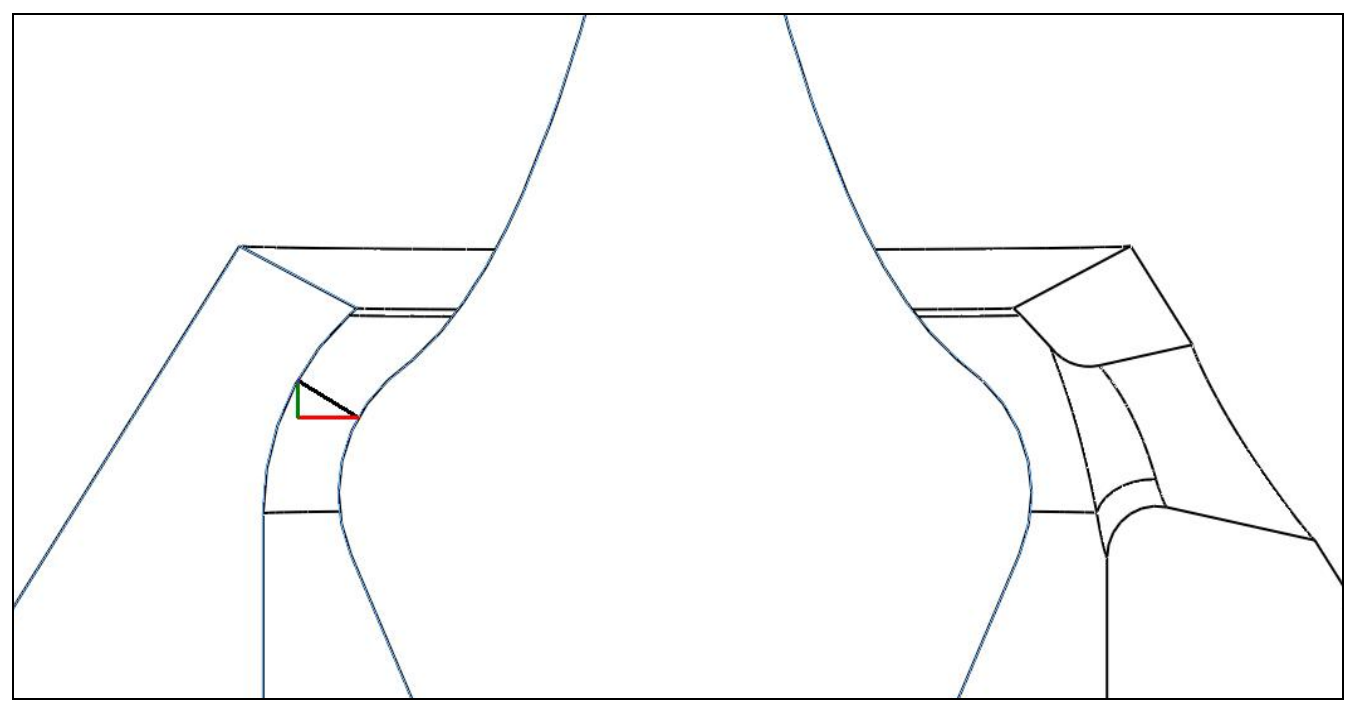

Figure 41: Throat location when the spike is throttled out $0.050 "$ ". 
Table 19: Summary of nozzle performance for the throttled vectored aerospike nozzle.

\begin{tabular}{|c|c|c|c|}
\hline Position / Run & $\begin{array}{c}\text { NPR } \\
-\end{array}$ & $\begin{array}{c}\mathbf{A}_{\mathbf{t}} \\
\mathrm{in}^{2}\end{array}$ & $\begin{array}{c}\mathbf{C}_{\mathbf{f}} \\
-\end{array}$ \\
\hline $\begin{array}{c}\text { Vectored } \\
\text { Throttling } \\
0.050\end{array}$ & 20.36 & 0.396 & 1.09 \\
0.025 & 20.51 & 0.278 & 1.36 \\
0 & 20.40 & 0.216 & 1.45 \\
-0.025 & 20.49 & 0.164 & 1.47 \\
-0.050 & 20.64 & 0.112 & 1.53 \\
-0.070 & 20.59 & 0.073 & 1.63 \\
\hline
\end{tabular}

The change in turn angle with respect to the throat area is shown in Figure 42. The data was obtained by inserting or removing shims underneath the spike to move the spike to a desired position and corresponding throat area. The first point at an area ratio of zero is an artificial point that corresponds to having all the thrust force, or mass flow, in the vectored direction, which corresponds to a $90^{\circ}$ turn angle. Such is the scenario when the throat is throttled completely closed and only the flow through the secondary port remains. The results show that as the nozzle is throttled closed, the resultant turn angle increases at a rate that is not linear. The force acting on the spike itself is shown as a function of spike location in Figure 42.

The change in resultant thrust force with respect to the spike location is shown in Figure 43. The trend looks very linear, but previous experiments performed and data taken at low pressure shows that the trend actually follows a sigmoidal shape, or " $\mathrm{S}$ " shape, with the inflection point centered at the nominal spike position [10]. Imagine the spike throttled completely closed; at this condition there is no thrust. The spike throttled completely closed is the lower bound. Now imagine that the spike throttles open. There is a point where if the spike is allowed to continue to translate to further open the throat, 
there will not be any increased thrust force because the throat area will not change anymore. Once the spike moves far enough into the nozzle, the spike contour is no longer creating the throat; the nozzle cowl lip is creating the throat (essentially a nozzle with the spike removed). The point where the spike contour no longer creates the throat is the upper bound on the thrust force. The force acting on the spike as a function of spike location is shown in Figure 43. 


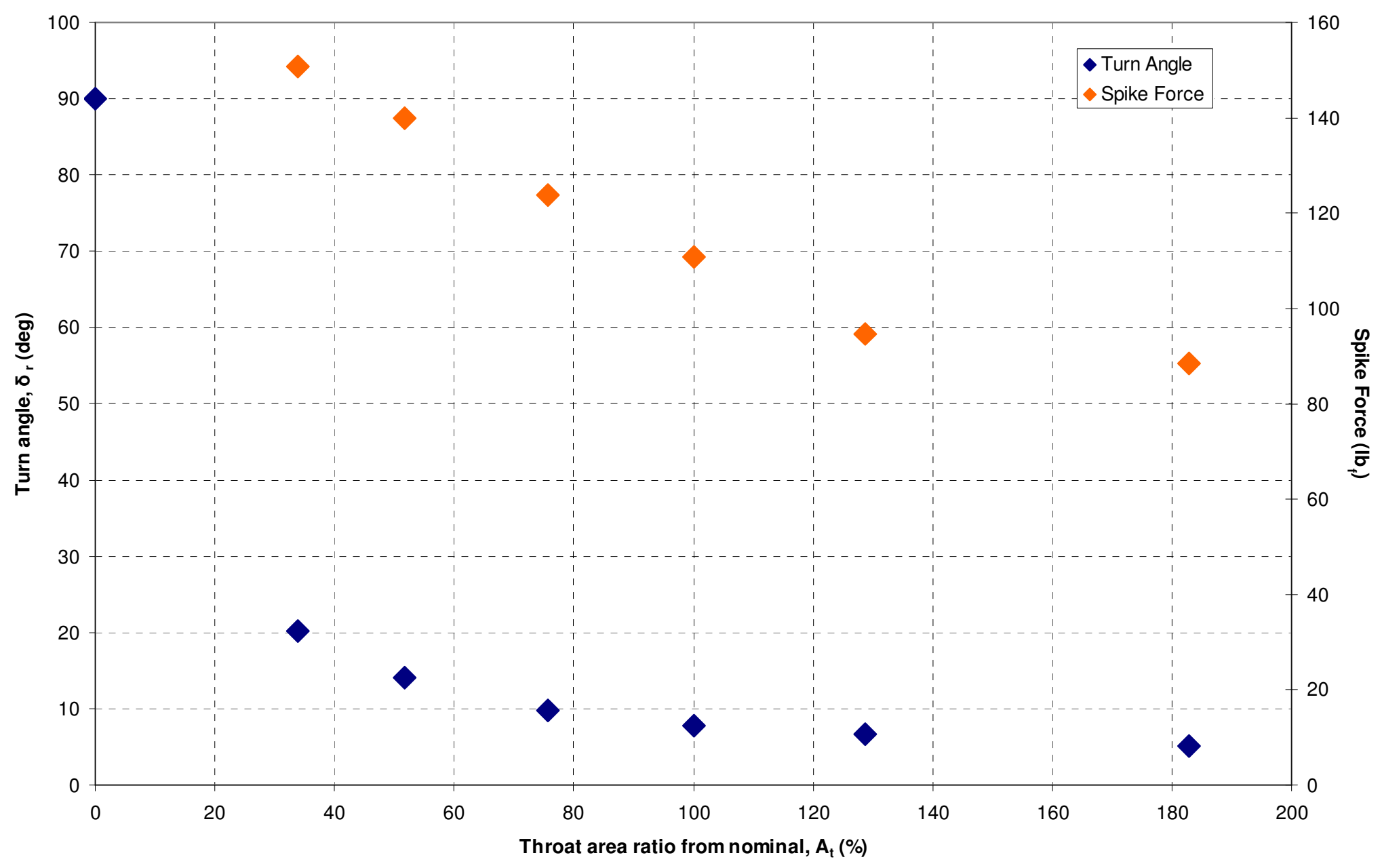

Figure 42: Turn angle and spike force as a function of throat area ratio for vectored flow. 


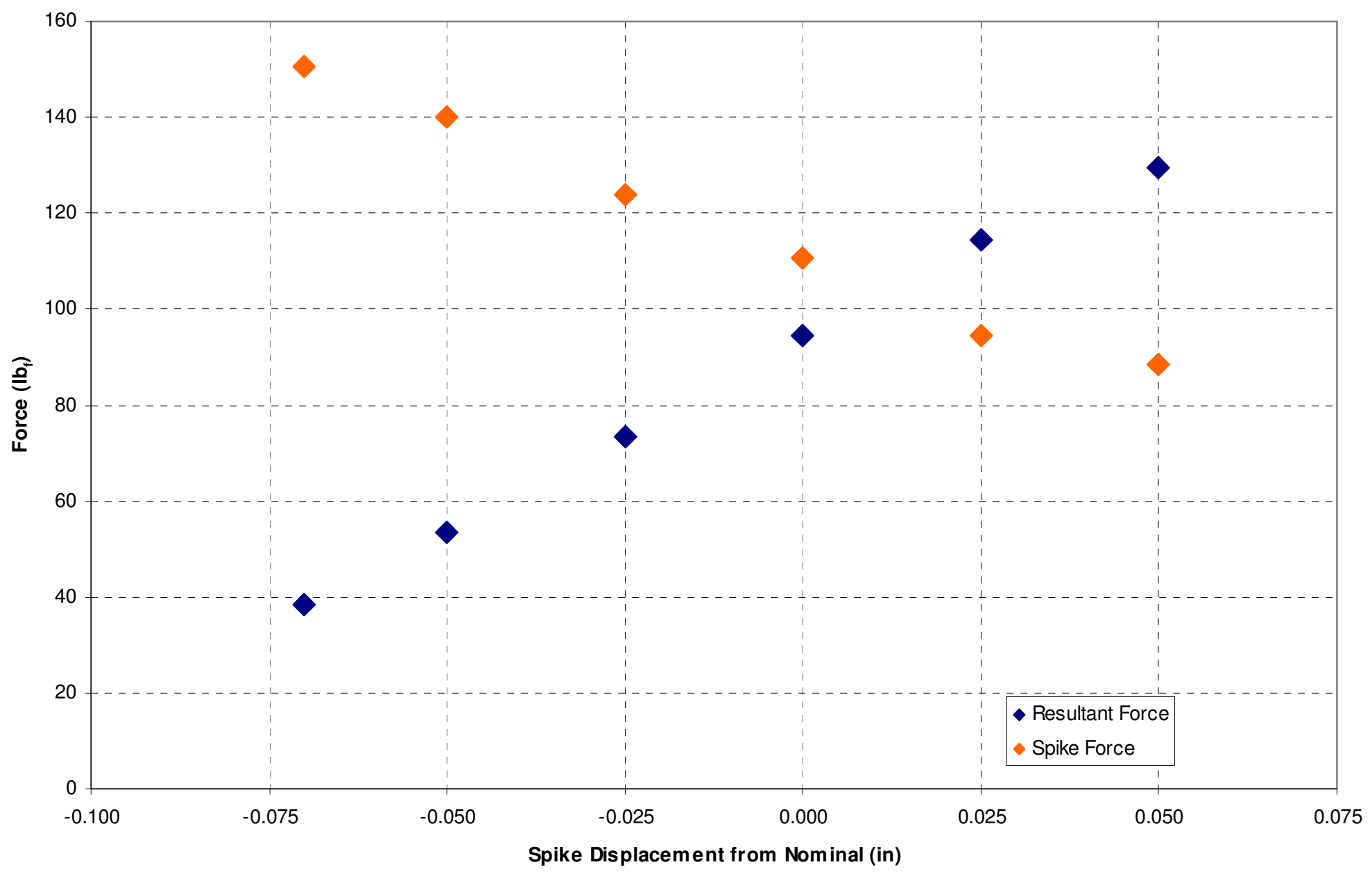

Figure 43: Resultant force and spike force as a function of spike location for vectored flow. 
While initially all throttling of the spike was accomplished by mechanically inserting or removing shims under shaft that holds the spike to get steady-state conditions and results, additional tests were conducted with a servo motor controlling the spike position in real time. Controlling the spike position in real time allows for testing to be performed at transient conditions and more closely models how the flow would behave in real applications. The data plot for the actively controlled spike can be seen in Appendix C.

A servo-controlled motor is used to drive the spike to any desired position. The motor is also used in a feedback control to maintain the chamber pressure at a desired value by throttling the spike and changing the throat area of the nozzle.

More specifically, the system used to control the spike consists of a linear stepper motor, an axial load-cell, and a connecting shaft. The connecting shaft bridged the loadcell, through the plenum chamber, to the spike. By raising and lowering the spike via the stepper motor, the throat area was able to be effectively changed, and thus control the down-stream pressure of the plenum chamber.

The stepper motor and in turn plenum pressure, was controlled using a FPGA (field programmable gate array), a custom stepper driver, an analog to digital converter, and an encoder. Specific details about the FPGA, stepper motor, and encoder, as well as some details of the software are reported in Appendix D. In general, the FPGA was programmed with a soft-core microcontroller. This microcontroller is able to accomplish the following tasks: move the spike using the stepper motor driver, read the plenum pressure using an analog to digital converter, read the axial position of the spike using an 
optical encoder mounted to the motor, and communicate with a Windows program via a serial connection.

The feedback control was achieved by taking the signal from the pressure transducer that reads the plenum pressure and comparing it to the desired pressure set point. The pressure transducer signal is adjusted to be as close as possible to the desired set point signal by changing the spike position which, in effect, changes the plenum pressure in the stand. So, as the supply pressure from the air cylinders outside of the test cell drops, the plenum pressure in the stand is maintained by throttling the spike. Throttling the spike closed raises the plenum pressure and reduces the flow rate compensating for a lack of available supply pressure. Conversely, throttling the spike open could compensate for a surge in supply/plenum pressure, if so desired.

The software was initially designed to be a proportional-integrator (PI) controller. Within a few tests it was determined that proportional control alone was sufficient to maintain plenum pressure. Adding even the smallest amount of integral control caused the system to oscillate about the set point. The oscillation was inherent in both a plot of the spike position a corresponding plot of the plenum pressure.

The control system was managed through a Windows interface (some detail of the Windows interface can be found in Appendix D). The Windows interface connected to the FPGA via a serial link and gave the user complete control over the static position of the spike as well as the active PI controller settings. The connection allows the user to rapidly vary the test conditions either by moving the spike to a predetermined position, or setting varied proportional and integral gains. 
In general, the spike actuation system used in the active throttling cold flow test stand was very successful. The system was shown to be very responsive to fluctuating supply conditions and has numerous applications in rocketry. Finally, being able to move the spike axially allowed the study of the effects that that throttling has on thrust vectoring the nozzle. 


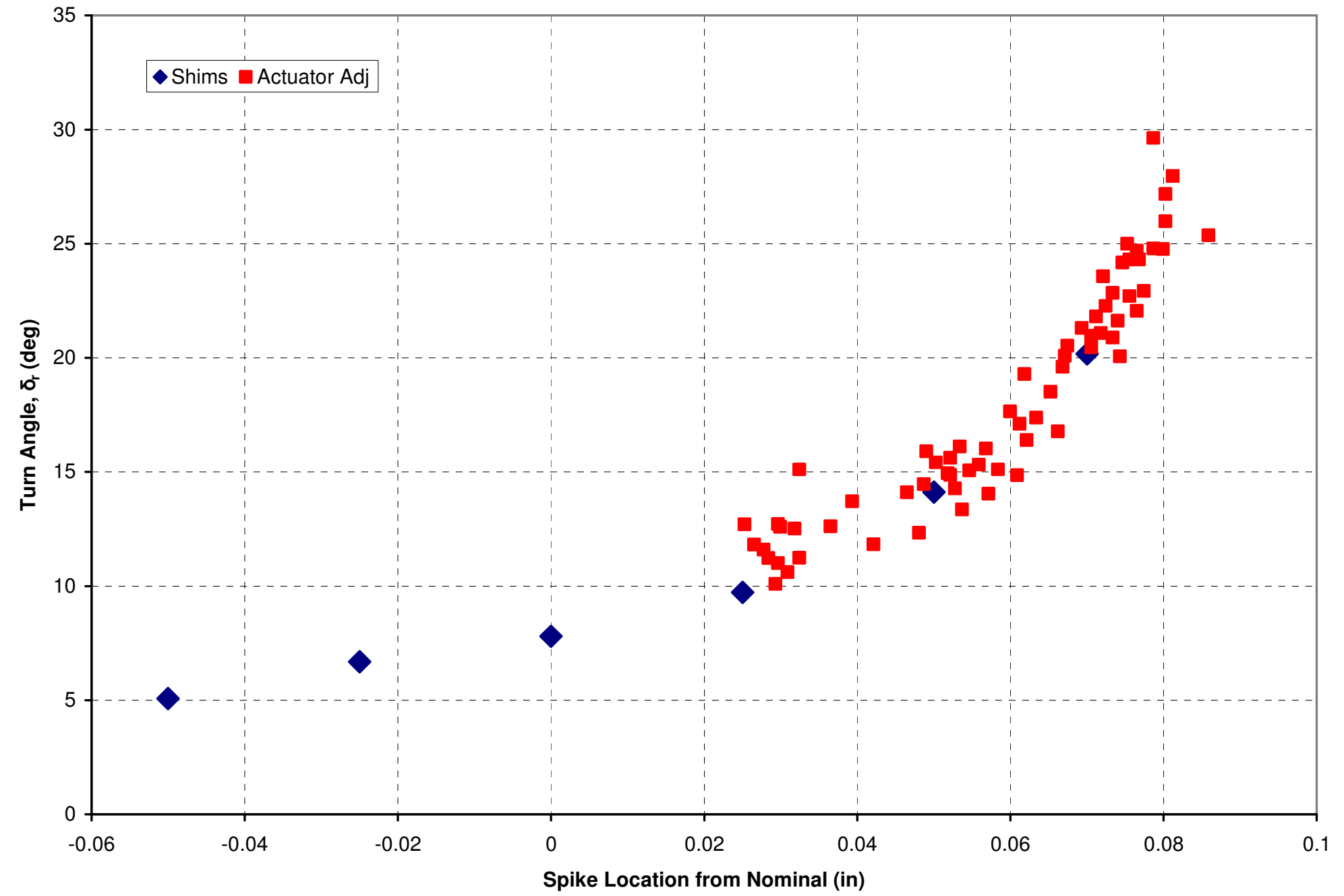

Figure 44: Plot of resultant turn angle as a function of spike location from nominal for the shimmed configuration and the servo motor controlled configuration. 


\section{REFERENCES}

1. Sutton, G.P. and O. Biblarz, eds. Rocket Propulsion Elements. 7th ed. 2001, John Wiley and Sons, Inc.: New York, USA.

2. Zucrow, Maurice and J. Hoffman, Gas Dynamics. Volume 1. 1976, John Wiley and Sons, Inc.: New York, USA.

3. Besnard, E., H. Chen and T. Mueller. Design, Manufacture and Test of a Plug Nozzle Rocket Engine. AIAA Paper No.02-4038. Huntington Beach, California.

4. Ruf, J.H. and P.K. McConnaughy. Design, The Plume Physics Behind Nozzle Altitude Compensation and Slipstream Effect. AIAA Paper No.97-3218. 1997. Huntsville, Alabama.

5. Berman, K. and F.W. Crimp Jr. Performance of Plug-Type Rocket Exhaust Nozzles. ARS Journal. 1961.

6. Carpenter, T., Lectures on Rocket Propulsion, ME541 Advanced Thermodynamics, Fall 2006.

7. O'Leary, R.A. and J.E. Beck. Nozzle Design. Threshold: Pratt and Whitney Rocketdyne's Engineering Journal of Power Technology. 1992.

8. Martinez-Sanchez, M., Lectures 3 Notes on Rocket Propulsion, Massachusetts Institute of Technology: Open Courseware, Fall 2005.

9. Ames Research Staff. Report 1135: Equations, Tables, and Charts for Compressible Flow, Massachusetts Institute of Technology: Moffett Field, Ca 2005.

10. Cal Poly, San Luis Obispo, Rolling Hills Research Corporation. Optimal Thrust Vectoring for an Annular Aerospike Nozzle. 2009.

11. “Altitude Compensation", (1997-2009), Aerospaceweb.org, Available: http://www.aerospaceweb.org/design/aerospike/compensation.shtml (Accessed 2008, December 10)

12. Carpenter, T.W., Kerho, M.F., Kramer, B.F., and Murray, W.R., "Optimal Thrust Vectoring for an Annualr Aerospike Nozzle," NASA STTR Grants: Phase II, Contract NND06AB82C, 6/06 - 6/08; Phase I, Contract NND05AA53C, 1/05 - 1/06. 
APPENDIX A: NOZZLE THRUST COEFFICIENT DERIVATION

$$
\begin{gathered}
C_{f}=\frac{F_{T}}{A_{t} P_{1}} \\
F_{T}=\dot{m} v_{2}+\left(P_{2}-P_{3}\right) \cdot A_{2}
\end{gathered}
$$

Neglecting potential energy, an increase in thermal energy, or enthalpy, results in an increase in kinetic energy as a direct result of a conservation of energy.

$$
\begin{gathered}
h_{0}=h+\frac{v^{2}}{2} \\
h_{2}-h_{1}=\frac{1}{2}\left(v_{2}^{2}-v_{1}^{2}\right)=C_{p}\left(T_{2}-T_{1}\right)
\end{gathered}
$$

Solving for the exit velocity, $\mathrm{v}_{2}$, gives:

$$
v_{2}=\sqrt{2 \cdot\left(h_{1}-h_{2}\right)}+v_{1}^{2}
$$

Using the following definition of $\mathrm{C}_{\mathrm{p}}$ :

$$
\begin{gathered}
C_{p}=\frac{\gamma \cdot R}{\gamma-1} \\
\frac{T_{1}}{T_{2}}=\left(\frac{\rho_{1}}{\rho_{2}}\right)^{\frac{\gamma-1}{\gamma}}=\left(\frac{v_{2}}{v_{1}}\right)^{\gamma-1}
\end{gathered}
$$

The inlet velocity of the nozzle, $v_{1}$, is zero because of the stagnation conditions in the supply chamber.

$$
v_{2}=\sqrt{\frac{2 \gamma}{\gamma-1} \cdot R T_{1} \cdot\left(1-\frac{P_{2}}{P_{1}}\right)^{\frac{\gamma-1}{\gamma}}}+\not_{1}^{2}
$$

The mass flow rate through the nozzle can be expressed as follows:

$$
\dot{m}=\rho_{t} \cdot v_{t} \cdot A_{t}
$$


Using the following equations for isentropic flow [2]:

$$
\begin{gathered}
\frac{\rho_{0}}{\rho}=\left(1+\frac{\gamma-1}{2} \cdot M^{2}\right)^{\frac{1}{\gamma-1}} \\
\rho_{t}=\rho_{1} \cdot\left(\frac{2}{\gamma+1}\right)^{\frac{1}{\gamma-1}}
\end{gathered}
$$

Using the ideal gas law, the density and acoustic velocity can be described as follows:

$$
\begin{gathered}
\rho_{1}=\frac{P_{1}}{R T_{1}} \\
v_{t}=\sqrt{\frac{2 \cdot \gamma}{\gamma+1} \cdot R T_{1}}=a_{t}=\sqrt{\gamma R T} \\
F_{T}=\frac{p_{1}}{\not K X_{1}} \cdot\left(\frac{2}{\gamma+1}\right)^{\frac{1}{\gamma-1}} \cdot \sqrt{\gamma K X_{1}} \cdot A_{t} \cdot \sqrt{\frac{2 \gamma}{\gamma-1} \cdot R X_{1} \cdot\left(1-\frac{P_{2}}{P_{1}}\right)^{\frac{\gamma-1}{\gamma}}}+\left(P_{2}-P_{3}\right) \cdot A_{2} \\
F_{T}=P_{1} \cdot A_{t} \cdot \sqrt{\frac{2 \gamma^{2}}{\gamma-1} \cdot\left(\frac{2}{\gamma+1}\right)^{\frac{\gamma+1}{\gamma-1}} \cdot\left(1-\frac{P_{2}}{P_{1}}\right)^{\frac{\gamma-1}{\gamma}}}+\left(P_{2}-P_{3}\right) \cdot A_{2}
\end{gathered}
$$

Using Equation (A.1), the nozzle thrust coefficient becomes:

$$
C_{f}=\sqrt{\frac{2 \gamma^{2}}{\gamma-1}\left(\frac{2}{\gamma+1}\right)^{\frac{\gamma+1}{\gamma-1}}\left[1-\left(\frac{P_{2}}{P_{1}}\right)^{\frac{\gamma-1}{\gamma}}\right]}+\frac{P_{2}-P_{3}}{P_{1}}\left(\frac{A_{2}}{A_{t}}\right)
$$

The theoretical maximum for a nozzle with air as the working fluid and an NPR of 20 at design condition (i.e., $\mathrm{P}_{2}=\mathrm{P}_{3}$ ) is as follows:

$$
C_{f}=\sqrt{\frac{2(1.4)^{2}}{0.4}\left(\frac{2}{2.4}\right)^{\frac{2.4}{0.4}}\left[1-\left(\frac{1}{20}\right)^{\frac{0.4}{1.4}}\right]}+0=1.374
$$




\section{APPENDIX B: MATLAB PROGRAM}

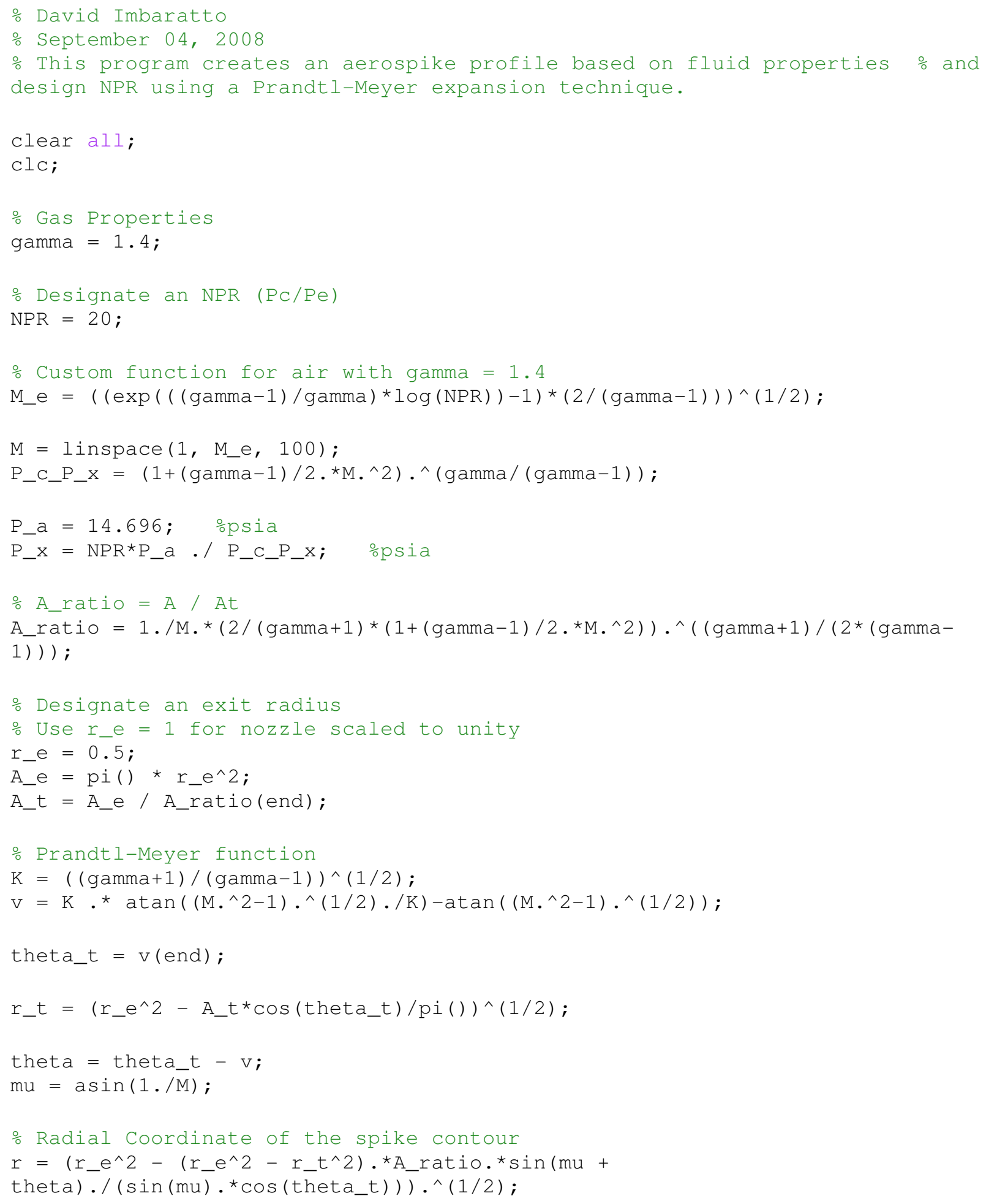




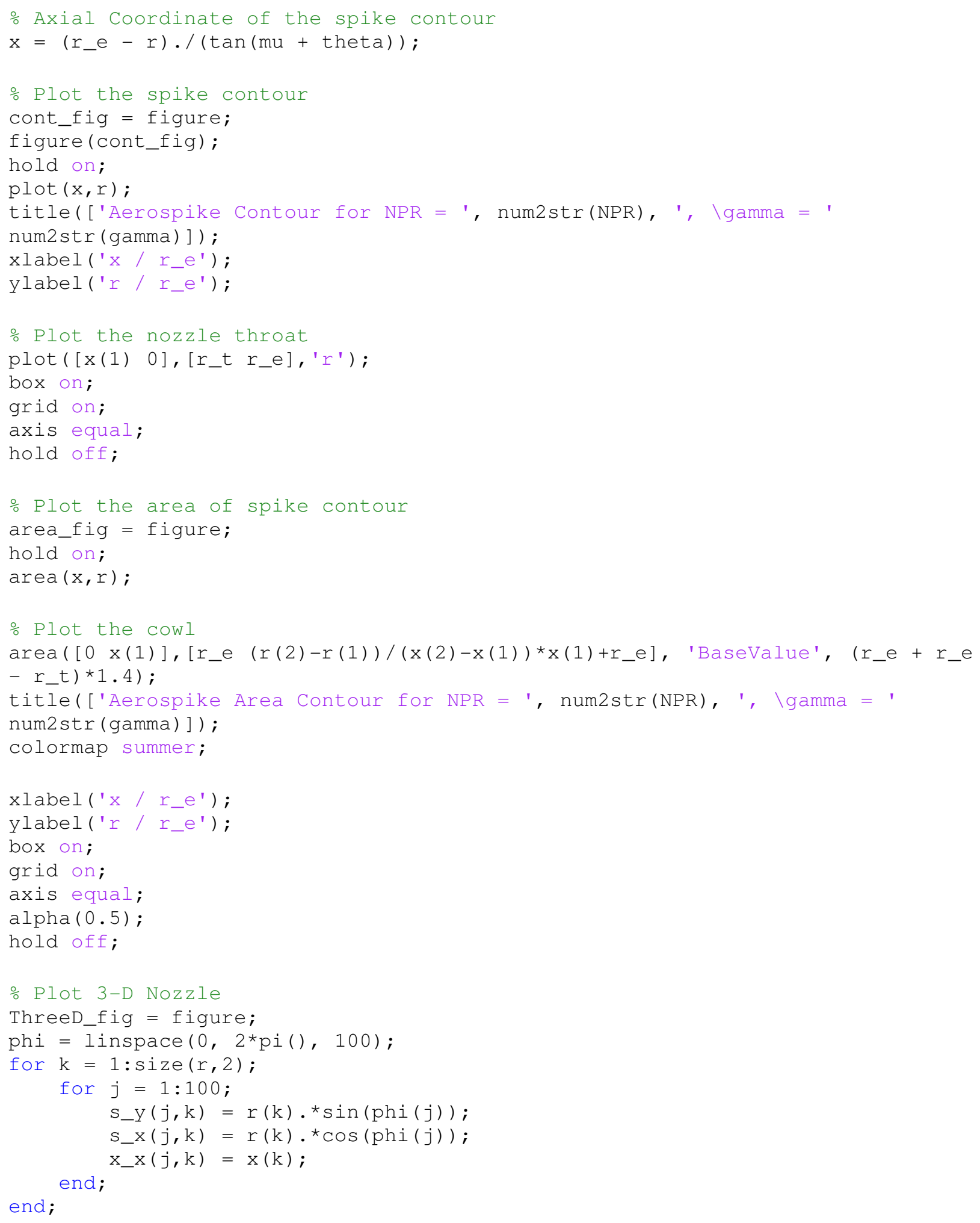




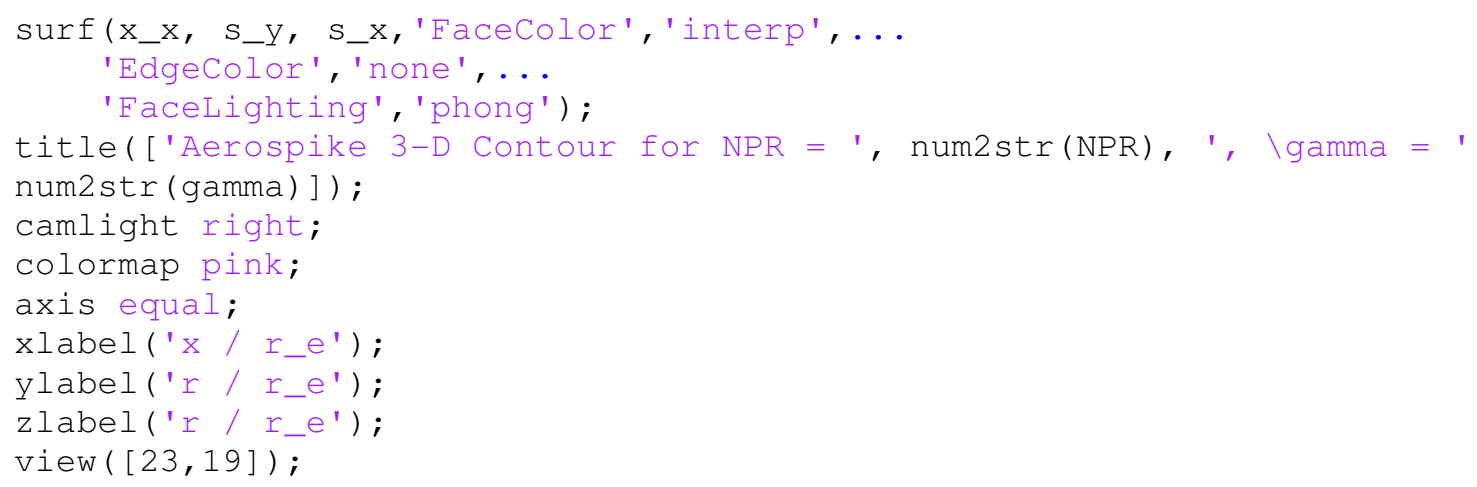


APPENDIX C: DATA PLOTS

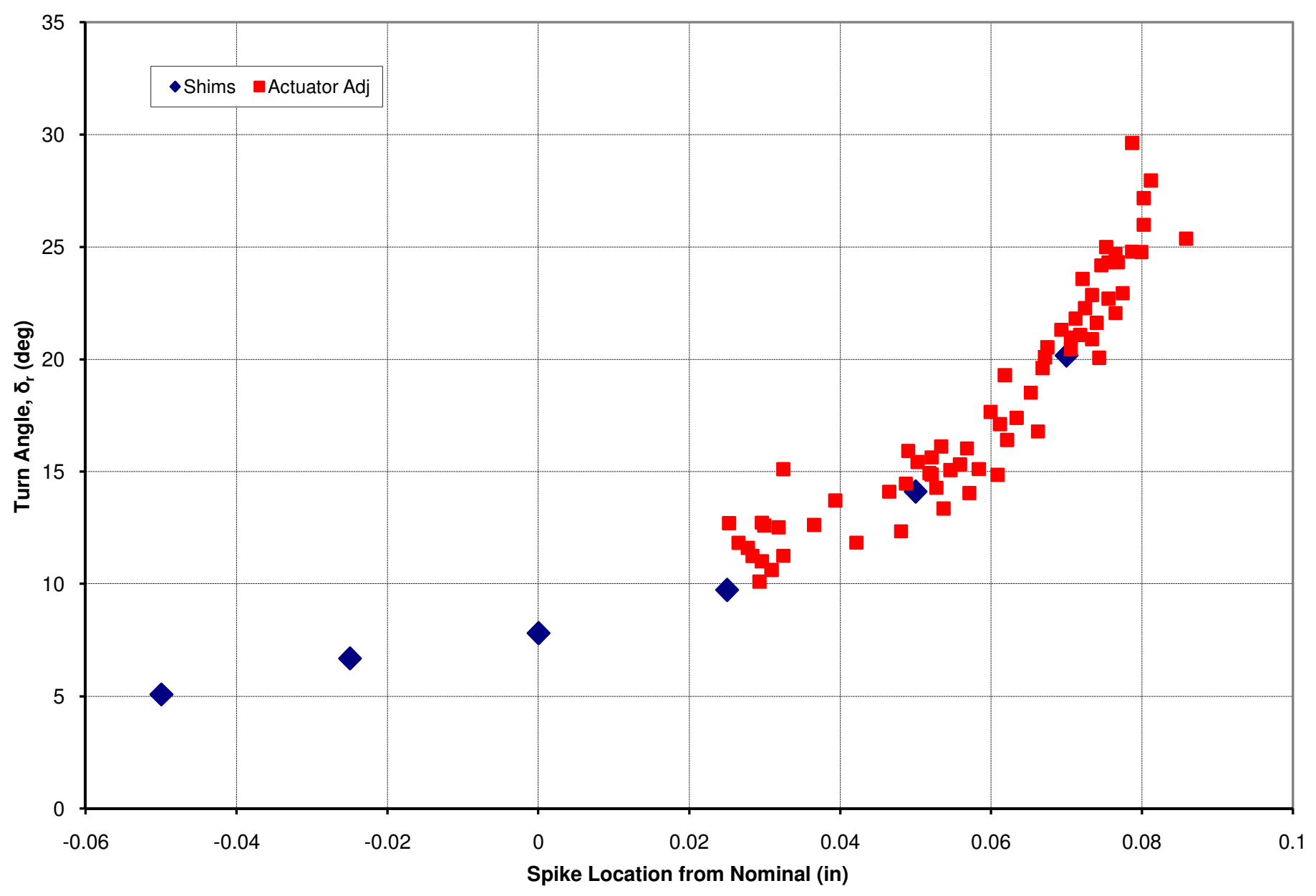

Figure 45: Turn angles for active and static throttling. 


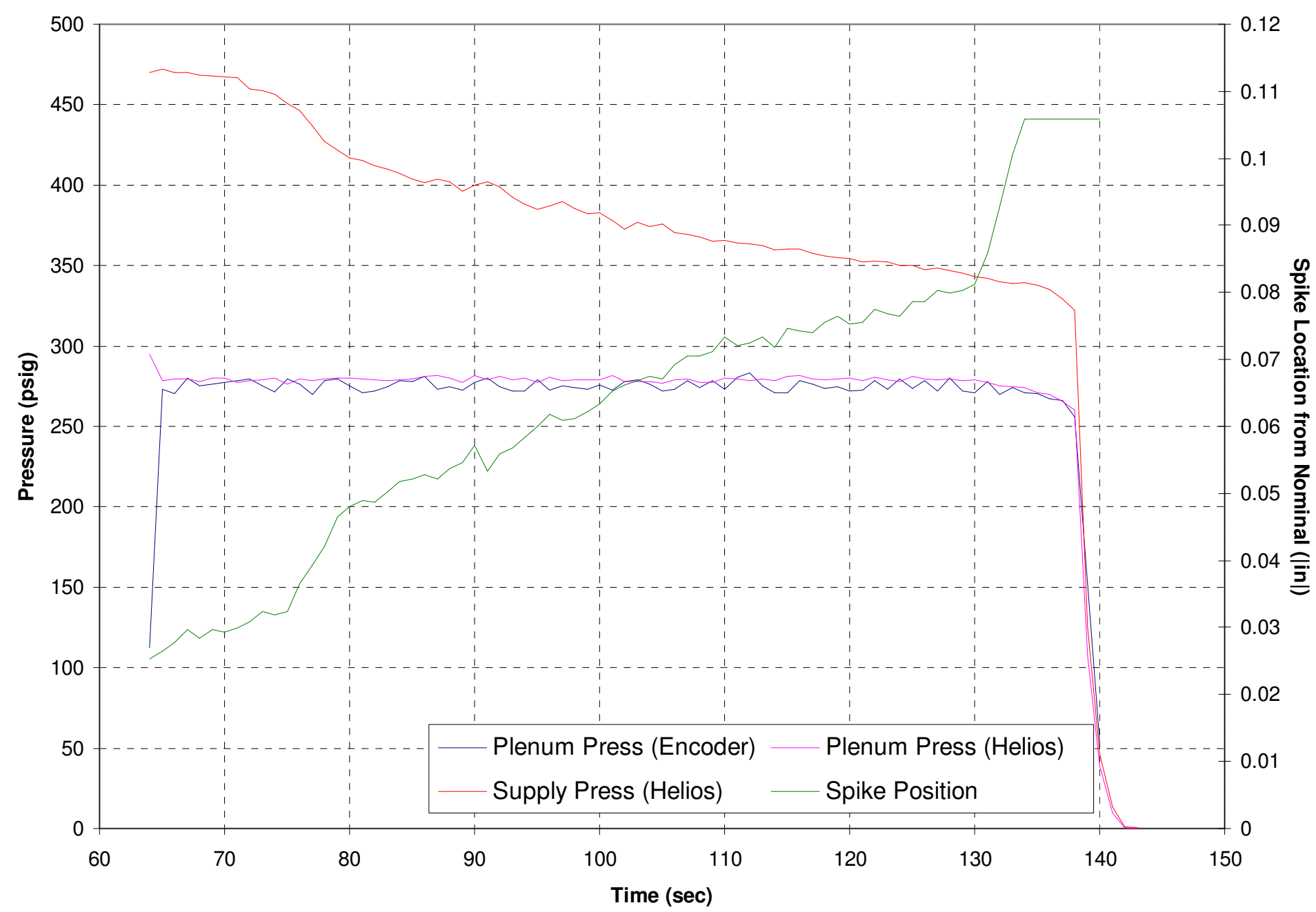

Figure 46: Pressure matching and spike location form Helios DAQ and encoder. 


\section{APPENDIX D: LINEAR STEPPER MOTOR CONTROLLER AND INTERFACE}

By Terry Cooke, Patrick McCarty, 3/15/2008.

Introduction

The Cal Poly Mechanical Engineering department is actively conducting research on advanced rocket nozzles. The purpose of this project was to build a stepper motor controller to raise and lower the plug of an aerospike nozzle.

This driver would control a Haydon Switch and Instruments linear stepper motor. This is a bipolar stepper motor, with 200 steps per rotation and a linear travel of 0.0003125 " per step. This motor also includes a 200 count Agilent Technologies HEDS quadrature encoder with index. In order to accurately position the motor, the encoder is used to measure absolute position. If steps do not cause actual movement of the spike, the encoder will still provide accurate positioning.

The stepper driver is centered around a NEXYS2 development system. The NEXYS2 has a Xilinx Spartan3e FPGA at its core, RS-232 level converters, switches, buttons, LEDs, and a wide variety of "off-board" interfaces to name a few of its features. Between the NEXYS2 and the linear stepper are two LMD18245 3A, 55V DMOS Full-Bridge Motor Driver. The LMD18245 full-bridge power amplifier incorporates all the circuit blocks required to drive and control current in a bipolar stepper motor.

System Requirements

1.) The embedded system should be able to drive a bipolar stepper motor in either direction at various speeds, and operate in both a manually and automatically controlled mode.

a) Manual Mode - this mode will allow the user to drive the stepper up or down at a hard-coded speed for a specified number of steps.

b) Automatic Mode - this mode will allow the user to specify the distance to move, the speed, and the ramp up/ramp down acceleration rate. The configured sequence will then be executed by the embedded system when the user clicks a start button.

2.) The movement parameters and control commands will be issued from a GUI program running on an ordinary Windows laptop or computer connected to the embedded system via a RS-232 serial cable.

3.) The embedded system will also be interfaced to a quadrature encoder installed on the stepper motor, to allow the system to keep track of the stepper's current position. The GUI program should be able to request the current position of the encoder and get a response using the serial port. 
4.) The GUI program should be simple and intuitive enough that users without any knowledge of how the embedded system works internally can understand how to use the program.

\section{System Specifications}

The embedded system will be implemented using a MicroBlaze soft-core processor synthesized on the NEXYS 2 Development Board. To interface with the necessary hardware, the following new IP cores will be used:

1. UART Lite - configured to operate at 115200 baud, 8 data bits, no parity, 1 stop bit

2. Quadrature Decoder Core - free IP core from Finger Lakes Engineering

Since the serial port can be used for most all user input and output, the user peripherals on the NEXYS2 board were only minimally used. The 7-segment display shows when the board is successfully initialized, one button is used for hardware reset, and one switch can disable the stepper motor. The devices on the board may be further utilized in future versions as more functionality is added to the system. 
System Architecture

NEXYS 2 Embedded System Architecture

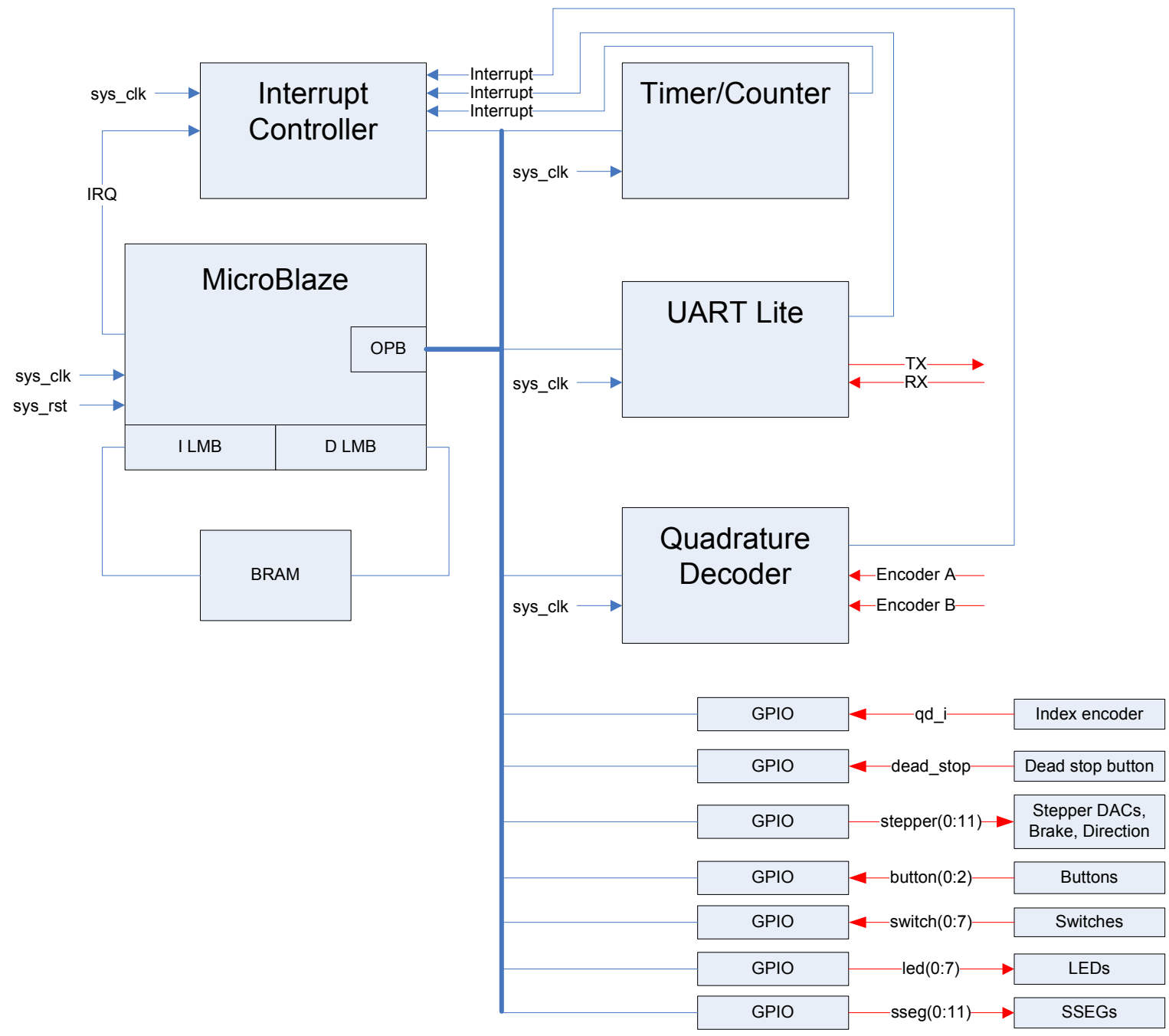

Figure 1 - Embedded System Architecture

\section{GUI Control Program Architecture}

The GUI is an important component of the stepper motor controller system, because it is the interface used to configure all settings and issue commands. The GUI was written in C\#, the most popular language used for developing programs for Microsoft's .NET Framework. Visual Studio 2005 was used as the development environment, which made laying out the GUI controls very easy. The program was written using the Microsoft .NET Framework 2.0, so this version of 
the framework must be installed in order to run the program. The program is organized using three tabs: Setup, Manual, and Auto.

\section{$\underline{\text { Setup Tab }}$}

The Setup tab, shown below, allows the user to select which COM port to use for communication with the embedded system. Upon clicking the Connect button, the program sends an initialization packet to the embedded system, which changes its 7-Segment display to indicate that it is ready, and allows it process stepper control packets. The embedded system also sends a response packet back to the GUI to acknowledge that it received the command. If the response is not received within a second, the GUI reports that the connection timed out and was unsuccessful. The baud rate is shown on this screen but it cannot be changed because the UART Lite core in the embedded system only supports a single chosen baud rate.

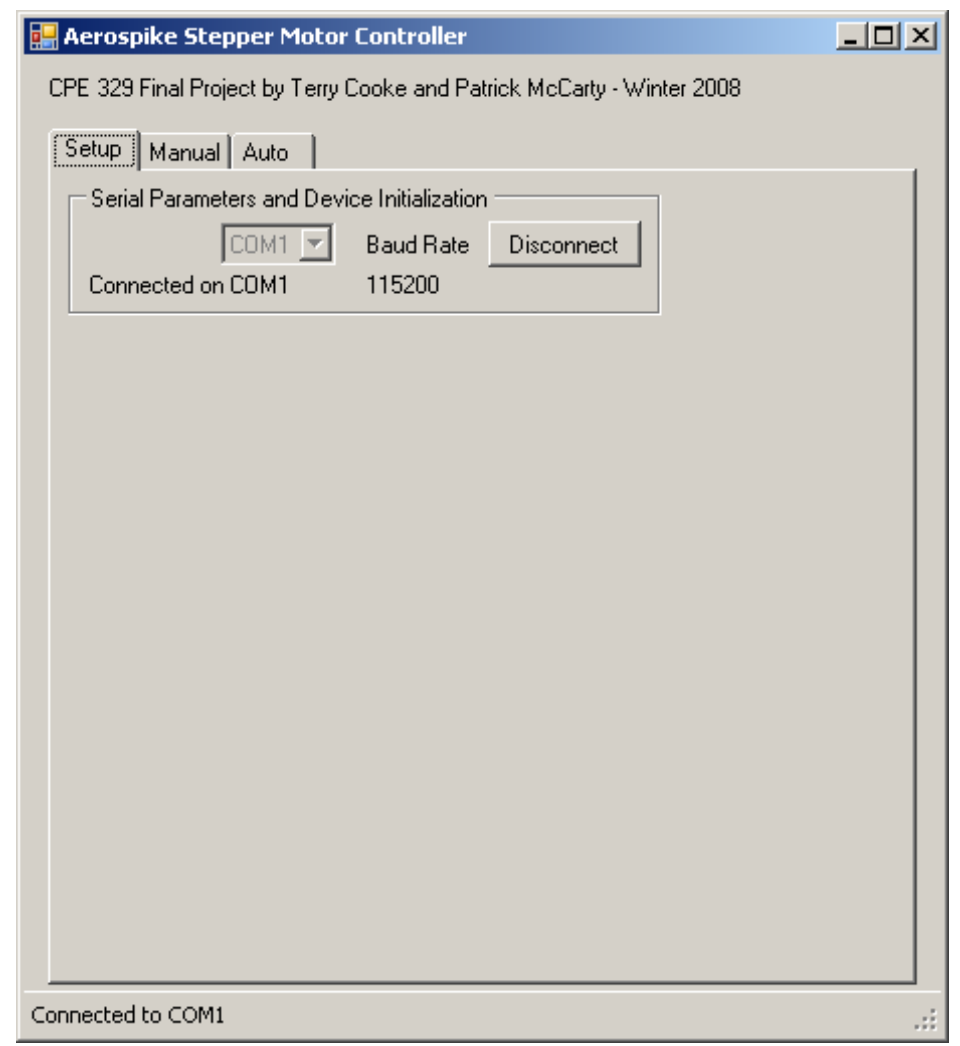

Figure 2 - Setup Tab to Configure Serial Parameters and Initialize Device

\section{Manual Tab}

The Manual tab, shown below, allows the user to manually drive the stepper motor up or down at a hard-coded speed by a specified number of full steps. After clicking Up or Down, the encoder tick count is read from the embedded system and the tick count and a computed distance is shown in the GUI. Additionally, this tab allows the user to manually request the current encoder position. Lastly, there is a feature to use a different zero-point for the numbers that are shown, in 
case the user wants to reference their measurements from a position different than the bottom position.

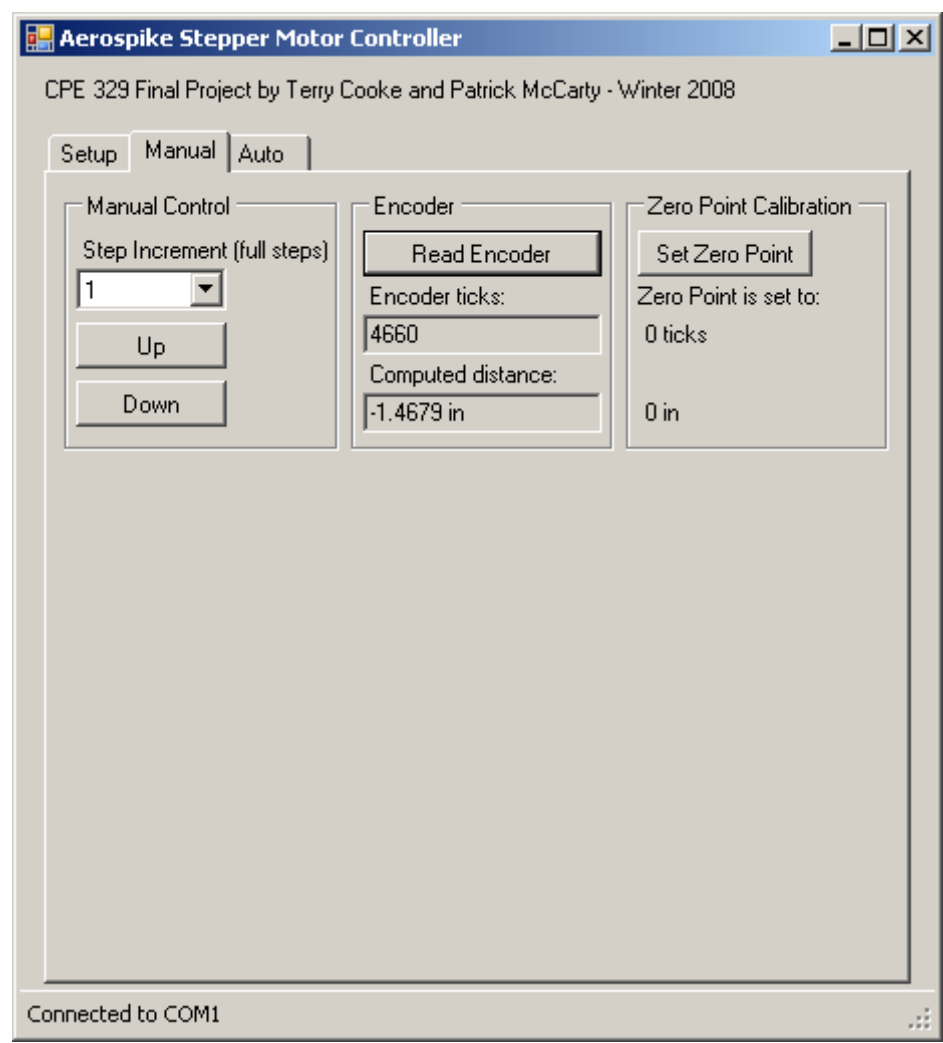

Figure 3 - Manual Tab to move the stepper directly, read encoder ticks, and configure zero reference point

\footnotetext{
Auto Tab

The Auto tab, shown below, allows the user to configure movement parameters, and then the movement sequence will be executed on the embedded system when the user clicks the Move! button. The stepper will accelerate at the rate specified in Ramp Up Accel, up to the Max Speed, and then decelerate at the rate specified in Ramp Down Accel, resulting in a movement of Distance to Move inches. The distance is also shown translated into steps when the Move! button is clicked. If the Use Max checkbox is selected, the Max Speed textbox is filled with the maximum supported speed. Note that the Apply Settings button must be clicked to send the chosen values to the embedded system before clicking the Move! button.
} 


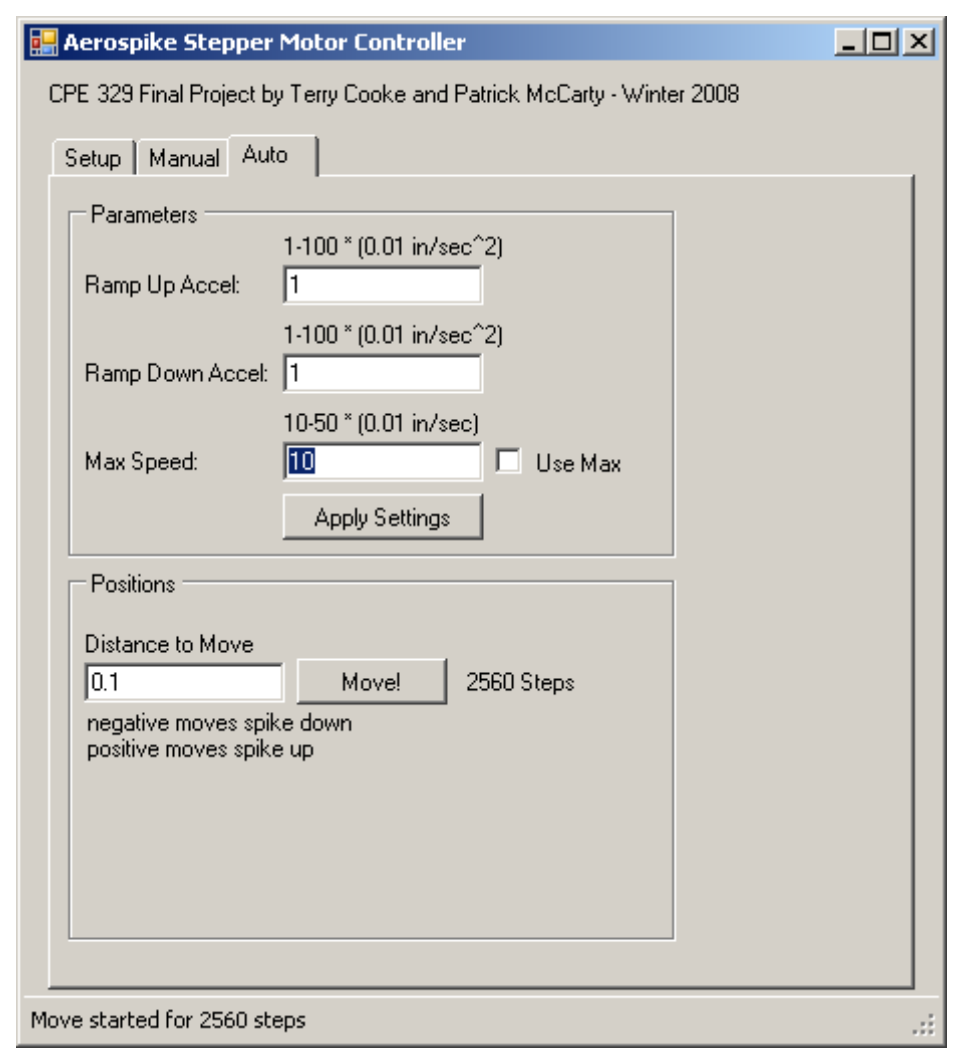

Figure 4 - Auto tab to configure and start a movement sequence

Component Design

Embedded Software Description

The Stepper motor controller design can be partition into two sections, the Main Program Loop (MPL) and the Timer Interrupt Service Routine (TISR). The main program loop is what is responsible for handing the user interface such as buttons, switches, Seven Segment Displays and LEDs, as well as serial communications with a remote application running on a windows PC. The Timer Interrupt Service Routine is what handles driving the stepper motor by calculating the correct time interval between steps and updating the Bridge Drivers. A representation of the software flow is shown in Figure 5 - MicroBlaze Software Flow Chart. 


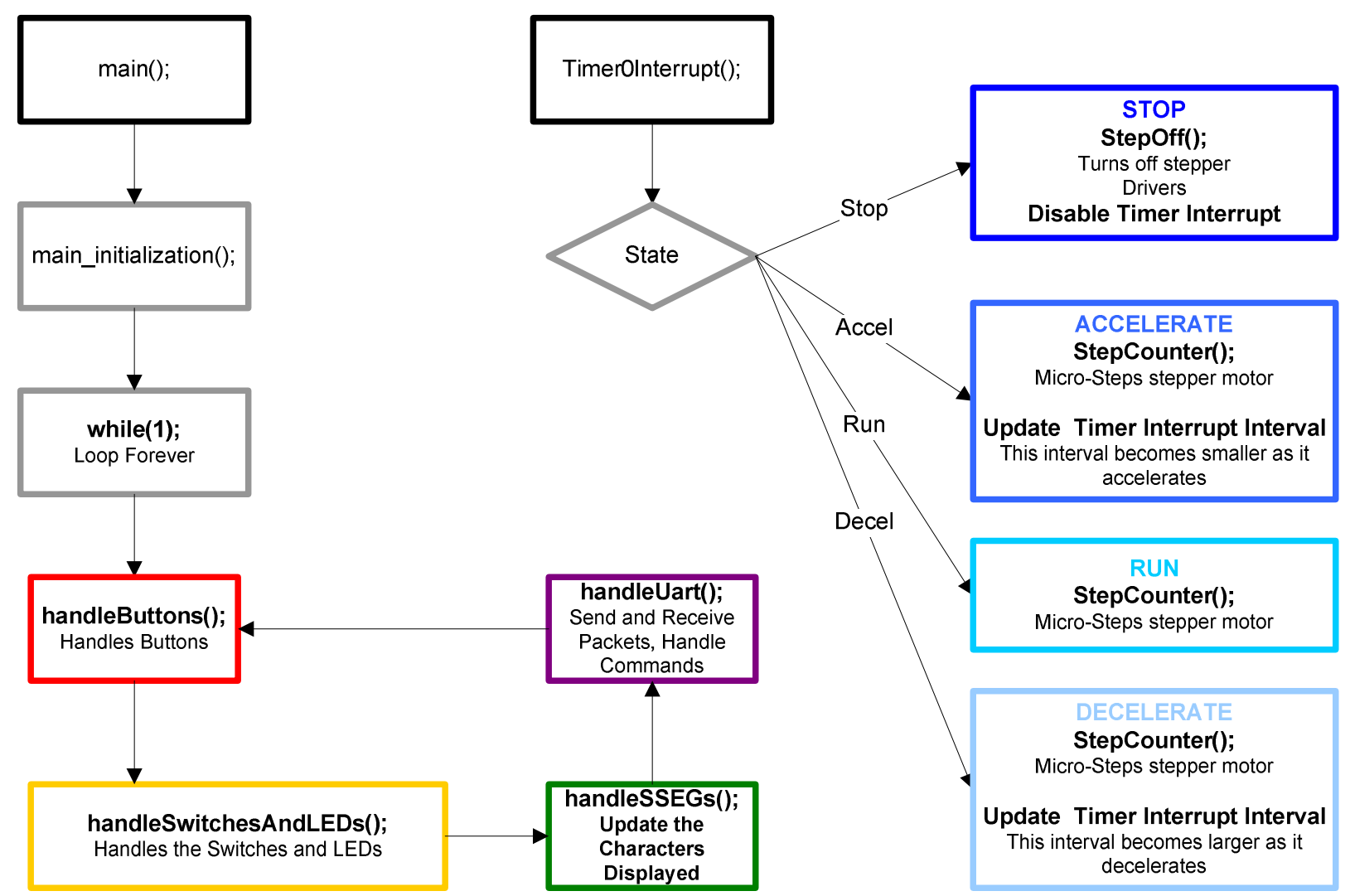

Figure 5 - MicroBlaze Software Flow Chart

\section{Main Program Loop}

The Main Program Loop as shown in "main();" above handles the user interface and communications with the PC GUI. It also initializes the hardware upon reset.

The initialization routine does the following. Upon power-up or from reset, the program first calls the initialization routine. This routine first sets up quadrature encoder debounce period and sets the register in the FLE quad decoder IP core to trigger once per cycle (see further explanation in the FLE Quad Decoder section below). It then initializes the timer IP core to count down, and sets it up to trigger an interrupt when it is enabled. It then initializes the UART IP core which waits for an acknowledge packet form the host PC (see further explanation in the UART section below).

The main loop calls each of the asynchronous tasks shown above. These tasks are handleButtons(), handleUart(), handleSwitchesAndLeds(), and handleSSEGs(). It calls these tasks in a continuous round-robin fashion. These tasks make decisions based on user input and call other functions that affect the stepper, timer, and UART.

handleButtons() and HandleSwitchesAndLeds() 
The only purpose of these functions at this time is to accommodate future software versions. Switch 6 however can be used as an emergency "shut-off" because it disables both the timer interrupt and the bridge drivers. An LED illuminates if the switch is active.

\section{handleSSEGs()}

This function refreshes the Seven Segment Displays. It displays a character sequence of "On_r" when the remote PC sends the proper initialization packet. It does this by showing each character for $\sim 50 \mu \mathrm{s}$ at a rate greater that $60 \mathrm{~Hz}$. It will stay illuminated until reset or power off.

\section{handleUart()}

This function handles both receiving and transmitting packets as well as command interpretation. It can be broken into two sections the "task" and the "Decision". A software flow chart is shown in Figure 6 - UART Software flow chart.

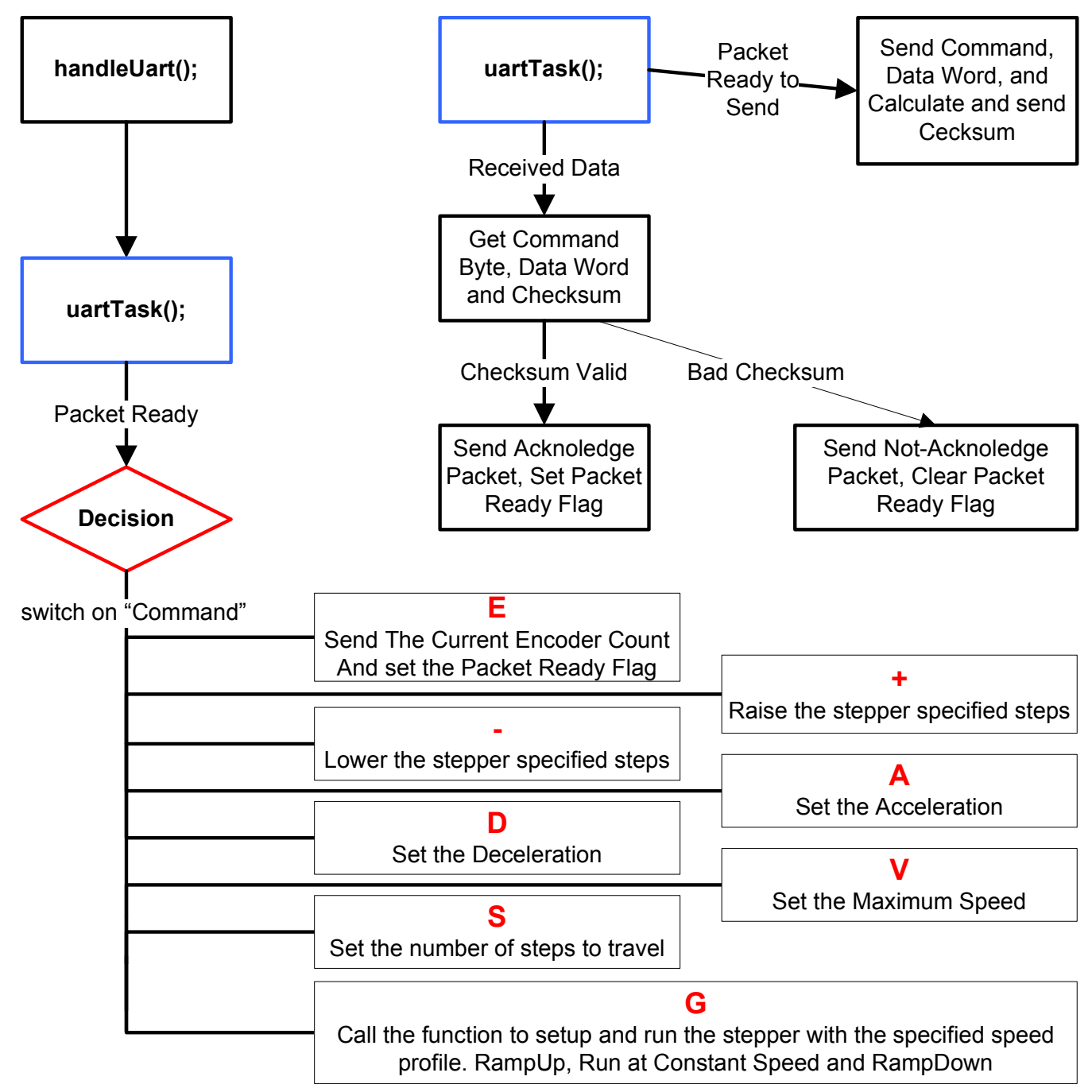

Figure 6 - UART Software flow chart 
The "Task" function checks first to see if new data is in the receive buffer. If new data is present it gets each of the respective parts of a packet and verifies the data with by comparing the received checksum with a calculated one. A packet has the format of: $1^{\text {st }}$ Byte - Command, $2^{\text {nd }} \&$ $3^{\text {rd }}$ Byte - Data Word, $4^{\text {th }}$ Byte - Checksum. If the checksum is good it sends four ACK's (0x06) an Acknowledge Packet, else it sends four NAK's (0x15) a Not-Acknowledge Packet.

The "Task" function then checks to see if a new packet is ready to send. If the packet ready flag is true then the function will send out the four bytes of the packet. It is important to note that there is no conformation that the packet was received correctly. Since this function is only called after a get encoder value call, the PC can just request the packet again if the checksum is invalid.

The "Decision" function checks the command byte of a received packet, and acts accordingly. A list of the commands and their actions is shown below, the command is in terms of an ASCII character.

- E-Causes the UART to send an Encoder packet with the Latest encoder reading

- $\quad+-$ Causes the Stepper Motor to move up a number of steps specified in the data word of a packet. It uses a hard coded acceleration, deceleration, and maximum.

- - - Causes the Stepper Motor to move down a number of steps specified in the data word of a packet. It uses a hard coded acceleration, deceleration, and maximum.

- $\mathrm{A}$ - Set the Acceleration in terms of data word $* 0.01 \mathrm{rad} / \mathrm{sec}^{\wedge} 2$

- $\mathrm{D}$ - Set the Deceleration in terms of data word $* 0.01 \mathrm{rad} / \mathrm{sec}^{\wedge} 2$

- $\mathrm{V}$ - Set the Maximum Speed in terms of data word*0.01 rad/sec

- $\mathrm{S}$ - Set the Number of steps to travel with the other given parameters such as acceleration, deceleration, and max speed

- $\mathrm{G}-$ Move the stepper with the given velocity profile and number of steps specified with A, D, V, S

Timer Interrupt Service Routine

The timer interrupt service routine is what actually causes the stepper to move. It has four different states as shown in Figure 5 - MicroBlaze Software Flow Chart; STOP, ACCELERATE, RUN, and DECELERATE.

STOP

This state disables the timer, clears the counting variables, and turns off the stepper drivers.

ACCELERATE

This state causes the stepper motor to turn/move. The delay between each micro step is calculated for each interrupt. This delay value decreases at the rate defined by the Acceleration. It continues to decrease until it reaches the defined maximum speed. It then either transitions to the RUN state or the DECELERATE state depending on situation. 
$R U N$

This state causes the stepper motor to turn/move at a constant speed defined by the maximum speed. This function transitions to the DECELERATE state when need in order for the stepper to stop at the defined number of steps.

\section{DECELERATE}

This state causes the stepper motor to slow down. The delay between each micro step is calculated for each interrupt. This delay value increases at the rate defined by the deceleration such that the stepper moves the exact number of steps specified. It transitions to the STOP state when it has reached the proper location.

The code that actually calculates the delays and transition points for each of the above states was adapted from an application example provided by Atmel, AVR446: Linear speed control of stepper motor. This code gave us an excellent starting point and greatly reduced the development time. For further information on how this code works, see the application note AVR446.

\section{Step Counter}

Lastly which is also shown in Figure 5 - MicroBlaze Software Flow Chart, is the call to the function StepCounter() by the ACCELERATE, RUN, and DECELERATE states. This function looks up a particular output voltage and pole polarity for a desired microstep position. It then writes this value to the output drivers, affecting the movement of the stepper. If you follow your way in a loop though the step table you can cause the stepper to turn/move.

The step tables were also derived from sample code. These Stepper Drivers are popular among the hobby machinist groups, and many different examples of how to properly use these driver chips with a bi-polar stepper motor are available. Our codes step tables were derived from several different examples of code, but has some similarities to code supplied by Embedded Acquisition Systems, www.embeddedtronics.com (mstep_cr_v2.c). They had a nicely defined macro which allows the user to choose whether to compile the tables for full steps, half steps, quarter steps, $1 / 8^{\text {th }}$ steps, or $1 / 10^{\text {th }}$ steps. However, their tables included some errors which were found and fixed, plus the data had to be reorganized into a short array rather than a byte array.

Quadrature Decoder Interface

This was a simple interface that was supplied as a MicroBlaze IP core by Finger Lakes Engineering. Description from the website:

The FLE Quadrature Decoder Core provides a complete interupt driven decoder to interface with an $A+A^{\prime}$ quadrature signal. This core provides a tunable digital filter to debounce the "noisy" quadrature signals and provide a clean detect, direction, and interrupt state to the MicroBlaze 
Using the included functions and prototypes provided with this core made keeping accurate tracking of the encoder possible. This is because we did not need to bog down system resources to keep track of the quadrature signals. Our software calls the included function which wither adds or subtracts $1,-1$, or 0 to the encoder count each timer interval.

Hardware Description

A complete hardware diagram is located in Figure 8 - Circuit Diagram. Also notice the pictures of the prototyped hardware. This hardware was soldered to perforated proto board. Because testing this circuit required relatively high currents only soldered connections would suffice.
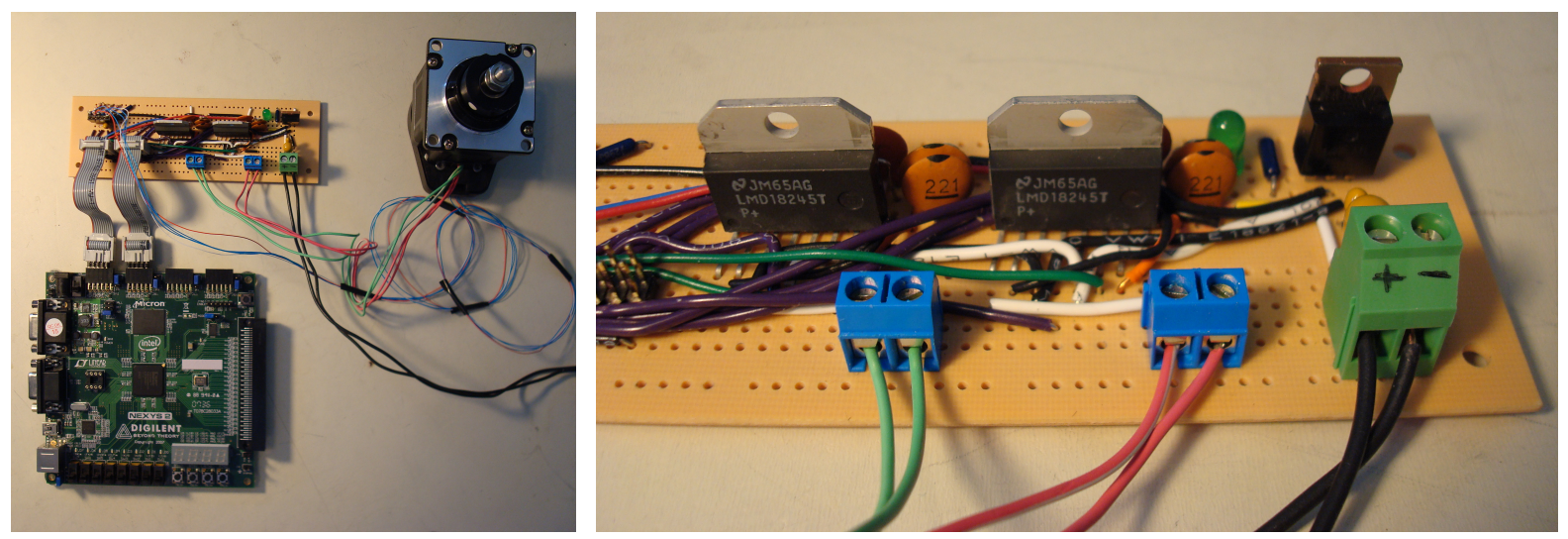

Figure 7 - Pictures of Prototyped Board and System

The circuit board has six connectors. These connectors are:

- Power in - +10 to +24 Vdc (+), and Ground (-)

- Motor A - Motor coil A + and -

- Motor B - Motor coil B + and -

- Encoder and Switch 1 - GND, 2 - I, 3 - A, 4 - +5V, 5 - B, 6 - Switch (+), 7 - Switch (-)

- JA1 - Nexus Port JA1 connector 1 - DirA, 2 - Brake A, 3 - Dir B, 4 - BrakeB, 7 - EncA, 8 - EncB, 9 - Index 10 - Switch, 5 \& 11 - Ground

- JB1 - Nexus Port JB1 connector 1-4 MA(1-4), 7-10 MB(1-4), 5 \& 11 - Ground

The circuit board was laid out so that ribbon connectors could be used between the NEXYS2 and prototype. The motor connectors and power input connectors are screw terminals rated for the LMD18245 maximum current. These terminals allow easy connection to the motor leads and the power input. 
The LMD18245 circuit layout comes directly from the data sheet's typical application circuit. Using a verified design makes a quick project like this come together smoothly. For further information about how this chip works see the data sheet.

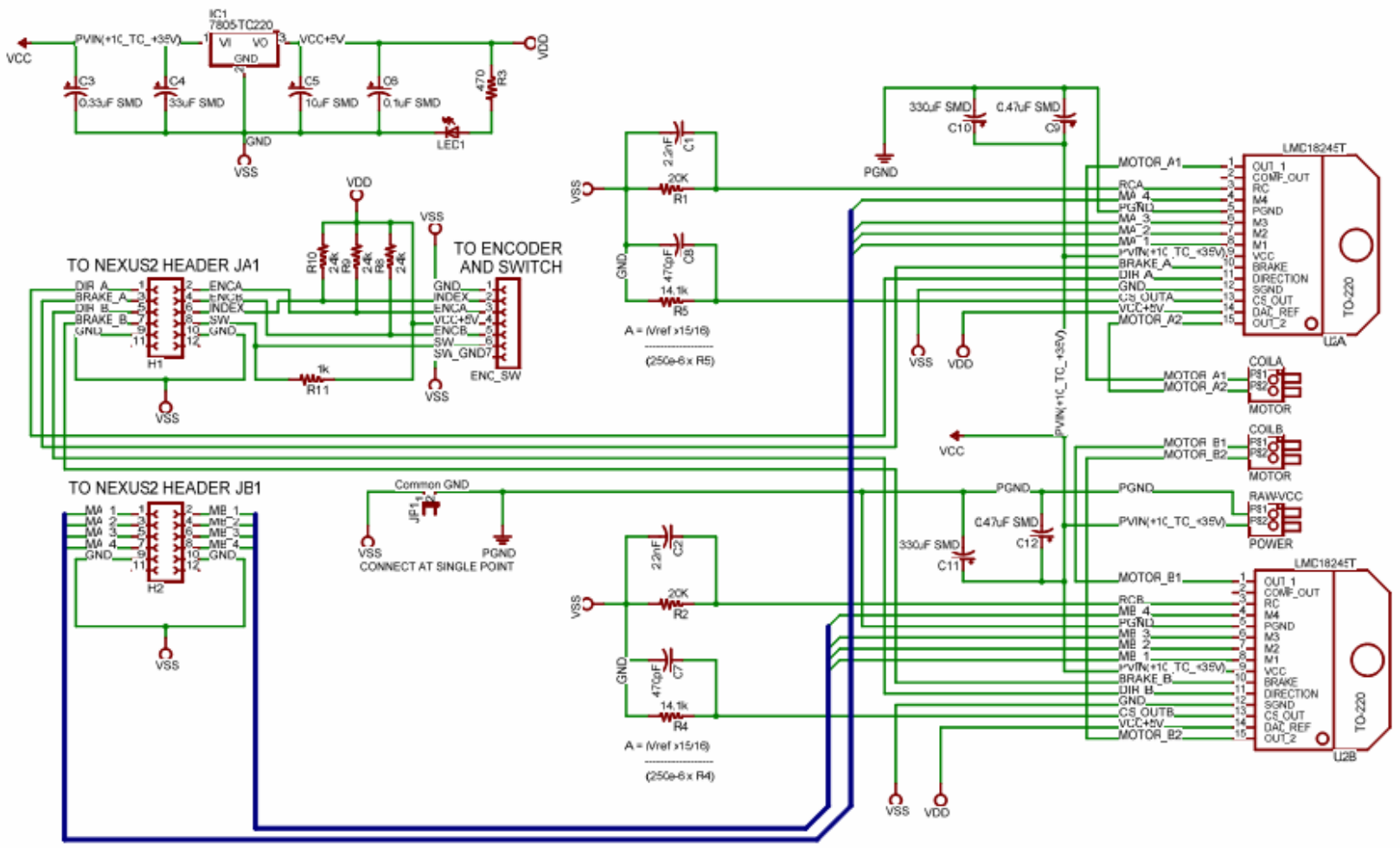

Figure 8 - Circuit Diagram

System Integration and Verification

The Current program size is 17682 bytes. Because we were working with the NEXYS2 and the Spartan3e we were able to create a memory space of $32 \mathrm{~kb}$. This leaves plenty of extra room for additional code and future upgrades. Below is the reported device usage such as the number of slices occupied, brams used, etc.

\section{Logic Utilization:}

Number of Slice Flip Flops: $\quad$ 2,054 out of $\quad 9,312 \quad 22 \%$

Number of 4 input LUTs: $\quad 2,285$ out of $9,312 \quad 24 \%$

\section{Logic Distribution:}

Number of occupied Slices:

2,178 out of $4,656 \quad 46 \%$

Number of Slices containing only related logic: $\quad 2,178$ out of $2,178100 \%$

Number of Slices containing unrelated logic:

0 out of $2,178 \quad 0 \%$

*See NOTES below for an explanation of the effects of unrelated logic 
Total Number of 4 input LUTs:

Number used as logic:

Number used as a route-thru:

Number used for Dual Port RAMs:

(Two LUTs used per Dual Port RAM)

Number used as Shift registers:

Number of bonded IOBs:

IOB Flip Flops:

Number of Block RAMs:

Number of GCLKs:

Number of MULT18X18SIOs:
2,900 out of $9,312 \quad 31 \%$

2,285

164

384

67

51 out of $232 \quad 21 \%$

49

16 out of $20 \quad 80 \%$

1 out of $24 \quad 4 \%$

3 out of $20 \quad 15 \%$

\section{Testing and Design Procedures}

Software testing closely followed hardware testing during the development of the stepper motor controller. The first goal was to build the prototype hardware. While the hardware was being built we worked on getting the serial communications working. When we were able to successfully send and receive characters to a terminal, we then proceeded to write packet software to make sending and receiving data possible.

When we completed the prototyped hardware we wrote software to step through the step table and turn the motor at a constant speed. Once we figured out the correct pin to bit combination this beginning code worked quite well. We did notice however that the motor could only start if the speed was set below a specific maximum value. Above this speed the motor would just jitter.

At this point we had two sets of working code: a packet system which could send and receive packets, and a drive system which could run the motor at a specific speed. We next worked on getting the encoder to properly read the encoder count using the Quadrature Encoder IP Core. We merged the two sets of code so that the motor would run while spiting out the encoder count through the UART.

Because with the current code we could only run the motor up to a maximum speed, we then began to look at ramping the motor speed up and down. That would allow us to reach much higher speeds than our old code. While one of us worked on this the other worked on a GUI to control the motor from the PC.

We made major advances in integration when we located the Atmel application note. Because of the limited time available to assemble this project internet recourses allowed us to quickly integrate the system.

Once all systems were written we then began testing them in concert. We first test the connection from the GUI to the MicroBlaze through the Packet interface. We then tested the manual control of the stepper motor, form the manual tab on the GUI. We adjusted the parameters and added features to make the interface work smoothly. Once we verified the manual controls, we began 
testing the automated setup. We changed the acceleration and deceleration parameters and verified that the motor moved the appropriate number of steps. We kept testing values until we found the maximums that still allowed the motor to run properly.

\section{Observations and Difficulties}

We had some trouble with software bugs in our embedded code initially. There was one bug where the first command issued would move the stepper fine, but the second time that a move command was sent there was a delay of approximately 2 minutes before it would move. We eventually found that our counter was going just one number too far, which resulted in a rollover that drastically increased the amount of time that it counted before interrupting and moving the stepper motor. Although the cause was fairly simple, this was a very difficult bug to track down.

We had another bug that prevented the stepper motor from ramping down. It was very noticeable because we could hear the changing pitch coming from the stepper when it ramping up, but not when it was ramping down; instead we could hear it stop abruptly. After some debugging, we eventually tracked down the issue to a single line containing a semi-complicated equation that calculated the time interval that the next deceleration step would occur at. We are still uncertain exactly why that line was always returning the same number despite the changing values of variables in its equation. However, the line included some signed numbers, multiplication, division, and casting, so it is likely that there were some problems with truncation or data type expansion. We found that we were able to solve the issue by using a couple extra variables to store intermediate results of parts of the equation instead of writing one complex equation.

When we setup and tested our project on the presentation day, we tried to use a power supply that had been checked out from the EE desk. However, it was not able to supply enough current, and we noticed an interesting symptom. Our ordinary, cheap 5V voltage regulator became significantly overheated. We decided this was because the chopper circuits driving the stepper were not able to get enough current from the low quality power supply, which resulted in extra noise on the supply rails and so the $5 \mathrm{~V}$ regulator was working extra hard to try to smooth the supply voltage out. After obtaining a better quality power supply rated for higher current, the $5 \mathrm{~V}$ regular ran cool.

\section{Conclusion}

This final project took a lot of time to complete, but was a very rewarding experience. We were lucky that we found several resources on the internet or we might not have completed this project on time. By using the reference design from the datasheet for the stepper motor driver chips, we did not have to worry much about testing the electronic circuitry. Additionally, we found a free IP core that performed the task of interpreting the signals from the two encoders, making it much easier for us to count encoder ticks. Most importantly, we were able to adapt sample code from an Atmel application note to do our interrupt interval calculations. Lastly, we found some tables for stepper motor microstepping values, which saved us from having to experiment with and generate these tables ourselves. 
By combining all these resources and the knowledge that we gained in CPE 329, we were able to meet our stated project requirements on time, and gained engineering experience in the process. Furthermore, the prototype system that we developed will actually be used for testing rocket engines and will continue to be improved. Eventually, the system may be integrated on a smaller, cheaper FPGA board than the NEXYS2, but so far the NEXYS2 has served us very well and proved to be very useful for flexible, rapid development of a prototype system. 